\title{
Evolution of oceanic margins: Rifting in the Gulf of California and sediment diapirism and mantle hydration during subduction
}

\author{
by
}

Nathaniel Clark Miller

B.S., Virginia Polytechnic Institute and State University (Virginia Tech), 2007

Submitted in partial fulfillment of the requirements for the degree of

Doctor of Philosophy

at the

MASSACHUSETTS INSTITUTE OF TECHNOLOGY

and the

WOODS HOLE OCEANOGRAPHIC INSTITUTION

June 2013

(C) 2013 Nathaniel Clark Miller. All rights reserved.

The author hereby grants to MIT and WHOI permission to reproduce and to distribute publicly paper and electronic copies of this thesis document in whole or in part in any medium now known or hereafter created.

Author

MIT/WHOI Joint Program in Oceanography/ Applied Ocean Science and Engineering

May 17, 2013

Certified by

Daniel Lizarralde

Thesis Supervisor

Associate Scientist, Department of Geology and Geophysics, WHOI

Accepted by

Rob Evans

Chairman, Joint Committee for Geology and Geophysics Senior Scientist, Department of Geology and Geophysics, WHOI 


\title{
Evolution of oceanic margins: Rifting in the Gulf of California and sediment diapirism and mantle hydration during subduction
}

\author{
by \\ Nathaniel Clark Miller
}

\begin{abstract}
Submitted to the MIT/WHOI Joint Program in Oceanography/Applied Ocean Science and Engineering on May 17, 2013 in partial fulfillment of the requirements for the degree of Doctor of Philosophy in Geophysics
\end{abstract}

\begin{abstract}
This thesis investigates three processes that control the evolution of oceanic margins. Chapter 2 presents seismic images of a $\sim 2$-km-thick evaporite body in Guaymas Basin, central Gulf of California. In rifts, evaporites form under conditions unique to the latest stages of continental rupture, and the presence, age, thickness, and shape place new constraints on the history of early rifting there. Chapter 3 presents numerical experiments that show that diapirs can form in sediments on the down-going plate in subduction zones and rise into the mantle wedge, delivering the sedimentary component widely observed in arc magmas. Chapter 4 presents measurements of seismic anisotropy from wide-angle, active-source data from the Middle America Trench that address the hypothesis that the upper mantle is hydrated by seawater flowing along outer-rise normal faults. These measurements indicate that the upper mantle is $\sim 1.57$ to $6.89 \%$ anisotropic, and this anisotropy can be attributed to bendingrelated faulting and an inherited mantle fabric. Accounting for anisotropy reduces previous estimates for the amount of water stored in the upper mantle of the downgoing plate from $\sim 2.5$ to $1.5 \mathrm{wt} \%$, a significant change in subduction zone water budgets.
\end{abstract}

Thesis Supervisor: Daniel Lizarralde

Title: Associate Scientist, Department of Geology and Geophysics, WHOI 


\section{Acknowledgements}

This thesis punctuates my own transformation from student to new scientist, but it also marks a change from many other states of incipiency to nascence. In any transformation and in any new thing there is woe. This woe can be wisdom, but it can also be madness. Dan Lizarralde has a knack for sorting wisdom from madness, and he showed me how to see the difference and navigate the space in between. I am grateful that he took a chance on me, first as a summer student at WHOI and then as a graduate student, and he never stopped holding the proverbial carrot at just the right distance.

Mark Behn and John Collins also understand wisdom and madness. They took an early interest in my work and have offered ceaseless encouragement since I first arrived at WHOI. They also provided the critical eyes that are essential to good science, and to the development of good scientists, and I am truly grateful for time I shared with these guys. Donna Shillington and Alison Malcolm had no hesitations about joining my thesis committee, and they have been nothing but supportive the whole time.

I am lucky to have spent 5 months at sea with the fine officers and crews of the $R / V$ Langseth, $R / V$ Endeavor, and $F / V$ Tiki. At WHOI, talented people like Jeff Dusenberry and Jonathan Murry kept our computers and code running. I am grateful that the folks in the education offices MIT and WHOI work hard to make the Joint Program the amazing experience it is. I am also thankful that the U.S. values scientists and students and supports us by giving grants like National Science Foundation (NSF) Division of Ocean Science (OCE) \#824497 and NSF OCE-MARGINS \#825178 and \#841063 to Dan Lizarralde, as well as NSF Division of Earth Sciences \#0652707 to Mark Behn.

Camilo Ponton can talk science, but he was also there as we figured out how to fish the eddies and ledges of Woods Hole, showing me a finesse learned in freshwater. Emily Roland, Arthur Olive, Min Xu, Claire Pontbriand, and Jake Siegel all have real geophysics chops and I am lucky to have shared classes and time at sea with them. Wilken-Jon von Appen got me out running and was there to talk about the dynamics of sea ice and anything else that came up on $15^{\circ} \mathrm{F}$ mornings. Julian Schanze pushed our sailboat and me through snotty seas, and while I would not know what a small craft warning or the U.S. Coast Guard are really all about without him, we always made it back. Jeff McGuire, Adam Soule, Steve Swift, Jian Lin, Ralph Steven, Maurice Tivey, and Pablo Canales offered wisdom and encouragement in classes and conversations from the halls of Clark Lab to the East Pacific Rise and Botswana. Karin Lemkau, Dorsey Wanless, Masako Tominaga, Jeff Kaeli, Carly Buchwald, Maya Yamato, Shane McGary, Helen Feng, and Greg Horning all made my time at WHOI more meaningful and fun. Danny Brothers introduced me to the USGS and to his own brand of rowdiness, and without him I would have had far fewer great conversations with good people like Laura Brothers, Uri ten Brink, Tommy O’Brien, and Nina Ivanova.

I am only beginning to learn all that I owe to my family. George and Maryethel, my parents, provided me with a test bed full of all sorts of experiences and let me find my own way, never forcing their own vision. My brother Alex was a vexation, but motivated me and stepped up with unwavering support just when I needed him most, and I will forever be grateful for that. Joyce and Hamilton, my grandparents, and the horde of aunts, uncles, and cousins they brought with them, have also given me a great sense of place and support for many years. 


\section{Table of Contents}

Abstract

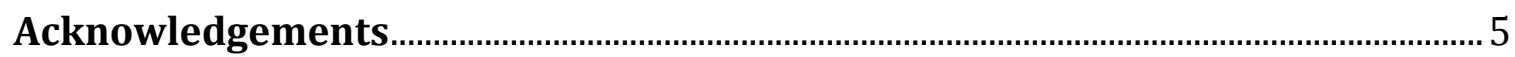

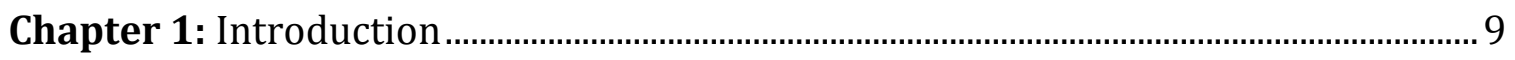

Chapter 2: Thick evaporites and early rifting in the Guaymas Basin,

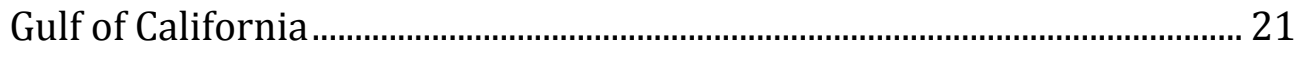

Chapter 3: Timescales for the growth of sediment diapirs in subduction zones ...... 35

Chapter 4: Upper-mantle anisotropy and hydration at the Middle America

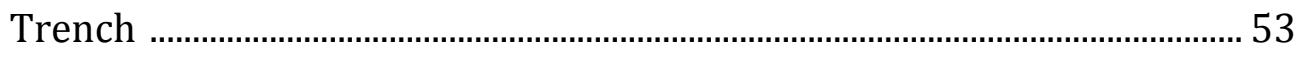




\section{Chapter 1:}

\section{Introduction}

Fundamental geologic processes that occur along oceanic margins regulate chemical cycles essential to life on Earth and provide energy and mineral resources that fuel the industrial and technological advancement of modern society. New ocean basins are created by tectonic extension and eventual rupture of the continental lithosphere. During this extension, upwelling in the mantle under thinned crust drives mantle melting. Magmatic intrusion into the crust and volcanism along rift zones, and the ensuing creation of new oceanic crust along seafloor-spreading centers, delivers heat to the Earth's surface, cooling the lithosphere and promoting mantle convection. This magmatism also returns chemicals-including water, carbon dioxide, and metalscycled through the mantle to the Earth's surface, supplying key nutrients to organisms and producing economically important mineral deposits. Marine life thrives in young, nutrient-rich rift basins, and these organisms, along with weathering of extended continental rocks, sequester carbon from the atmosphere and ocean into marine sediments, influencing global climate. These carbon-rich sediments accumulate first in shallow rift basins and later on continental margins, and heat supplied by riftmagmatism drives alteration of these sediments into the world's major deposits of hydrocarbons such as coal, oil, and natural gas.

Oceanic crust is returned to the mantle by subduction at oceanic trenches, completing a global-scale cycle. During subduction, water stored in the oceanic lithosphere is released into the mantle, where it has a significant effect on rock rheology 
and geochemistry. Water supplied to the mantle wedge from the subducting lithosphere drives mantle melting and arc volcanism (Davies and Stevenson, 1992; Iwamori, 1998; Grove et al., 2006), and promotes secondary convection that incorporates sediments from the top of the subducting slab into these magmas (Gerya et al., 2003; Behn et al., 2011). Over-pressuring and weakening caused by the presence of water at the interface between the overriding and down-going plates enables the oceanic lithosphere to subduct (Wang et al., 1995), and water fluxing through the down-going slab may force the transition from gabbro to eclogite at depth (John and Schenk, 2003), increasing slab density and promoting subduction. Globally, rheologic weakening caused by widespread hydration of the upper mantle allows for the movement of tectonic plates (Hirth and Kohlstedt, 1996). Without this weakening, plate tectonics may be impossible, with mantle convection on Earth resembling the "stagnant-lid" convection thought to occur on the other terrestrial planets (Solomatov and Moresi, 1996). Together, plate tectonics, volcanism, and mantle convection, enable global geochemical cycles, and sustaining these processes through recycling of water and other chemicals into the mantle at subduction zones is essential for life on Earth.

Geologic processes at oceanic margins are also responsible for natural disasters and catastrophic events. Megathrust earthquakes at subduction zones and resulting tsunamis have claimed nearly 500,000 human lives and cost nearly 500 billion in U.S. dollars in the last two decades alone (Athukorala and Resosudarmo, 2005; World Bank, 2011). Violent eruptions of arc volcanoes, such as Krakatoa and Mount St. Helens, have also caused substantial losses of life and property throughout human history (Saarinen and Sell, 1985; Winchester, 2013). The world's largest magmatic provinces are located 
in rift zones, and these eruptions have been associated with rapid climate change and mass extinctions throughout Earth's history (Marzoli et al., 2004; Kozur and Weems, 2011). Long after rifting has progressed to seafloor spreading, submarine landslides on rifted margins have generated tsunamis and destroyed seafloor and coastal infrastructure (Masson et al., 2006). Understanding the processes that create, shape, and destroy oceanic margins is a critical component in mitigating risk to society from these natural hazards, as well as in extracting natural resources and understanding the role margins play in the interconnected dynamics of a changing planet.

Studying oceanic margin processes requires a scientific approach that spans spatial and temporal scales, as well as disciplines. For example, the shape of a rift basin is related to global plate motions, regional- and global-scale dynamics and geochemistry of the upper mantle, and, more locally, to the strength of crustal rocks. Seismic images of such a basin can be used to test interpretations of regional geologic history, geodynamic models of lithospheric-scale extension, and models of mantle melting and magmatism during rifting. Conversely, the chemistry of rocks forming and filling basins can be used to constrain the age and evolution of rifts, and geodynamic models test interpretations of structures in seismic images. Similarly, using seismic wavespeeds to measure the effects of chemical and physical processes in mantle rocks requires integrating knowledge from fields such as rock mechanics, crystallography, and geochemistry.

In this thesis, I present research on three specific processes that shape oceanic margins, and each topic is approached from a different perspective. Chapter 2 presents seismic reflection images of a thick salt deposit in the Gulf of California and investigates 
implications for the kinematics of early rifting there. The Gulf of California occupies the boundary between the Pacific and North American plates, and, at present, extension at seafloor spreading centers accommodates a majority of relative motion between these plates. These spreading centers are oriented perpendicularly to the direction of relative Pacific-North America motion, but this trend is $\sim 30^{\circ}$ from the orientation of the Gulf's rifted margins. This obliquity suggests that a fundamental change occurred in how extension was accommodated within this region between ca. $12 \mathrm{Ma}$, when continental extension accelerated as subduction stalled offshore (Atwater and Stock, 1998), and lithospheric rupture and the onset of seafloor spreading at ca. 6.3 Ma (Oskin and Stock, 2003).

The seismic data come from the Guaymas Basin of the central Gulf of California, and these data image a 2 -km-thick evaporite body that appears to have formed on extended continental crust during the Late Miocene (11.2 to 5.3 Ma). Thick evaporites have not been previously documented in the Gulf of California. In rifts, evaporites typically form under conditions unique to the latest stages of continental rupture and the onset of seafloor spreading (Evans, 1978). Thus, the presence, age, thickness, and shape of the evaporite in the Guaymas Basin place new constraints on the history of marine incursions and early basin development during this transitional stage. In particular, the large volume of evaporites, and a correlation to dated gypsum beds on the Gulf's western margin, indicate that substantial marine incursions and subsequent evaporite deposition occurred ca. $7 \mathrm{Ma}$ and prior to lithospheric rupture. Furthermore, the seismic images, along with gravity data, indicate that the basin is " $\mathrm{S}$ "-shaped, a 
geometry indicative of transtensional basins, suggesting that oblique extension existed in the central Gulf of California ca. 7 Ma.

Chapter 3 presents numerical experiments and a scaling analysis that shows that diapirs can form in sediments on the down-going plate in subduction zones and rise into the mantle wedge, delivering a sedimentary component widely observed in the geochemistry of arc magmas (Plank and Langmuir, 1998). Modern subduction-zone thermal models (Wada and Wang, 2009; Syracuse et al., 2010) predict slab-surface temperatures in excess of the fluid saturated solidus for subducted metasediments, implying that subducted sediments may melt at the slab surface. However, recent traceelement-depletion trends in metasedimentary rocks that endured subduction to high pressures $(>2 \mathrm{GPa})$ and temperatures suggest that key trace elements associated with the observed "sediment-melt signature" are not released until temperatures exceed $\sim 1050^{\circ} \mathrm{C}$ (Behn et al., 2011)-significantly hotter than slab-surface temperatures at similar pressures in the subduction zone thermal models. Behn et al. (2011) interpreted this discrepancy as evidence that, although melting may begin at lower temperatures, the sediment-melt signature is retained to higher temperatures, and proposed that sediments detach from the slab and rise diapirically into the overlying mantle wedge. These diapirs would undergo decompression melting as they ascend into the hot mantle wedge (Gerya and Yuen, 2003), rapidly cycling sediment-derived melts and volatiles into arc magma systems.

The numerical experiments in Chapter 3 predict timescales for the growth of sediment diapirs over a range of subduction conditions. Diapir growth in these models depends strongly on the temperature of the subducting slab and mantle wedge, yet 
sediments can form diapirs that detach from the slab at locations corresponding to the location of arc volcanism over a wide range of slab thermal structures. In 'hot' subduction zones with young slabs and/or slow convergence rates (e.g., Cascadia), effective viscosities are relatively small, enabling instabilities to form over a broad range of sediment thicknesses and mantle-wedge thermal and strain rate structures. In colder subduction zones with old slabs and/or fast convergence rates (e.g., Izu-Bonin), effective viscosities are greater, slowing instability growth, and secondary controls such as the ratio of sediment to mantle viscosities and the length scale of viscous decay in the mantle play a more significant role in the development of sediment diapirs.

Chapter 4 presents measurements of seismic anisotropy from wide-angle, activesource data that constrain the flux of water delivered into the mantle at the Middle America Trench. Water carried to depth by subducting oceanic lithosphere is the primary source of mantle hydration, an essential component of many arc- and globalscale processes. The upper mantle is often assumed to be efficiently dehydrated by melting at ridges, but recent seismic-reflection images of bending-induced normal faults extending into the upper mantle (Ranero et al., 2003; Nedimović et al., 2009) and reduced upper-mantle seismic velocities under the outer rise near trenches (Van Avendonk et al., 2011) have been interpreted as evidence that the subducting mantle is pervasively hydrated via serpentinization by seawater penetrating through the crust along plate-bending-induced faults. This seawater may fill cracks in the upper mantle with free water; react strongly with olivine in upper mantle peridotite, filling cracks and fault zones with serpentinite; and/or diffuse between fault zones, pervasively serpentinizing the upper mantle. 
The seismic velocity of serpentinized rocks is much slower than that of unaltered mantle rocks, and much of the support for the hypothesis that subducting mantle is commonly hydrated near the outer rise comes from isotropic seismic velocity analyses that assume observed slow velocity anomalies can be entirely attributed to the presence of serpentine. However, the outer-rise normal faults themselves, as well as inherited, strain-induced crystal-preferred orientation (CPO) of mineral grains in the upper mantle can produce azimuthally dependent seismic wave speeds that are up to $\sim 0.5$ $\mathrm{km} / \mathrm{s}$ slower in one direction than in another, an effect comparable to the change in velocity due to $\sim 20 \%$ pervasive serpentinization (Christensen, 1966). To accurately estimate the degree of serpentinization at the outer rise and trench using seismic travel times, the azimuthal variation of seismic wave speed must be determined, and the competing effects of a CPO of mantle minerals, faulting, and hydration, each with their own azimuthal dependence, must be distinguished.

The wavespeed measurements shown in Chapter 4 indicate that the upper mantle is between $\sim 1.6$ and $4.4 \%$ anisotropic beneath the outer rise. This anisotropy can be explained by combining wavespeed variations from an alignment of olivine grains in a relic mantle fabric with anisotropy from cracks and/or joints aligned along the strike of bending-related normal faults. Measurements made using rays that turn at different depths indicate that this anisotropy varies with depth in the mantle, with anisotropy from aligned cracks composing a larger portion of the wavespeed variations in the upper-most mantle. Anisotropy in both the upper-most mantle and over depths up to 24 $\mathrm{km}$ below the Moho appears to include a significant component attributable to large joints aligned with the bending-induced faults, although it is unclear how much of this 
signal can be explained by crustal, as opposed to mantle, faulting. Accounting for up to $\sim 4.4 \%$ upper-mantle anisotropy in seismic-velocity-based measurements of serpentinization reduces current estimates for the water content of the upper mantle offshore of Nicaragua from $\sim 2.5$ to $1.5 \mathrm{wt} \%$, a significant difference in the water input to the mantle at subduction zones (Rüpke et al., 2004). 


\section{References}

Athukorala, P.-C., and Resosudarmo, B.P., 2005, The Indian Ocean Tsunami: Economic Impact, Disaster Management, and Lessons: Asian Economic Papers, v. 4, no. 1, p. 1-39, doi: 10.1080/00074910500072641.

Atwater, T., and Stock, J., 1998, Pacific-North America Plate Tectonics of the Neogene Southwestern United States: An Update: International Geology Review, v. 40, no. 5, p. 375-402, doi: 10.1080/00206819809465216.

Behn, M.D., Kelemen, P.B., Hirth, G., Hacker, B.R., and Massonne, H.-J., 2011, Diapirs as the source of the sediment signature in arc lavas: Nature Geoscience, v. 4, no. 9, p. 641-646, doi: $10.1038 /$ ngeo 1214 .

Christensen, N.I., 1966, Elasticity of ultrabasic rocks: Journal of Geophysical Research, v. 71, no. 24, p. 5921-5931, doi: 10.1029/JZ071i024p05921.

Davies, J.H., and Stevenson, D.J., 1992, Physical model of source region of subduction zone volcanics: Journal of Geophysical Research, v. 97, no. B2, p. 2037, doi: 10.1029/91JB02571.

Evans, R., 1978, Origin and significance of evaporites in basins around Atlantic margin: Am. Assoc. Petrol. Geol. Bull, v. 62, no. 2, p. 223-234.

Gerya, T.V., and Yuen, D.A., 2003, Rayleigh-Taylor instabilities from hydration and melting propel "cold plumes" at subduction zones: Earth and Planetary Science Letters.

Gerya, T.V., Gerya, T.V., Yuen, D.A., and Yuen, D.A., 2003, Rayleigh-Taylor instabilities from hydration and melting propel "cold plumes" at subduction zones: Earth and Planetary Science Letters, v. 212, no. 1-2, p. 47-62.

Grove, T.L., Chatterjee, N., and Parman, S.W., 2006, The influence of H2O on mantle wedge melting: Earth and Planetary Science Letters, v. 249, p. 74-89.

Hirth, G., and Kohlstedt, D.L., 1996, Water in the oceanic upper mantle: implications for rheology, melt extraction and the evolution of the lithosphere: Earth and Planetary Science Letters, v. 144, p. 93-108.

Iwamori, H., 1998, Transportation of $\mathrm{H} 2 \mathrm{O}$ and melting in subduction zones: Earth and Planetary Science Letters, v. 160, p. 65-80.

John, T., and Schenk, V., 2003, Partial eclogitisation of gabbroic rocks in a late Precambrian subduction zone (Zambia): prograde metamorphism triggered by fluid infiltration: Contributions to Mineralogy and Petrology, v. 146, no. 2, p. 174-191, doi: $10.1007 /$ s00410-003-0492-8. 
Kozur, H.W., and Weems, R.E., 201 1, Detailed correlation and age of continental late Changhsingian and earliest Triassic beds: Implications for the role of the Siberian Trap in the Permian-Triassic biotic crisis: Palaeogeography, v. 308, p. 22-40.

Marzoli, A., Bertrand, H., Knight, K.B., Cirilli, S., Buratti, N., Vérati, C., Nomade, S., Renne, P.R., Youbi, N., Martini, R., Allenbach, K., Neuwerth, R., Rapaille, C., Zaninetti, L., et al., 2004, Synchrony of the Central Atlantic magmatic province and the Triassic-Jurassic boundary climatic and biotic crisis: ..., v. 32, no. 11, p. 973976.

Masson, D.G., Harbitz, C.B., Wynn, R.B., Pedersen, G., and Løvholt, F., 2006, Submarine landslides: processes, triggers and hazard prediction: Philosophical Transactions of the Royal Society A: Mathematical, Physical and Engineering Sciences, v. 364, no. 1845, p. 2009-2039, doi: 10.1046/j.1365-

3091.2000.0470s 1239.x.

Nedimović, M.R., Bohnenstiehl, D.R., Carbotte, S.M., Canales, J.P., and Dziak, R.P., 2009, Faulting and hydration of the Juan de Fuca plate system: Earth and Planetary Science Letters, v. 284, no. 1-2, p. 94-102, doi: 10.1016/j.epsl.2009.04.013.

Oskin, M., and Stock, J., 2003, Pacific--North America plate motion and opening of the Upper Delfín basin, northern Gulf of California, Mexico: Geological Society of America Bulletin, v. 115, no. 10, p. 1173-1190, doi: 10.1130/B25154.1.

Plank, T., and Langmuir, C.H., 1998, The chemical composition of subducting sediment and its consequences for the crust and mantle: Chemical Geology, v. 145, p. 325394.

Ranero, C.R., Phipps Morgan, J., McIntosh, K., and Reichert, C., 2003, Bending-related faulting and mantle serpentinization at the Middle America trench: Nature, v. 425, no. 6956 , p. 367-373, doi: 10.1038/nature01961.

Rüpke, L.H., Morgan, J.P., Hort, M., and Connolly, J., 2004, Serpentine and the subduction zone water cycle: Earth and Planetary Science Letters, v. 223, p. 17-34.

Saarinen, T.F., and Sell, J.L., 1985, Warning and Response to the Mount St. Helen's Eruption: SUNY Press.

Solomatov, V.S., and Moresi, L.N., 1996, Stagnant lid convection on Venus: Journal of Geophysical Research, v. 101, no. E2, p. 4737, doi: 10.1029/95JE03361.

Syracuse, E.M., van Keken, P.E., and Abers, G.A., 2010, The global range of subduction zone thermal models: Physics of the Earth and Planetary Interiors, v. 183, no. 1-2, p. 73-90, doi: 10.1016/j.pepi.2010.02.004. 
Van Avendonk, H.J.A., Holbrook, W.S., Lizarralde, D., and Denyer, P., 201 1, Structure and serpentinization of the subducting Cocos plate offshore Nicaragua and Costa Rica: Geochemistry, Geophysics, Geosystems, v. 12, no. 6, doi:

10.1029/2011GCo03592.

Wada, I., and Wang, K., 2009, Common depth of slab-mantle decoupling: Reconciling diversity and uniformity of subduction zones: Geochemistry, Geophysics, Geosystems, v. 10, no. 10, doi: 10.1029/2009GC002570.

Wang, K., Mulder, T., Rogers, G.C., and Hyndman, R.D., 1995, Case for very low coupling stress on the Cascadia Ssubduction Fault: Journal of Geophysical Research, v. 100, no. B7, p. 12907, doi: 10.1029/95JB00516.

Winchester, S., 2013, Krakatoa: The Day the World Exploded: August 27, 1883:

World Bank, 2011, The Recent Earthquake and Tsunami in Japan: Implications for East Asia:, 1-2 p. 


\title{
Chapter 2:
}

\section{Thick evaporites and early rifting in the Guaymas Basin, Gulf of California*}

\begin{abstract}
Multichannel seismic transects reveal an $\sim 2$-km-thick, $\sim 50 \times 100 \mathrm{~km}$ evaporite body under the shelf on the eastern margin of the Guaymas Basin, central Gulf of California (Mexico). These thick newly discovered evaporites appear to be correlated with well-known gypsum beds near Santa Rosalía to the northwest, on the Baja California peninsula. Closing the Gulf of California along kinematic flow lines suggests that the thin, scattered, ca. 7 Ma Santa Rosalía gypsum beds formed on the fringe of the much thicker evaporite deposit. This correlation, and the large volume of the Guaymas evaporates, implies that substantial marine incursions and subsequent evaporite deposition occurred during the Late Miocene and prior to lithospheric rupture. Furthermore, the shape of the Guaymas evaporite is indicative of a transtensional basin, suggesting that oblique extension existed in the central Gulf of California ca. 7 Ma.
\end{abstract}

* Originally published as: Miller, N.C., and Lizarralde, D., 2012, Thick evaporites and early rifting in the Guaymas Basin, Gulf of California: Geology, p. 1-4, doi: 10.1130/G33747.1.

Reprinted with permission from the Geologic Society of America. 


\title{
Thick evaporites and early rifting in the Guaymas Basin, Gulf of California
}

\author{
Nathaniel C. Miller ${ }^{1 *}$ and Daniel Lizarralde ${ }^{2}$ \\ ${ }^{1}$ Marine Geology and Geophysics, Massachusetts Institute of Technology/Woods Hole Oceanographic Institution Joint Program, \\ 266 Woods Hole Road, Woods Hole, Massachusetts 02543, USA \\ 2Department of Geology and Geophysics, Woods Hole Oceanographic Institution, 266 Woods Hole Road, Woods Hole, \\ Massachusetts 02543, USA
}

\begin{abstract}
Multichannel seismic transects reveal an $\sim 2$-km-thick, $\sim 50 \times 100 \mathrm{~km}$ evaporite body under the shelf on the eastern margin of the Guaymas Basin, central Gulf of California (Mexico). These thick newly discovered evaporites appear to be correlated with well-known gypsum beds near Santa Rosalía to the northwest, on the Baja California peninsula. Closing the Gulf of California along kinematic flow lines suggests that the thin, scattered, ca. 7 Ma Santa Rosalía gypsum beds formed on the fringe of the much thicker evaporite deposit. This correlation, and the large volume of the Guaymas evaporates, implies that substantial marine incursions and subsequent evaporite deposition occurred during the Late Miocene and prior to lithospheric rupture. Furthermore, the shape of the Guaymas evaporite is indicative of a transtensional basin, suggesting that oblique extension existed in the central Gulf of California ca. 7 Ma.
\end{abstract}

\section{INTRODUCTION}

The Gulf of California (Mexico) is part of a young rift system that occupies the boundary between the Pacific and North American plates. In the modern Gulf of California, 92\% of Pacific-North America relative motion is accommodated at short seafloor-spreading centers offset by long transform faults (Fig. 1; DeMets and Dixon, 1999; Dixon et al., 2000). These spreading centers are perpendicular to the direction of Pacific-North America relative motion, but they are oblique, by $\sim 30^{\circ}$, to the rifted margins of the Gulf of California. This obliquity suggests that there was a fundamental change in how extension was accommodated within the region between ca. $12 \mathrm{Ma}$, when continental extension accelerated as subduction stalled offshore (Atwater and Stock, 1998), and lithospheric rupture and the onset of seafloor spreading ca. 6.3 Ma (Oskin and Stock, 2003).

Two distinct models have been proposed for how Pacific-North America relative motion was accommodated in the Gulf of California region prior to lithospheric rupture. One model argues that early strain was partitioned between NNW-trending dextral strike-slip faults west of the modern Baja California peninsula and NNW-striking normal faults within the protogulf (e.g., Oskin and Stock, 2003). A second model argues that, prior to rupture, extension was accommodated by transtensional deformation across the proto-gulf region, with a smaller amount of strike-slip motion west of the peninsula (Fletcher et al., 2007; Sutherland et al., 2012; Bennett et al., 2012a). In

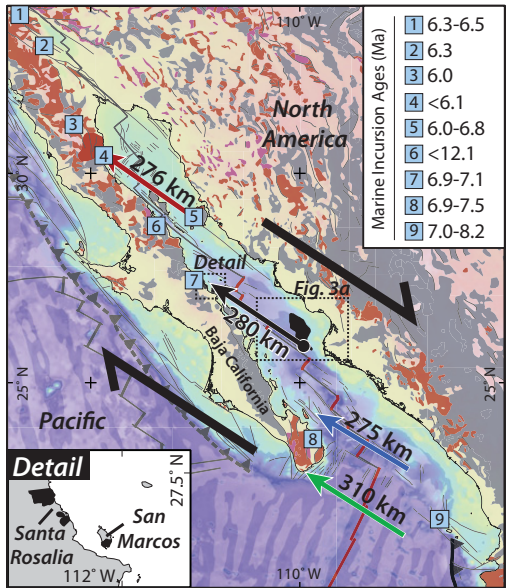

Figure 1. Geology and tectonics of southwestern North America. Black arrow indicates amount of post-rupture displacement between east Guaymas evaporite (EGE) and gypsums near Santa Rosalía, Baja California Sur, Mexico (detail after Wilson and Rocha, 1955). Colored arrows indicate other estimates of displacement since onset of seafloor spreading (green-Fletcher et al., 2007; blue-Sutherland et al., 2012; red-Oskin and Stock, 2003). Blue boxes show locations and (references in Table DR1 [see footnote 1]) Map background is shaded relief map (Smith and Sandwell, 1997) with overlain intrusive (red), volcanic (gray), and metamorphic (magenta) rocks (after Reed et al., 2005) and magnetic anomalies (blue-after Maus et al., 2009). Plate boundaries (black, red, and gray lines) are after Fletcher et al. (2007). ages (see key) of earliest marine sediments this model, basins within the proto-gulf have morphologies similar to the rhomboid-shaped pull-apart basins of the modern Salton Trough region, where Pacific-North America relative motion is accommodated by basin-scale strain partitioning and wrench tectonics (e.g., Axen and Fletcher, 1998). These two kinematic models predict different patterns of faulting in the proto-gulf, and imaging of the early extensional basins under the thick sediments of the eastern margin of the Gulf of California can improve our understanding of early rift evolution in the gulf.

We present multichannel seismic (MCS) data from the 2002 R/V Maurice Ewing cruise EW0210 (part of the PESCADOR seismic experiment) that cross the eastern Guaymas Basin (Fig. 1). These data image a unit that we interpret as an $\sim 2$-km-thick evaporite body that formed on extended continental crust during the Late Miocene. Thick evaporites have not been previously documented in the Gulf of California. In rifts, evaporites typically form under conditions unique to the latest stages of continental rupture and the onset of seafloor spreading (Evans, 1978). Thus, the presence, age, thickness, and shape of the evaporite in the Guaymas Basin place new constraints on the history of marine incursions and early basin development during this transitional stage in the Gulf of California.

\section{THICK EVAPORITE IN GUAYMAS} BASIN

A prominent feature of stacked MCS data from the eastern Guaymas Basin is a bright undulating reflector at $\sim 1.5-2.0 \mathrm{~s}$ two-way traveltime (TWT) (Fig. 2; see the GSA Data Repository $\left.^{1}\right)$. We interpret this reflector as the top of a thick evaporite unit, which we refer to as the east Guaymas evaporite (EGE). This interpretation is based on the similarity of features in these data to the structure and seismic character of well-studied salt bodies, such as Late Miocene Mediterranean evaporites (e.g., Fiduk, 2009). The polarity of the high-amplitude reflection from the top of salt is consistent with

\footnotetext{
*E-mail: ncm@mit.edu. geosociety.org or Documents Secretary, GSA, P.O. Box 9140, Boulder, CO 80301, USA.

[GEOLOGY Data Repository item 2013070 | doi:10.1130/G33747.1

(c) 2012 Geological Society of America. For permission to copy, contact Copyright Permissions, GSA, or editing@geosociety.org.
}

${ }^{1}$ GSA Data Repository item 2013070, Figures DR1-DR4 (high-resolution plots and interpretations of seismic data), Figure DR5 (cross section and ca. 7 Ma reconstruction), and Table DR1 (locations and ages of earliest marine sediments), is available online at www.geosociety.org/pubs/ft2013.htm, or on request from editing@ 


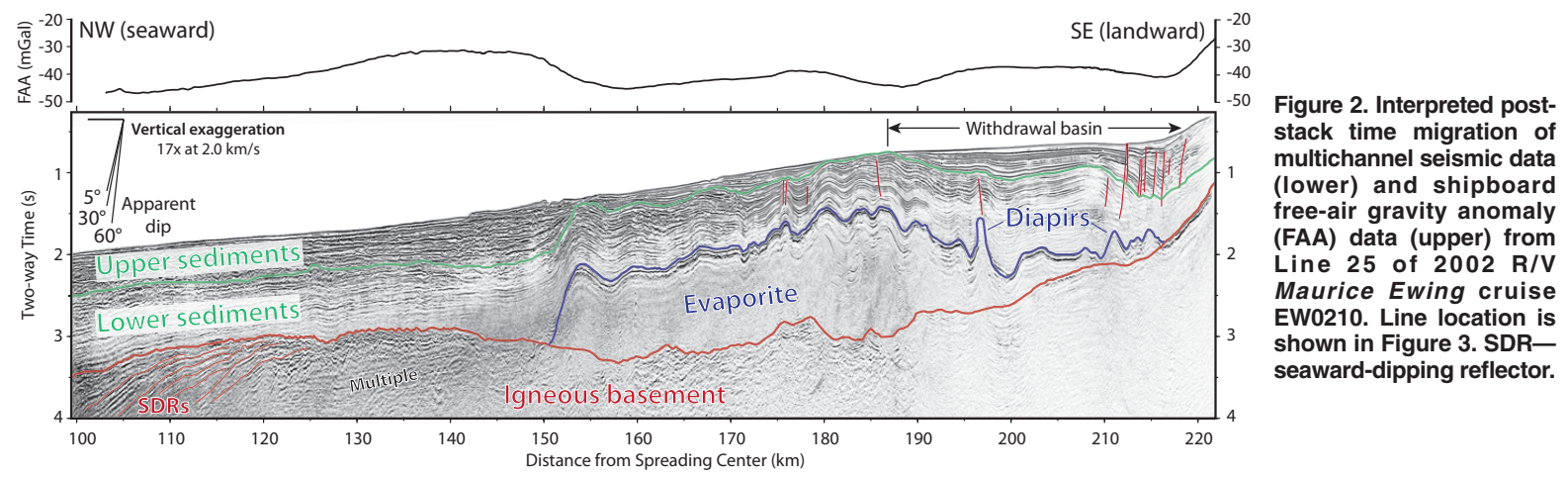

evaporites underlying sediments. The salt body is seismically transparent, with a base defined by an irregular reflection at $\sim 3 \mathrm{~s}$ TWT. A seismic velocity model across the Guaymas Basin (Lizarralde et al., 2007) resolves the imaged evaporite body as a region with velocities of $\sim 4.0-4.5 \mathrm{~km} / \mathrm{s}$, consistent with halite or gypsum (e.g., Sharma, 1997). Using these velocities, we estimate that the evaporite is $\sim 2 \mathrm{~km}$ thick.

Deformation in the EGE is consistent with models and observations of salt flowing seaward on a subsiding margin (e.g., Brun and Fort, 2011). To the southeast, the evaporite is overlain by an $~ 30-\mathrm{km}$-wide basin, and the salt is thinned and diapiric, features indicative of salt withdrawal (Vendeville, 1992). To the northwest, the evaporite is thickened by gentle folds, indicating that the salt was compressed as it flowed downslope from beneath the withdrawal basin.

Sediments overlying the EGE can be divided into upper and lower sections, separated by an angular unconformity that marks the onset of salt deformation. In the 750 -m-thick lower section, folds are parallel to the top of the evaporite, indicating that these sediments were deposited on a flat evaporite surface, and the salt began to flow seaward later, presumably after margin subsidence and sediment load reached a critical point. The upper sedimentary section is characterized by mostly undeformed sediments that onlap the folded lower section surface. The dip in these beds decreases upsection, indicating that deposition of the upper section was synchronous with the seaward flow of the salt. These sediments are as thick as $\sim 750 \mathrm{~m}$ in the center of the withdrawal basin and pinch out against topographic highs in the lower sediments. Where the salt is thickest (180-190 km; Fig. 2), this upper section is absent and the lower sediments are pushed up to the seafloor. At the southeastern edge of the withdrawal basin, beds are offset by normal faults and form a roll-over anticline, a feature of syntectonic sedimentation. These faults offset the seafloor, indicating that salt withdrawal is ongoing. The same thickness of sediment appears to have been deposited seaward of the salt, but these units were undisturbed by salt flow and thus lack the angular unconformity that separates the units over the evaporite.

The areal extent of the EGE is constrained by the edge of salt on four seismic lines that cross the unit and by gravity data. The imaged salt body is coincident with a low free-air anomaly observed in shipboard gravity profiles along the MCS lines (Fig. 2). A low in altimetry-derived gravity appears to be the same feature imaged by the MCS data (Fig. 3A). This $\sim 50 \times 100 \mathrm{~km}$ anomaly traces a north-south-trending western margin, which correlates with the western evaporite edge revealed by the MCS data, and a northeast-southwest-trending southeastern margin. To the north and south, the anomaly and imaged evaporite terminate against the North Guaymas and Carmen Fracture Zones, respectively (Lines 26 and 1183-1184; see the Data Repository). Near its center and near the South Guaymas Fracture Zone, the basin appears to step to the southeast.

The EGE is on extended continental crust with rift-related, magmatic intrusions (Lizarralde et al., 2007). The MCS data show that the seaward (northwestern) edge of the evaporite is abrupt and steeply dipping. Seaward of this edge, the basement reflector is bright and rough, suggestive of extrusive igneous rocks. A seaward-dipping reflector sequence is present just seaward of this rough basement. Seaward-dipping reflectors are commonly attributed to subaerial lava flows near the continent-ocean transition of volcanic rifted margins (e.g., White and McKenzie, 1989). In the seismic velocity model, a lateral change in lower crustal seismic velocities from continental (intermediate) to oceanic (mafic) is centered below the seaward-dipping reflectors, suggesting that the edge of the evaporate is near the continent-ocean transition and the onset of new igneous crustal production.

\section{CORRELATION TO THE SANTA ROSALÍA EVAPORITES}

Scattered gypsum beds are well documented to the northwest near Santa Rosalía, on the Baja California peninsula (Fig. 1). On the southern end of Isla San Marcos, a continuous outcrop of gypsum, $2 \times 4 \mathrm{~km}$ in areal extent, is exposed by one of the world's largest gypsum mines (Ochoa-Landín et al., 2000; Founie, 2007). In the nearby Santa Rosalía Basin, scattered gypsum beds extend over an $\sim 10 \times 30 \mathrm{~km}$ region and locally reach thicknesses of as much as $\sim 70 \mathrm{~m}$ (Wilson and Rocha, 1955).
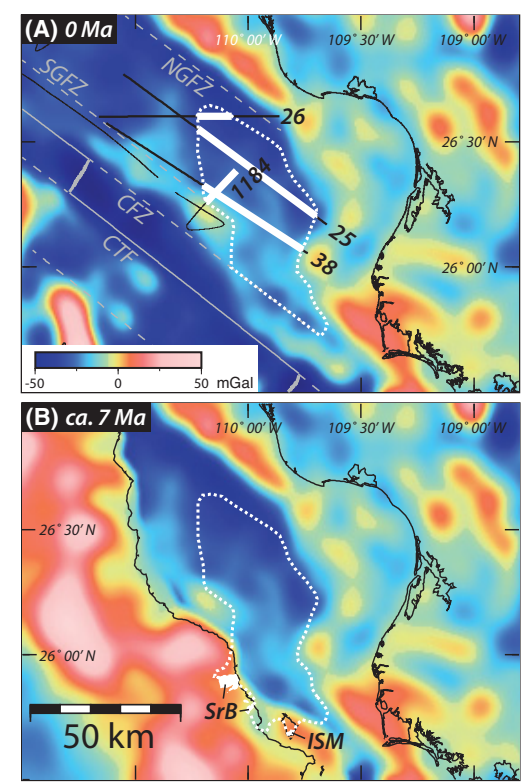

Figure 3. A: Satellite-derived free-air gravity anomaly (FAA) data (Sandwell and Smith, 2009) in eastern Guaymas Basin (Gulf of California, Mexico) with interpreted extents of east Guaymas evaporite (EGE, white dotted line) based on extent of salt imaged by multichannel seismic data (thick white lines) NGFZ-North Guaymas Fracture Zone, SGFZ-South Guaymas Fracture Zone, CFZ-Carmen Fracture Zone, and CTF-Carmen transform fault. B: Reconstruction of EGE, gypsums in Santa Rosalía basin (SrB) and on Isla San Marcos (ISM), FAA gravity data, and modern coastlines obtained by displacing Baja California peninsula by $280 \mathrm{~km}$ along azimuth of $126^{\circ}$. 
It is likely that the Santa Rosalía evaporites formed at the same time and place as the EGE. These gypsum beds reconstruct to the southern edge of the EGE basin if the Guaymas rift segments and the Carmen segment are closed by $280 \pm 20 \mathrm{~km}$ along an azimuth of $306^{\circ}$, parallel to the modern spreading direction and bounding transform faults and fracture zones (Fig. 3). The $\pm 20 \mathrm{~km}$ uncertainty is the half-width of the EGE border along the Carmen Fracture Zone. This reconstruction places the relatively thin northwestern evaporites at the edge of the more extensive, $\sim 2$-km-thick EGE. The relative thickness of the two units makes sense if the Santa Rosalía evaporites formed along the fringe of the larger EGE basin, as suggested by the reconstruction.

The $\sim 280 \mathrm{~km}$ displacement vector implied by the correlation of the EGE with gypsum units near Santa Rosalía is in close agreement to two independent estimates of post-rupture extension, implying that the reconstruction represents a time just before lithospheric rupture and the onset of seafloor spreading. Using seismic refraction data, Lizarralde et al. (2007) estimated $280 \mathrm{~km}$ of new igneous crust formation along the modern spreading direction in the northern Guaymas rift segment. Oskin and Stock (2003) correlated and dated volcanic tuffs in the northern Gulf of California and estimated $276 \pm 13 \mathrm{~km}$ of post-rupture separation along an azimuth of $315^{\circ}$ across the Upper Delfín BasinTiburón Basin rift segment since ca. 6.3 Ma. Similar magnitude, post-rupture displacements of $\sim 275-310 \mathrm{~km}$ have been suggested for the southern Gulf of California (Fig. 1; Fletcher et al., 2007; Sutherland et al., 2012).

The Santa Rosalía gypsums are generally underlain by and locally interbedded with limestones (Wilson and Rocha, 1955) that contain Late Miocene (11.2-5.3 Ma) marine fauna (Ortlieb and Colletta, 1984). Holt et al. (2000) concluded that these marine rocks were deposited by 6.93-7.09 Ma, based on an ${ }^{40} \mathrm{Ar}-{ }^{39} \mathrm{Ar}$ age of $6.76 \pm 0.9 \mathrm{Ma}$ for the Cinta Colorada, an andesitic tuff that overlies the limestone and gypsum units, and magnetostratigraphy. This well-constrained age for the Santa Rosalía gypsums suggests that the EGE also formed during the Late Miocene, beginning ca. $7 \mathrm{Ma}$.

\section{EARLY MARINE INCURSIONS AND BASIN FORMATION}

Evaporite volume is a function of sourcewater salinity, evaporation efficiency, and deposition duration. Complete evaporation of a 100-m-deep column of typical ocean water ( $\sim 3.5 \mathrm{wt} \%$ dissolved salt) produces a total evaporite thickness of $\sim 1.7 \mathrm{~m}$ (Warren, 2006). Thus, $\sim 115 \mathrm{~km}$ of seawater is needed to produce the $\sim 2$-km-thick EGE. This is a substantial amount of seawater, and the required amount would be even greater if the brine water was less saline than seawater. For this reason, marine-fed brines have been invoked as the source of salt deposits of similar thickness (Warren, 2006), such as those in the Mediterranean (e.g., Hsü et al., 1973) and the Atlantic (e.g., Evans, 1978; Jackson and Cramez, 2000). The observed $2 \mathrm{~km}$ of salt could have been deposited in as few as 57-115 k.y., assuming an initial brine with the salinity of seawater and modern subtropical net evaporation rates of 1-2 m/yr (e.g., Schanze et al., 2010). We thus infer that the EGE resulted from substantial, repeated marine incursions, and, based on the correlation with the Santa Rosalía gypsum units, we infer that these incursions began just prior to ca. $7 \mathrm{Ma}, \sim 0.5-1.0 \mathrm{~m}$.y. before the earliest marine incursions in the northern Gulf of California (e.g., McDougall, 2008; Dorsey et al., 2011; Bennett et al., 2012b)

The Late Miocene rocks of the Santa Rosalía Basin inform us of conditions during deposition of the associated EGE. This basin is floored by scattered marine limestone and gypsum units that unconformably overlie heavily faulted prerift Comondu arc volcanic rocks (Wilson and Rocha, 1955), indicating that these units represent the first deposition in proto-gulf extensional basins. Color banding in the gypsum units suggests that brine chemistry varied through time, and the gypsum is interbedded with thin clastic horizons (Ochoa-Landín et al., 2000), suggesting that sediment supply also varied. Both the basal marine limestone and gypsum are overlain by a sequence of prograding fan-delta deposits that formed during repeated periods of basinfloor subsidence, a result of synrift extensional faulting (Wilson and Rocha, 1955; OchoaLandín et al., 2000). These sequences suggest that a series of marine incursions flooded the Santa Rosalía Basin through the end of the Late Miocene into the Pleistocene (Ochoa-Landín et al., 2000). Large positive values of $\delta^{34} S$ in the gypsum units (Ortlieb and Colletta, 1984) have been interpreted as evidence that they formed by evaporation of seawater in isolated basins (Ochoa-Landín et al., 2000). A similar setting has been invoked to explain the deposition of thin gypsum deposits in Late Miocene basins of the northern Gulf of California (EscalonaAlcázar et al., 2001). These observations and interpretations suggest that the EGE formed in an isolated basin supplied by a series of marine flooding events.

In the proto-gulf, extensional tectonics and volcanic ridges would have created elongate basins with restricted access to inundating seawater, conditions favorable for sustaining hypersaline brines throughout the deposition of thick evaporites (e.g., Warren, 2006). A modern analogue of such a setting is the Danakil Depression (Afar triangle, Africa; Orszag-Sperber et al., 1998; Jackson and Cramez, 2000), where marine water from the Red Sea seeps through and/or periodically spills over an emerging horst, supplying brine water to fault- and lava flow-bounded basins (Manighetti et al., 1997; Jackson and Cramez, 2000). In these isolated basins, the resupply of saline water is outpaced by evaporation, enabling brines to maintain saturation and precipitate thick salt deposits (Friedman, 1972). These Afar evaporites are forming directly on proto-oceanic crust in the latest stages of a transition from continental extension to seafloor spreading, similar to the rift stage suggested for formation of the EGE by the proximity of seaward-dipping reflectors (Fig. 2) and fast lower crustal velocities. In the Afar triangle, heat supplied by rift-related magmatism aides in evaporation from brines, as may have been the case during magma-rich rifting of the Guaymas Basin (Lizarralde et al., 2007).

\section{IMPLICATIONS FOR THE KINEMATICS OF EARLY RIFTING}

The margins of the evaporite likely follow the orientation of basin-bounding faults, providing constraints on models of strain partitioning during the earliest stages of rifting. The interpreted western edge of the EGE basin trends northsouth, implying that, without regional rotation, early basin-forming faults along this edge also trended approximately north-south, and that some component of proto-gulf extension was oriented east-west (Fig. 3). The southeastern edge of the evaporite trends northeast-southwest. This edge is colocated with a 5-km-deep escarpment in the crustal velocity model (see the Data Repository). This escarpment also appears to trend northeast-southwest in the gravity data, implying that a significant component of early extension was oriented parallel to the modern, northwest-southeast spreading direction. Furthermore, the EGE steps to the southeast near the South Guaymas Fracture Zone, creating an S-shaped outline that is similar to the shape of a salt deposit in the transtensional Laguna Salada Basin of the southern Salton Trough (e.g., Axen and Fletcher, 1998). Together, these observations suggest that early extension, as it localized within the Gulf of California ca. $7 \mathrm{Ma}$, was partitioned onto both north-south- and northeastsouthwest-striking normal faults within transtensional basins. This conclusion is consistent with the model Bennett et al. (2012a) proposed to explain transtensional deformation in coastal Sonora that accelerated ca. 6.5 Ma.

\section{CONCLUSIONS}

Seismic data reveal a large evaporate unit that formed during repeated marine incursions into the Late Miocene proto-Gulf of California. Closing the gulf along northwest-striking fracture zones places evaporites near Santa Rosalía along the southern edge of the EGE, suggesting that these gypsum units formed along the fringe of the much larger EGE and that the evaporites were deposited prior to lithospheric rupture. The 
shape and size of the basin, and our inferred age for the evaporite, support a kinematic model in which a significant portion of Pacific-North America relative motion is accommodated by transtensional shearing along the eastern protoGulf of California ca. $7 \mathrm{Ma}$.

\section{ACKNOWLEDGMENTS}

We are grateful to Cathy Busby and Paul Umhoeffer for discussions about the Santa Rosalía gypsum units and to three anonymous reviewers for thei critiques of this paper. This work was funded by a grant from the U.S. National Science Foundation MARGINS program.

\section{REFERENCES CITED}

Atwater, T., and Stock, J., 1998, Pacific-North America plate tectonics of the Neogene southwestern United States: An update: International Geology Review, v. 40, p. 375-402, doi: 10.1080 100206819809465216

Axen, G.J., and Fletcher, J.M., 1998, Late MiocenePleistocene extensional faulting, northern Gulf of California, Mexico and Salton Trough, California: International Geology Review, v. 40, p. 217-244, doi:10.1080/00206819809465207.

Bennett, S.E., Oskin, M.E., and Iriondo, A., 2012a, Progressive localization of dextral shear in the late proto-Gulf of California: Geological Society of America Abstracts with Programs, v. 44, no. 3 , p. 5 .

Bennett, S.E., Oskin, M.E., Dorsey, R.J., and Iriondo, A., 2012b, Volcanic rocks and microfossils confirm a Late Miocene age for marine strata on Isla Tiburon, Gulf of California: Geological Society of America Abstracts with Programs, v. 44 , no. 3 , p. 19

Brun, J.-P., and Fort, X., 2011, Salt tectonics at passive margins: Geology versus models: Marine and Petroleum Geology, v. 28, p. 1123-1145, doi:10.1016/j.marpetgeo.2011.03.004

DeMets, C., and Dixon, T.H., 1999, New kinematic models for Pacific-North America motion from $3 \mathrm{Ma}$ to present, I: Evidence for steady motion and biases in the NUVEL-1A model: Geophysical Research Letters, v. 26, p. 19211924, doi:10.1029/1999GL900405.

Dixon, T., Farina, F., DeMets, C., Suarez-Vidal, F., Fletcher, J., Marquez-Azua, B., Miller, M., Sanchez, O., and Umhoefer, P., 2000, New kinematic models for Pacific-North America motion from 3 Ma to present, II: Evidence for a "Baja California shear zone": Geophysical Research Letters, v. 27, p. 3961-3964, doi:10.1029 /2000GL008529.

Dorsey, R.J., Housen, B.A., Janecke, S.U., Fanning, C.M., and Spears, A.L.F., 2011, Stratigraphic record of basin development within the San Andreas fault system: Late Cenozoic Fish Creek-Vallecito basin, southern California: Geological Society of America Bulletin, v. 123, p. 771-793, doi:10.1130/B30168.1.

Escalona-Alcázar, F.J., Delgado-Argote, L.A., López-Martínez, M., and Rendón-Márquez, G., 2001, Late Miocene volcanism and marine incursions in the San Lorenzo Archipelago, Gulf of California, Mexico: Revista Mexicana de Ciencias Geologicas, v. 18, p. 111-128.
Evans, R., 1978, Origin and significance of evaporites in basins around Atlantic margin: American Association of Petroleum Geologists Bulletin, v. 62, p. 223-234.

Fiduk, J.C., 2009, Evaporites, petroleum exploration, and the Cenozoic evolution of the Libyan shelf margin, central North Africa: Marine and Petroleum Geology, v. 26, p. 1513-1527, doi:10.1016/j.marpetgeo.2009.04.006.

Fletcher, J.M., Grove, M., Kimbrough, D., Lovera, O., and Gehrels, G.E., 2007, Ridge-trench interactions and the Neogene tectonic evolution of the Magdalena shelf and southern Gulf of California: Insights from detrital zircon $\mathrm{U}-\mathrm{Pb}$ ages from the Magdalena fan and adjacent areas: Geological Society of America Bulletin, v. 119, p. 1313-1336, doi:10.1130/B26067.1.

Founie, A., 2007, Gypsum: U.S. Geological Survey 2006 Minerals Yearbook, v. I-Metals and minerals, p. 33.1-33.12

Friedman, G.M., 1972, Significance of Red Sea in problem of evaporites and basinal limestones: American Association of Petroleum Geologist Bulletin, v. 56, p. 1072-1086.

Holt, J.W., Holt, E.W., and Stock, J.M., 2000, An age constraint on Gulf of California rifting from the Santa Rosalía basin, Baja California Sur Mexico: Geological Society of America Bulletin, v. 112, p. 540-549, doi:10.1130/0016 -7606(2000)112<540:AACOGO>2.0.CO;2.

Hsü, K., Ryan, W., and Cita, M., 1973, Late Miocene desiccation of the Mediterranean: Nature, v. 242, p. 240-244, doi:10.1038/242240a0.

Jackson, M., and Cramez, C., 2000, Role of subaeria volcanic rocks and mantle plumes in creation of South Atlantic margins: Implications for sal tectonics and source rocks: Marine and Petroleum Geology, v. 17, p. 477-498, doi:10.1016 /S0264-8172(00)00006-4.

Lizarralde, D., Axen, G.J., Brown, H.E., Fletcher, J.M., Gonzalez-Fernandez, A., Harding, A.J., Holbrook, W.S., Kent, G.M., Paramo, P., Sutherland, F., and Umhoefer, P.J., 2007, Variation in styles of rifting in the Gulf of California: $\mathrm{Na}$ ture, v. 448 , no. 7152 , p. 466-469, doi: 10.1038 /nature06035.

Manighetti, I., Tapponnier, P., Courtillot, V., Gruszow, S., and Gillot, P., 1997, Propagation of rifting along the Arabia-Somalia plate boundary: The Gulfs of Aden and Tadjoura: Journal of Geophysical Research, v. 102 , p. 2681-2710, doi 10.1029/96JB01185

Maus, S., and 22 others, 2009, EMAG2: A 2-arc min resolution Earth Magnetic Anomaly Grid compiled from satellite, airborne, and marine magnetic measurements: Geochemistry, Geophysics, Geosystems, v. 10, Q08005, doi:10.1029 /2009GC002471.

McDougall, K., 2008, Late Neogene marine incursions and the ancestral Gulf of California, in Reheis, M., et al., eds., Late Cenozoic drainage history of the southwestern Great Basin and lower Colorado River region: Geologic and biotic perspective: Geological Society of America Special Paper 439, p. 355-373, doi:10.1130/2008.2439(16).

Ochoa-Landín, L., Ruiz, J., Calmus, T., Pérez-Segura, E., and Escandón, F., 2000, Sedimentology and stratigraphy of the Upper Miocene El Boleo Formation, Santa Rosalía, Baja California, Mex- ico: Revista Mexicana de Ciencias Geologicas, v. 17 , no. 2 , p. $83-96$.

Orszag-Sperber, F., Harwood, G., Kendall, A., and Purser, B.H., 1998, A review of the evaporites of the Red Sea-Gulf of Suez rift, in Purser, B.H., and Bosence, D.W., eds., Sedimentation and tectonics in rift basins: Red Sea-Gulf of Aden: London, Chapman and Hall, p. 409-426.

Ortlieb, L., and Colletta, B., 1984, Sintesis cronoestratigrafica sobre el Neogeno y el Cuaternario marino de la cuenca Santa Rosalía, Baja California Sur, Mexico, in Malpica-Cruz, V., et al., eds., Neotectonics and sea level variations in the Gulf of California area, a symposium: Universidad Nacional Autónoma de México, Instituto de Geologica Revista, v. 8, p. 241-260.

Oskin, M., and Stock, J., 2003, Pacific-North America plate motion and opening of the Upper Delfín basin, northern Gulf of California, Mexico: Geological Society of America Bulletin, v. 115, p. 1173-1190, doi:10.1130/B25154.1.

Reed, J.C., Wheeler, J.O., and Tucholke, B.E., 2005, Geologic map of North America: Geological Society of America Continental-Scale Map CSM001, scale 1:5,000,000.

Sandwell, D.T., and Smith, W.H.F., 2009, Global marine gravity from retracked Geosat and ERS-1 altimetry: Ridge segmentation versus spreading rate: Journal of Geophysical Research, v. 114, B01411, doi:10.1029/2008JB006008.

Schanze, J.J., Schmitt, R.W., and Yu, L.L., 2010, The global oceanic freshwater cycle: A state-of-the-art quantification: Journal of Marine Research, v. 68 , p. 569-595, doi:10.1357/002224010794657164.

Sharma, P., 1997, Environmental and engineering geophysics: Cambridge, UK, Cambridge University Press, 500 p.

Smith, W.H.F., and Sandwell, D.T., 1997, Global seafloor topography from satellite altimetry and ship depth soundings: Science, v. 277, p. 19561962, doi:10.1126/science.277.5334.1956

Sutherland, F.H., Kent, G.M., Harding, A.J., Umhoefer, P.J., Driscoll, N.W., Lizarralde, D., Fletcher, J.M., Axen, G.J., Holbrook, W.S., GonzalezFernandez, A., and Lonsdale, P., 2012, MidMiocene to Early Pliocene oblique extension in the southern Gulf of California: Geosphere, v. 8, p. 752-770, doi:10.1130/GES00770.1.

Vendeville, B., 1992, The rise of diapirs during thinskinned extension: Marine and Petroleum Geology, v. 9, p. 331-354, doi:10.1016/0264-8172 (92)90047-I.

Warren, J.K., 2006, Evaporites: Sediments, resources and hydrocarbons: Berlin, Heidelberg, Springer Verlag, $1036 \mathrm{p}$.

White, R., and McKenzie, D., 1989, Magmatism at rift zones-The generation of volcanic continental margins and flood basalts: Journal of Geophysical Research, v. 94, p. 7685-7729, doi:10.1029 /JB094iB06p07685.

Wilson, I.F., and Rocha, V.S., 1955, Geology and mineral deposits of the El Boleo copper district, Baja California, Mexico: U.S. Geological Survey Professional Paper 273, 134 p.

Manuscript received 14 June 2012

Revised manuscript received 12 September 2012

Manuscript accepted 21 September 2012

Printed in USA 


\section{Supplementary materials for Chapter 2}

These supplementary materials were originally published as GSA Data Repository Item 2013070. Included are a higher-resolution plot of seismic data and interpretations for Line 25 (Figure A-1) and seismic data and interpretations from additional lines crossing the East Guaymas Evaporite (EGE) (Figures A-2 through A-4). These seismic data, along with gravity data, form the basis of our interpreted evaporite basin extents shown in Figure 3 of the paper. Figure A-5 shows the position of the EGE in the crustal velocity model of Lizarralde et al. (2007), as well as within a cross section and map-view reconstruction for $\sim 7$ Ma. Table A-1 includes references for the locations and ages of earliest marine sediments shown in the Figure 1 of the paper.

\section{Supplementary Tables}

Table A-1. Locations and ages of earliest marine sediments in the Gulf of California.

\begin{tabular}{|c|c|c|c|c|c|}
\hline Locality $^{1}$ & Latitude & Longitude & Location & Unit & Age (Reference) \\
\hline 1 & 33.9063 & -116.6856 & $\begin{array}{l}\text { San Gorgonio } \\
\text { Pass }\end{array}$ & $\begin{array}{l}\text { Imperial } \\
\text { Formation }\end{array}$ & $\begin{array}{l}\text { 6.3-6.5 Ma } \\
\text { (McDougall et al., 1999) }\end{array}$ \\
\hline 2 & 33.0144 & -116.0761 & $\begin{array}{l}\text { Imperial } \\
\text { Valley }\end{array}$ & $\begin{array}{l}\text { Fish Creek } \\
\text { Gypsum }\end{array}$ & $\begin{array}{l}6.3 \mathrm{Ma} \\
\text { (Dorsey et al., 2007; } \\
\text { Dorsey et al., 2011) }\end{array}$ \\
\hline 3 & 31.1155 & -115.3572 & $\begin{array}{l}\text { Sierra San } \\
\text { Felipe }\end{array}$ & $\begin{array}{l}\text { San Felipe marine } \\
\text { sequence }\end{array}$ & $\begin{array}{l}\text { 5.5-6.0 Ma (Boehm, 1984) } \\
{[6.8 \pm 0.3 \mathrm{Ma}](\text { Stock, 1997) }}\end{array}$ \\
\hline 4 & 30.3888 & -114.6442 & $\begin{array}{l}\text { Arroyo } \\
\text { Matomi }\end{array}$ & $\begin{array}{l}\text { Puertecitos } \\
\text { Formation }\end{array}$ & $\begin{array}{l}3.27 \pm 0.04 \\
\text { (Martín-Barajas et al., 1997) } \\
{[6.1 \pm 0.5] \text { (Nagy et al., 1999) }}\end{array}$ \\
\hline 5 & 28.8779 & -112.5377 & Isla Tiburon & $\begin{array}{l}\text { SW Isla Tiburon } \\
\text { marine sequence }\end{array}$ & 6.0-6.8 Ma (Bennett et al., 2012) \\
\hline 6 & 28.6919 & -113.3762 & $\begin{array}{l}\text { Bahia de Los } \\
\text { Angeles }\end{array}$ & $\begin{array}{l}\text { Unnamed marine } \\
\text { sedimentary rocks }\end{array}$ & $\begin{array}{l}{[12.1 \pm 0.1 \mathrm{Ma}]} \\
\text { (Delgado-Argote et al., 2000) }\end{array}$ \\
\hline 7 & 27.4192 & -112.3580 & Santa Rosalia & Boleo Formation & 6.93-7.09 Ma (Holt et al., 2000) \\
\hline 8 & 23.5790 & -109.5913 & $\begin{array}{l}\text { San Jose del } \\
\text { Cabo }\end{array}$ & $\begin{array}{l}\text { Trinidad } \\
\text { Formation }\end{array}$ & $\begin{array}{l}\text { 6.9 Мa (Carreño, 1992) } \\
\text { 7.5 Ma (Molina-Cruz, 1994) }\end{array}$ \\
\hline 9 & 21.6312 & -106.5811 & $\begin{array}{l}\text { Islas Tres } \\
\text { Marias }\end{array}$ & $\begin{array}{l}\text { Arroyo Hondo } \\
\text { sedimentary rocks }\end{array}$ & $\begin{array}{l}\text { Late Miocene - Early Pliocene } \\
\text { (Carreño, 1985) } \\
\text { 7.0-8.2 (McCloy et al., 1988) }\end{array}$ \\
\hline
\end{tabular}

\footnotetext{
${ }^{1}$ Locality numbers refer to the numbers in the blue boxes in Figure 1 of the paper.
} 


\section{Supplementary Figures}

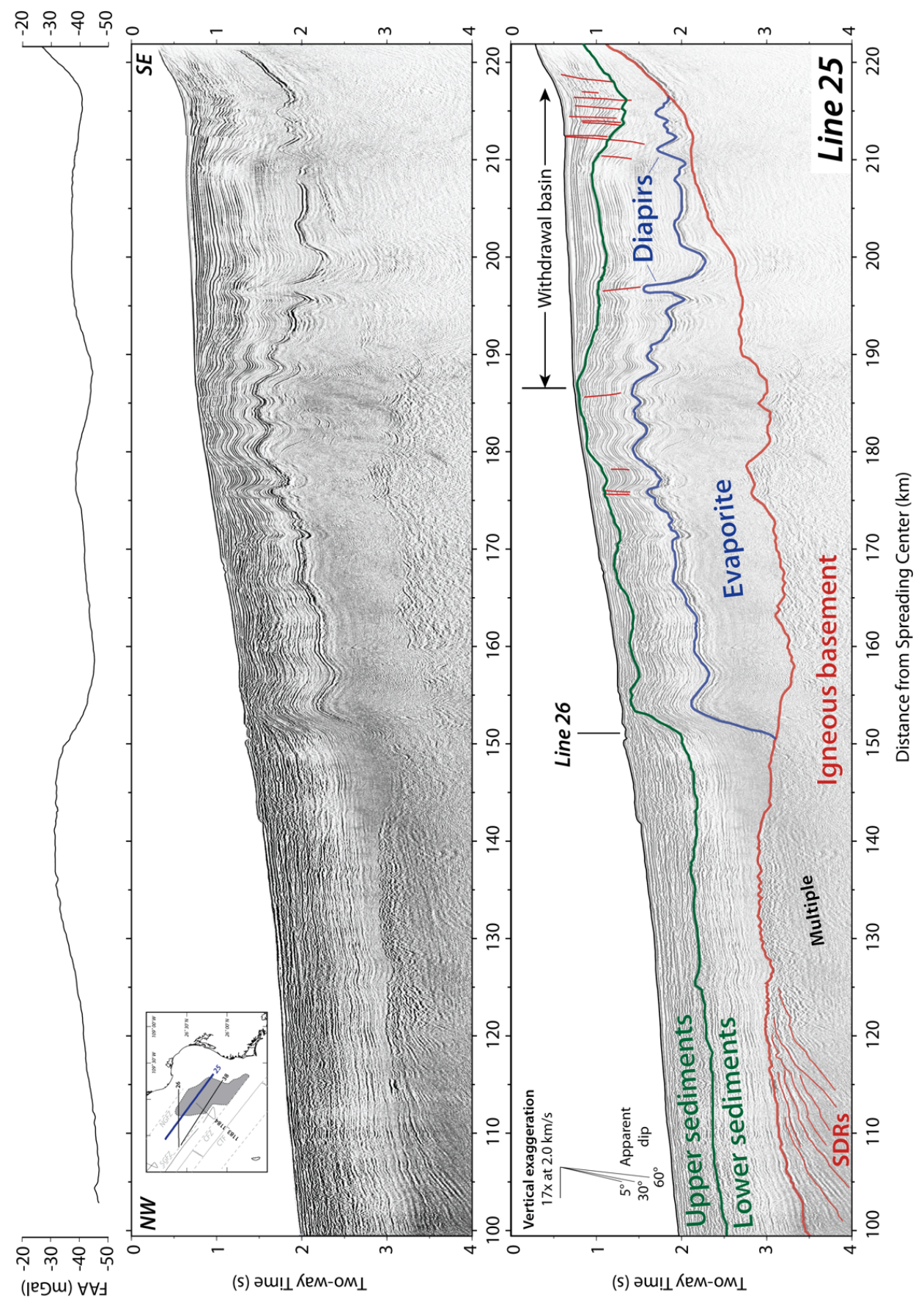

Figure A-1. Shipboard free-air gravity anomaly (top), post-stack time migration of MCS data (middle), and seismic data interpretations (bottom) along Line 25 of cruise EW0210. EW02 10 data were collected using the Ewing's 20-element airgun array and a 6-km-long hydrophone streamer. The shot spacing for this line was $100 \mathrm{~m}$. Data were processed by common-midpoint (CMP) sorting, band-pass filtering, velocity analysis, normal move out, inside and outside muting, stacking, post-stack wavenumber filtering to remove energy from the water-bottom multiple, and post-stack time migration. Line location is shown in the inset. 


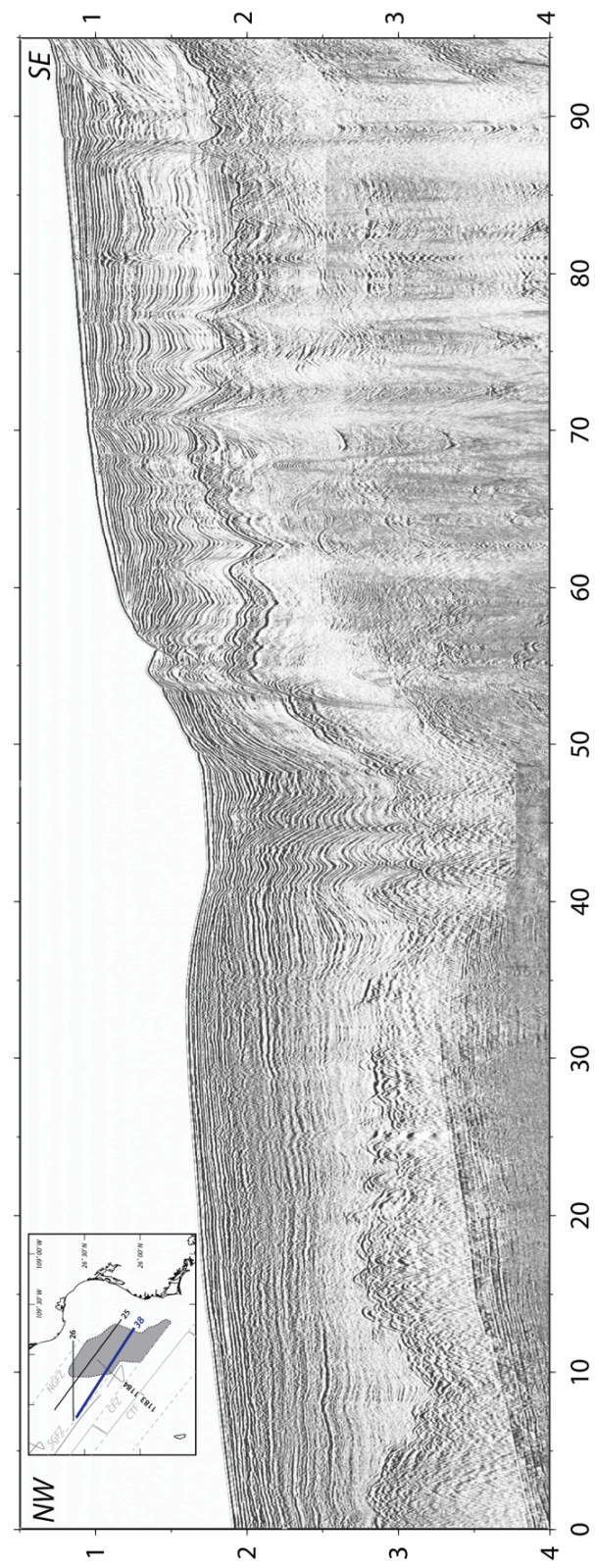

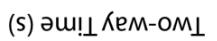

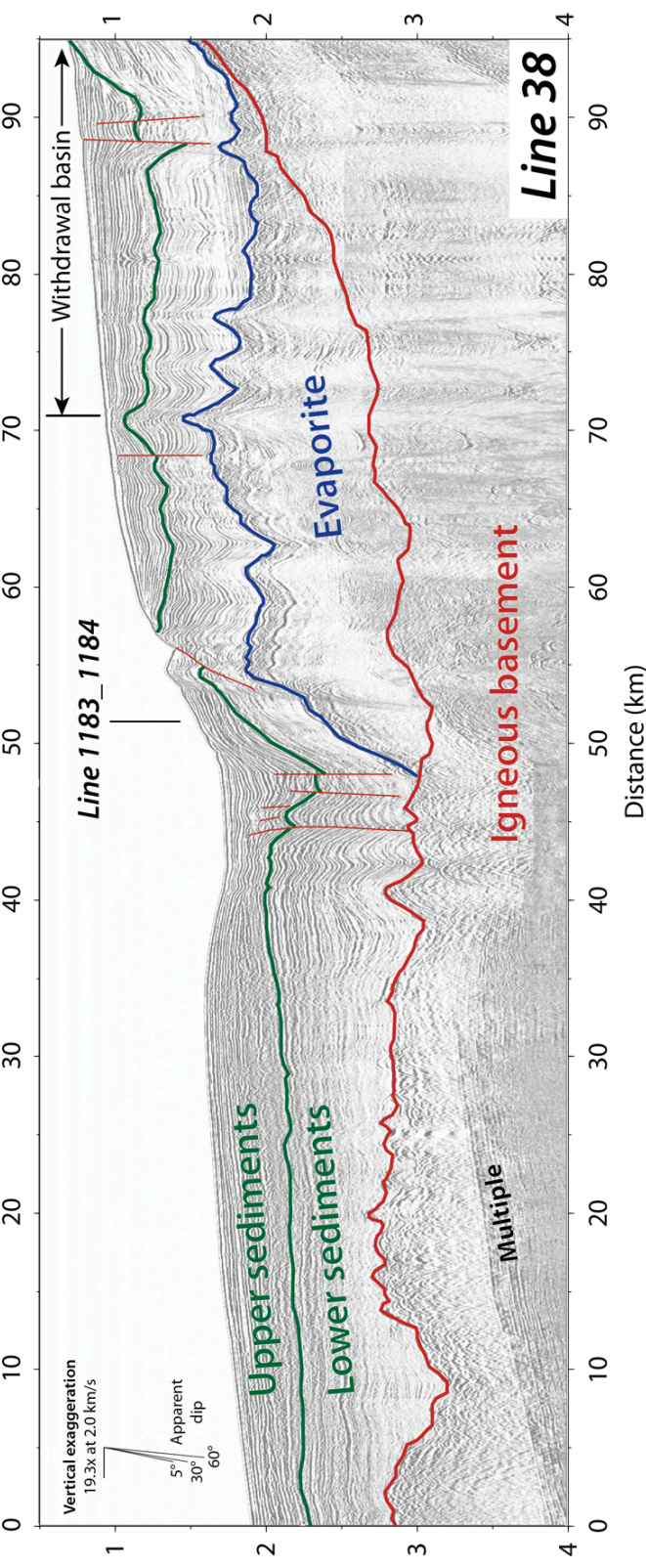

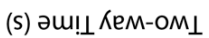

Figure A-2. Stacked MCS data (above) and interpretations (below) along Line 38 of cruise EW0210. The shot spacing for this line was $50 \mathrm{~m}$. Data were processed using a standard flow of CMP sorting, band-pass filtering, velocity analysis, normal move out, inside and outside muting, and stacking. Line location is shown in the inset. 


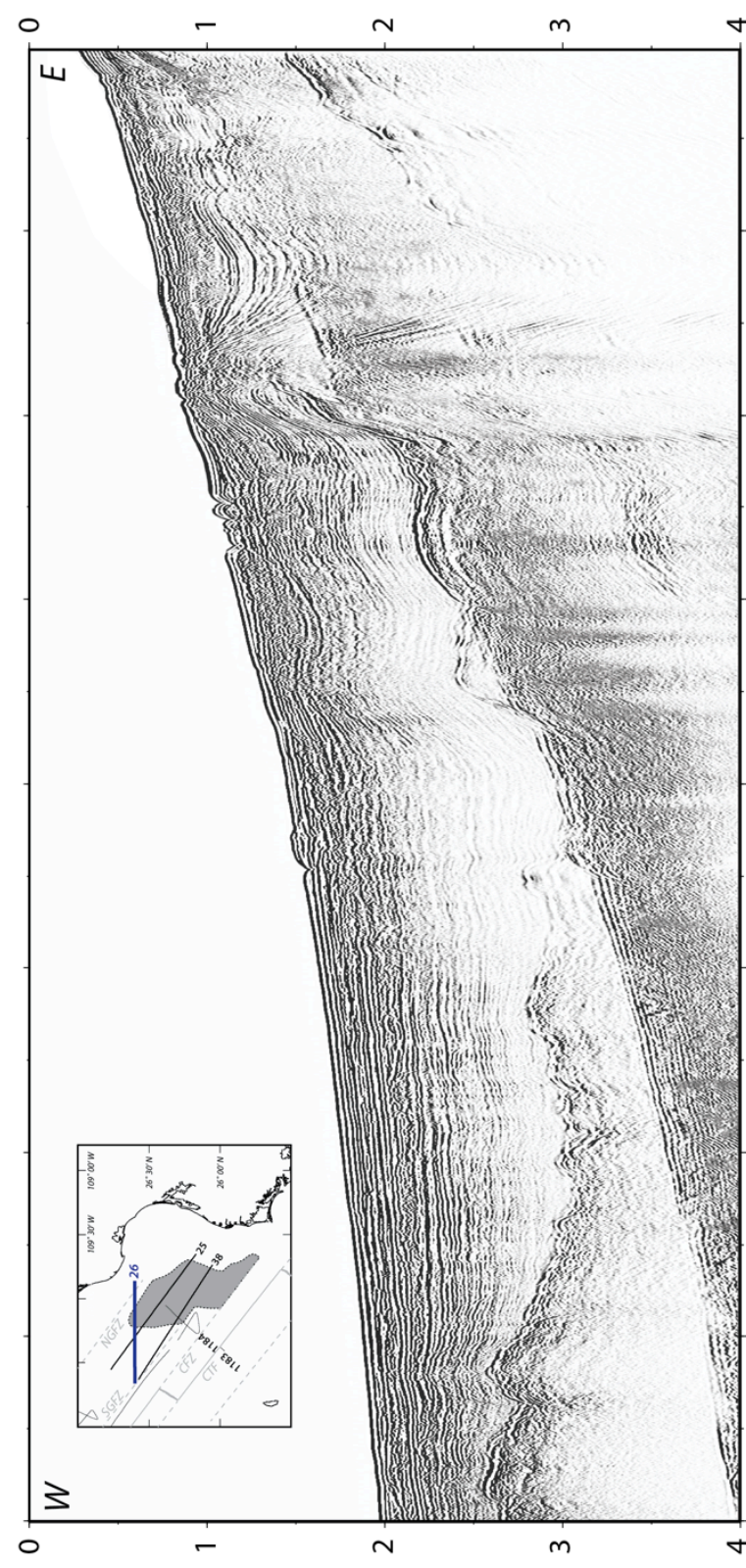

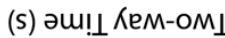

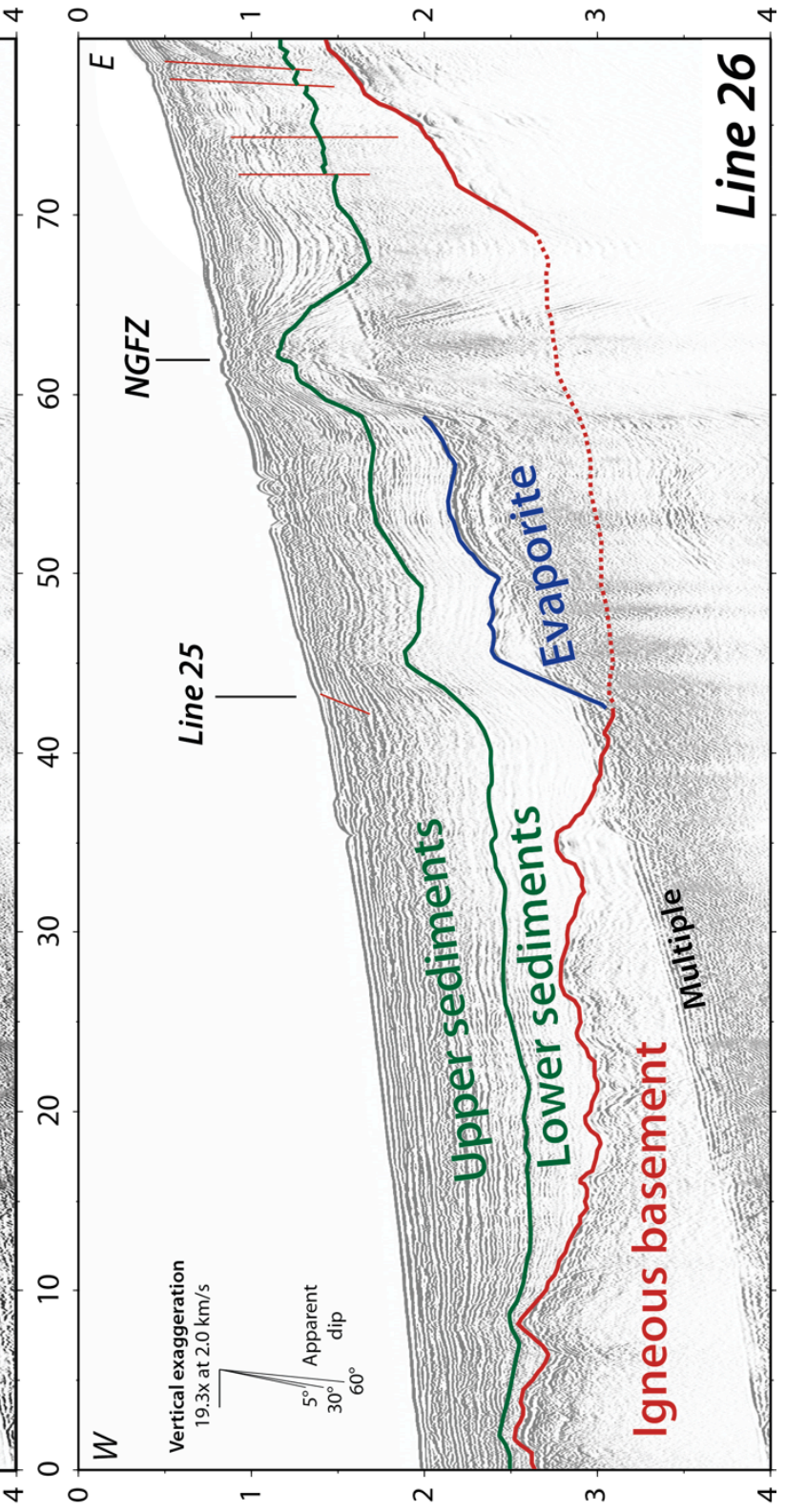

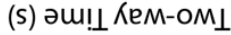

Figure A-3. Stacked MCS data (above) and interpretations (below) along Line 26 of cruise EWo210. The shot spacing for this line was $100 \mathrm{~m}$. Line location is shown in the inset. Data were processed as in Figure A-2. NGFZ - North Guaymas Fracture Zone (Figure 3 of the paper). 


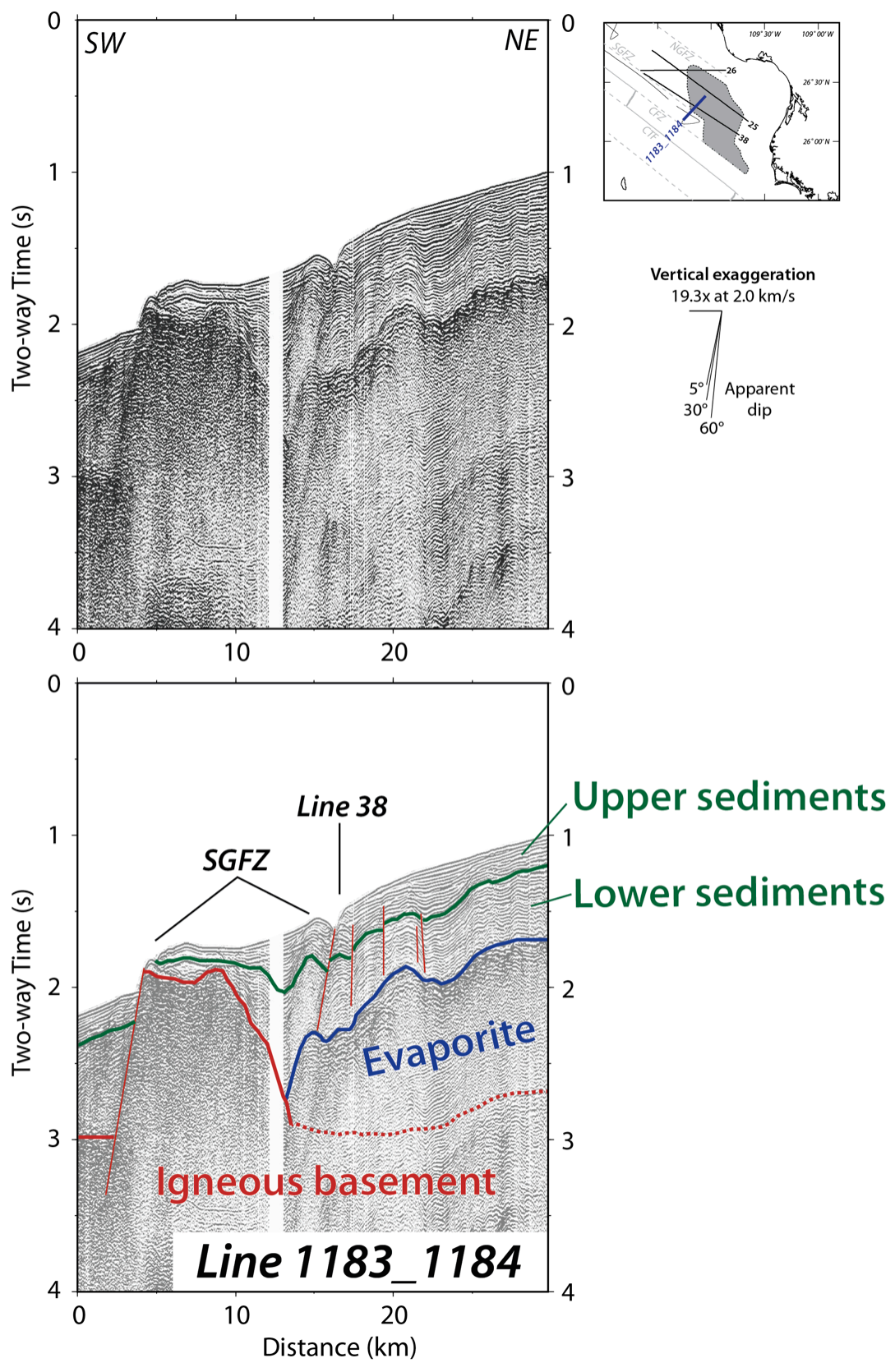

Figure A-4. Stacked MCS data (above) and interpretations (below) along Lines 1183 and 1184 (referred to collectively as "Line 1183_1184") of cruise GUAYo2WT. SGFZ_-South Guaymas Fracture Zone (Figure 3 of the paper). These data were collected using an MCS system, operated by the Scripps Institution of Oceanography (SIO), consisting of a 3-element airgun array towed at $\sim 3 \mathrm{~m}$ and a 1920-mlong, 24-channel hydrophone streamer. Shots were fired at a spacing of $\sim 50 \mathrm{~m}$. Stacked data shown here for Line 1183_1184 were processed by SIO and were obtained from the Academic Seismic Portal at the University of Texas Institute for Geophysics (http://www.ig.utexas.edu/sdc/). Data from GUAY02WT were originally processed and interpreted by Albertin (1989), but this work did not report evaporites in the Guaymas Basin. 


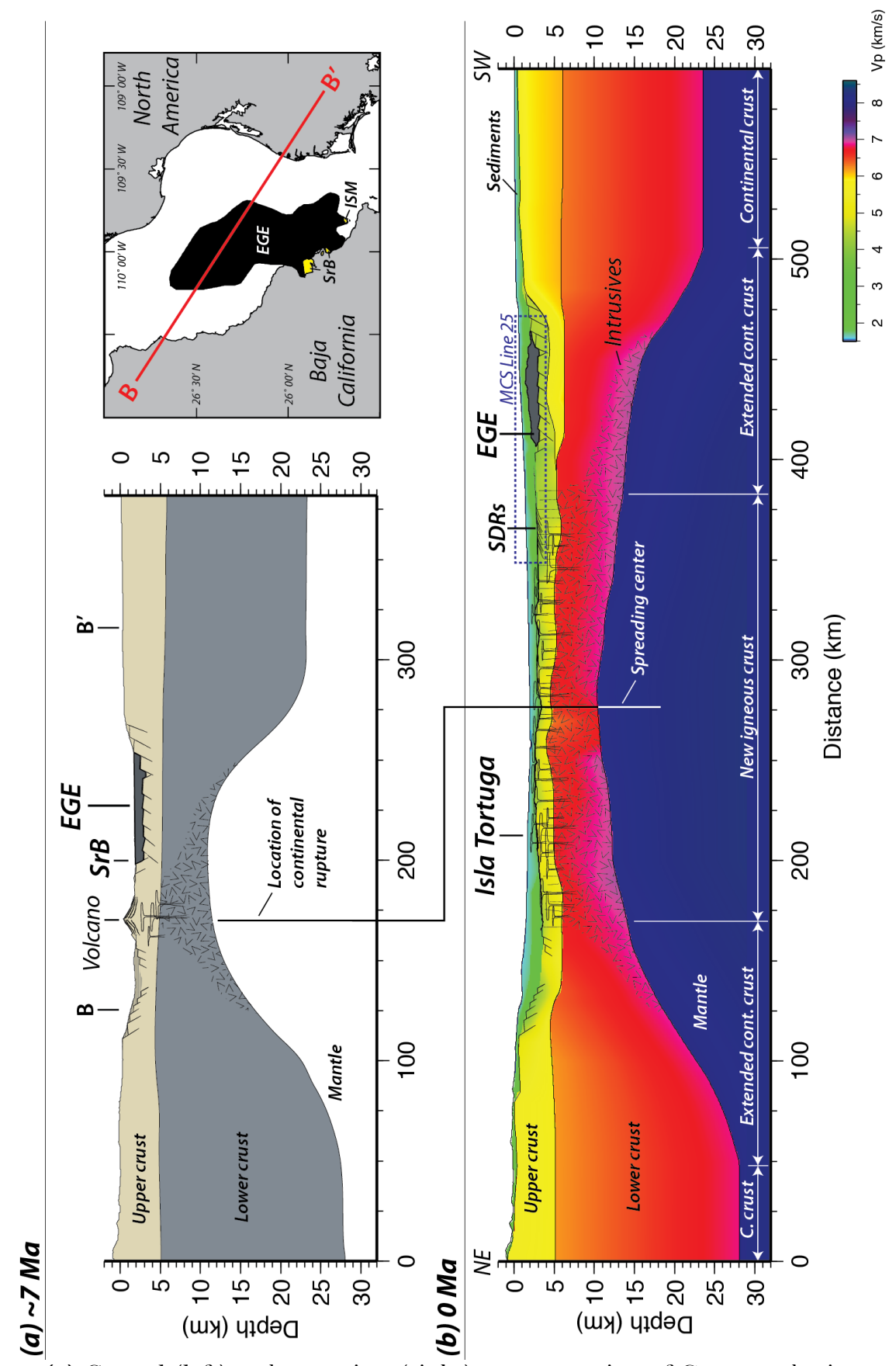

Figure A-5. (a) Crustal (left) and map-view (right) reconstruction of Guaymas basin to $\sim 7.1 \mathrm{Ma}$. The crustal model is based on removing $280 \mathrm{~km}$ of crust produced by seafloor spreading from the velocity model of Lizarralde et al. (2007). Similarly, the map-view reconstruction was produced by closing the North and South Guaymas spreading segments by $280 \mathrm{~km}$. This reconstruction places gypsum units from the Santa Rosalía Basin (SrB) and Isla San Marcos (ISM) on the southern edge of the east Guaymas evaporite (EGE). (b) Interpreted velocity model of Lizarralde et al. (2007) showing the position of the EGE and seaward-dipping reflectors (SDRs) as imaged by the multichannel-seismic data on Line 25 (Figure A-1). 


\section{References for the Supplement}

Albertin, M.L., 1989, Interpretations and analysis of Guaymas Basin Multi-channel Seismic Reflection Profiles: Implications for Tectonic History: University of Texas at Austin.

Bennett, S.E., Oskin, M.E., Dorsey, R.J., and Iriondo, A., 2012b, Volcanic rocks and microfossils confirm a late Miocene age for marine strata on Isla Tiburon, Gulf of California. Geological Society of America Abstracts with Programs, v. 44, No. 3, p. 19.

Boehm, M.C., 1984, An overview of the lithostratigraphy, biostratigraphy, and paleoenvironments of the late Neogene San Felipe marine sequence, Baja California, Mexico, in Frizzell, V.A., ed., Geology of the Baja California peninsula: Los Angeles, California, Pacific Section, Society of Economic Paleontologists and Mineralogists, p. 253-265.

Carreño, A.L., 1985, Biostratigraphy of the late Miocene to Pliocene on the Pacific island Maria Madre, Mexico: Micropaleontology, v. 31, p. 139-166.

Carreño, A.L., 1992, Neogene microfossils from the Santiago Diatomite, Baja California Sur, Mexico: Paleontología Mexicana, v. 59, p. 1-38.

Delgado-Argote, L.A., López-Martínez, M., and Perrilliat, M.C., 2000, Geologic reconnaissance and age of volcanism and associated fauna from sediments of Bahia de Los Angeles Basin, central Gulf of California, in Stock, J., et al., eds., Cenozoic tectonics and volcanism of Mexico: Geological Society of America Special Paper 334, p. 111-121.

Dorsey, R.J., Fluette, A., McDougall, K., Housen, B.A., Janecke, S.U., Axen, G.J., and Shirvell, C.R., 2007, Chronology of Miocene-Pliocene deposits at Split Mountain Gorge, southern California: A record of regional tectonics and Colorado River evolution: Geology, v. 35, no. 1, p. 57-60, doi:10.1130/G23139A.1.

Dorsey, R.J., Housen, B.A., Janecke, S.U., Fanning, C.M., \& Spears, A.L.F., 2011 , Stratigraphic record of basin development within the San Andreas fault system: Late Cenozoic Fish Creek-Vallecito basin, southern California. Geological Society of America Bulletin, v.123, no. 5-6, 771-793, doi:10.1130/B30168.1.

Holt, J.W., Holt, E.W., and Stock, J.M., 2000, An age constraint on Gulf of California rifting from the Santa Rosalía basin, Baja California Sur, Mexico: Geological Society of America Bulletin, v. 112, p. 540-549, doi:10.1130/0016-7606(2000) $112<540$ :AACOGO>2.0.CO;2.

Lizarralde, D., Axen, G.J., Brown, H.E., Fletcher, J.M., Gonzalez-Fernandez, A., Harding, A.J., Holbrook, W.S., Kent, G.M., Paramo, P., Sutherland, F., and 
Umhoefer, P.J., 2007, Variation in styles of rifting in the Gulf of California.: Nature, v. 448 , no. 7152 , p. $466-469$.

Martín-Barajas, A., Telléz-Duarte, M., and Stock, J.M., 1997, The Puertecitos Formation: Pliocene volcaniclastic sedimentation along an accommodation zone in northeastern Baja California, in Johnson, M.E., and Ledesma-Vasquez, J., eds., Pliocene carbonate and related facies flanking the Gulf of California, Baja California, Mexico: Geological Society of America Special Paper 318, p. 1-24.

McCloy, C., Ingle, J.C., and Barron, J.A., 1988, Neogene stratigraphy, foraminifera, diatoms, and depositional history of Maria Madre Is- land, Mexico: Evidence of early Neogene marine conditions in the southern Gulf of California: Marine Micropaleontology, v. 13, p. 193-212.

McDougall, K., Poore, R.Z., and Matti, J.C., 1999, Age and environment of the Imperial Formation near San Gorgonio Pass, California: Journal of Foraminiferal Research, v. 29, p. 4-25.

Molina-Cruz, A., 1994, Biostratigraphy and paleoceanographic significance of the radiolarians from the protomouth of the Gulf of California: Ciencias Marinas, v. 20, p. $441-465$.

Nagy, E.A., Grove, M., and Stock, J.M., 1999, Age and stratigraphic relationships of pre- and syn-rift volcanic deposits in the northern Puertecitos volcanic province, Baja California, Mexico: Journal of Volcanology and Geothermal Research, v. 93, p. $1-30$.

Plattner, C., Malservisi, R., Dixon, T.H., LaFemina, P., Sella, G.F., Fletcher, J., and Suarez-Vidal, F., 2007, New constraints on relative motion between the Pacific Plate and Baja California microplate (Mexico) from GPS measurements:

Geophysical Journal International, v. 170, no. 3, p. 1373-1380.

Stock, J.M., 1997, Age and source of pumice lapilli within the San Felipe marine sequence, northeast Baja California: International meeting on the geology of the Baja California Peninsula, Ensenada, Baja California Norte, April 6-9, 1997: Ensenada, Baja California, Peninsular Geological Society, p. 98. 


\title{
Chapter 3:
}

Timescales for the growth of sediment diapirs in subduction zones*

\begin{abstract}
In this study, we calculate timescales for the growth of gravitational instabilities forming in the sediment layer on the downgoing slab at subduction zones. Subducted metasediments are buoyant with respect to the overlying mantle and may form diapirs that detach from the slab and rise upwards into the mantle wedge. We use a particle-incell, finite-difference method to calculate growth rates for instabilities forming within a buoyant, wet-quartz metasediment layer underlying a dense mantle half-space composed of wet olivine. These growth rates are used to determine where sediment diapirs initiate and detach from the slab over a range of subduction zone thermal structures. We find that, given a sufficient layer thickness $(200-800 \mathrm{~m}$, depending on slab-surface and mantle-wedge temperatures), sediment diapirs begin to grow rapidly at depths of $\sim 80 \mathrm{~km}$ and detach from the slab within 1-3 Myr at tempera- tures $\leq 900^{\circ} \mathrm{C}$ and at depths roughly corresponding to the location of the slab beneath the arc. Diapir growth is most sensitive to absolute slab temperature, however it is also affected by the viscosity ratio between the sediment layer and the mantle wedge and the length-scale over which viscosity decays above the slab. These secondary affects are most pronounced in colder subduction systems with old slabs and faster subduction rates. For a broad range of subduction zone thermal conditions, we find that diapirs can efficiently transport sediments into the mantle wedge, where they would melt and be incorporated into arc magmas. Thus, we conclude that sediment diapirism is a common feature of many subduction zones, providing a potential explanation for the 'sediment signature' in the chemistry of arc magmas.
\end{abstract}

\footnotetext{
* Originally published as: Miller, N.C., and Behn, M.D., 2012, Timescales for the growth of sediment diapirs in subduction zones: Geophysical Journal International, p. 1361-1377, doi: 10.1111/j.1365246X.2012.05565.x.

Reprinted with permission from Geophysical Journal International.
} 


\title{
Timescales for the growth of sediment diapirs in subduction zones
}

\author{
Nathaniel C. Miller ${ }^{1}$ and Mark D. Behn ${ }^{2}$ \\ ${ }^{1}$ Marine Geology and Geophysics, MIT/WHOI Joint Program, 266 Woods Hole Road, Woods Hole, MA 02543, USA. E-mail: ncm@mit.edu \\ ${ }^{2}$ Department of Geology and Geophysics, Woods Hole Oceanographic Institution, 266 Woods Hole Road, Woods Hole MA 02543, USA
}

Accepted 2012 June 7. Received 2012 June 7; in original form 2012 February 3

\begin{abstract}
SUM M A R Y
In this study, we calculate timescales for the growth of gravitational instabilities forming in the sediment layer on the downgoing slab at subduction zones. Subducted metasediments are buoyant with respect to the overlying mantle and may form diapirs that detach from the slab and rise upwards into the mantle wedge. We use a particle-in-cell, finite-difference method to calculate growth rates for instabilities forming within a buoyant, wet-quartz metasediment layer underlying a dense mantle half-space composed of wet olivine. These growth rates are used to determine where sediment diapirs initiate and detach from the slab over a range of subduction zone thermal structures. We find that, given a sufficient layer thickness (200$800 \mathrm{~m}$, depending on slab-surface and mantle-wedge temperatures), sediment diapirs begin to grow rapidly at depths of $\sim 80 \mathrm{~km}$ and detach from the slab within 1-3 Myr at temperatures $\leq 900{ }^{\circ} \mathrm{C}$ and at depths roughly corresponding to the location of the slab beneath the arc. Diapir growth is most sensitive to absolute slab temperature, however it is also affected by the viscosity ratio between the sediment layer and the mantle wedge and the length-scale over which viscosity decays above the slab. These secondary affects are most pronounced in colder subduction systems with old slabs and faster subduction rates. For a broad range of subduction zone thermal conditions, we find that diapirs can efficiently transport sediments into the mantle wedge, where they would melt and be incorporated into arc magmas. Thus, we conclude that sediment diapirism is a common feature of many subduction zones, providing a potential explanation for the 'sediment signature' in the chemistry of arc magmas.
\end{abstract}

Key words: Numerical approximations and analysis; Subduction zone processes; Dynamics of lithosphere and mantle; Mechanics, theory, and modelling; Diapir and diapirism.

\section{INTRODUCTION}

It is well established that subducted sediments are incorporated into magmatic systems beneath arcs and that these sediment melts influence the production and chemical composition of new continental crust. Despite an abundance of isotopic and trace-element evidence for a sedimentary component in arc magmas (e.g. Armstrong 1968, 1991; Sun 1980; Karig et al. 1981; White et al. 1985; Tera et al. 1986; Plank \& Langmuir 1993, 1998), as well as geochemical (e.g. Elliott et al. 1997; Hawkesworth et al. 1997; Behn et al. 2011) and geophysical (e.g. Vogt 1974; Marsh 1979; de Bremond d'Ars et al. 1995) constraints on subduction zone melting processes, the mechanism for sediment melting and the transport of these melts to the surface remains uncertain. Two primary classes of models have been proposed: (1) slab-surface melting of sediments with subsequent porous or diapiric flow of the melts to the surface (e.g. Spiegelman \& McKenzie 1987; Hall \& Kincaid 2001) and (2) 'cold' diapirism in which the sediment layer detaches from the downgoing slab and melts as it ascends through the hot mantle wedge (e.g. Kelemen et al. 2003). In the latter case, diapirism can be driven by hydration and partial melting of the mantle wedge at the slab surface (e.g. Gerya \& Yuen 2003; Gerya et al. 2006; Castro \& Gerya 2008) or by the intrinsic buoyancy of the sediment layer itself (Currie et al. 2007; Behn et al. 2011).

Modern subduction zone thermal models that include temperature- and stress-dependent viscosities (van Keken et al. 2002; Kelemen et al. 2003; Conder 2005; Arcay et al. 2007; Wada \& Wang 2009; England \& Katz 2010; Syracuse et al. 2010) and recent geothermometry (Plank et al. 2009) predict slab-surface temperatures in excess of the fluid-saturated solidus for metasediments at slab depths corresponding to the location of the volcanic arc $\left(\sim 650{ }^{\circ} \mathrm{C}\right.$ at $2 \mathrm{GPa}$; Nichols et al. 1994; Schmidt et al. 2004), implying that sediments may melt at the slab surface. However, trace-element-depletion trends in metasedimentary rocks that endured subduction to pressures in excess of $2 \mathrm{GPa}$ suggest that key trace elements associated with the observed 'sediment-melt signature' are not released until temperatures exceed $\sim 1050{ }^{\circ} \mathrm{C}$ (Behn et al. 2011)-significantly hotter than slab-surface temperatures at similar pressures in subduction zone thermal models (e.g. van Keken et al. 2002; Wada et al. 2008). Behn et al. (2011) interpreted this discrepancy to imply that, although melting may commence at lower temperatures, the sediment-melt signature is retained in 
accessory mineral phases (e.g. phengite, monazite, allanite) to higher temperatures, and proposed that sediments detach from the slab and rise diapirically into the overlying mantle wedge. These diapirs would undergo melting as they ascend into the hot mantle wedge (e.g. Gerya \& Yuen 2003), rapidly cycling sediment-derived melts and volatiles into arc magma systems.

The growth of diapiric, Rayleigh-Taylor-type instabilities in a buoyant sediment layer underlying a dense mantle half-space is controlled by the layer buoyancy and the absolute and relative viscosities of both materials (e.g. Rayleigh 1883; Taylor 1950; Chandrasekhar 1961; Whitehead \& Luther 1975). Increasing density contrasts and/or layer thicknesses increase buoyancy, promoting faster instability growth. Diapirs form more readily at lower absolute viscosities, and the dependence of viscosity on strain rate has a significant effect on instability growth. Specifically, diapirs in linear (i.e. Newtonian) rheologies grow exponentially whereas materials with strain-rate-dependent, nonlinear (i.e. non-Newtonian) rheologies weaken as they deform, giving rise to superexponential growth (e.g. Conrad \& Molnar 1997; Houseman \& Molnar 1997; Jull \& Kelemen 2001). The relative viscosities of the sediment layer and mantle half-space also play a key role in controlling the growth of diapirs, with a larger layer-to-half-space viscosity ratio promoting faster growth (e.g. Conrad \& Molnar 1997; Houseman \& Molnar 1997; Jull \& Kelemen 2001)

Previous scaling analyses (Behn et al. 2011) and geodynamic models (Currie et al. 2007), suggest that subducted metasediments are buoyant in the mantle and may form diapiric instabilities. Assuming a fixed ratio of sediment and mantle viscosities, background strain rate and density contrast, Behn et al. (2011) showed that, for typical subduction zone thermal structures (Wada \& Wang 2009), instabilities would form over a broad range of sediment layer thicknesses. However, the densities and viscosities of the sediment layer and overlying mantle wedge are expected to evolve independently as the slab warms during subduction, causing the key controls on diapir growth (i.e. density contrast, viscosity ratio and half-space viscosity structure) to vary with depth along the slab interface. Currie et al (2007) included these depth-dependent effects in subduction-zonescale geodynamic models that characterized the fate of subducted sediments. Although this work explored the sensitivity of diapir growth to sediment and mantle material parameters, the effect of far-field parameters (e.g. slab age/temperature, convergence rate and depth of mechanical decoupling between the slab and mantle wedge) was not investigated. Further, these models lacked the resolution required to accurately quantify the growth of small-scale instabilities in sediment layers $<2 \mathrm{~km}$ thick.

In this study, we used a finite-difference method (Gerya 2010) to determine timescales for the growth of individual instabilities initiating within a wet-quartz metasediment layer underlying an olivine mantle wedge, with independent temperature- and strainrate-dependent viscosities in each layer. To predict the location of diapir formation, we integrated these timescales over time- and depth-varying thermal structures and background strain rates from a range of modern subduction zone thermal models (Wada \& Wang 2009; Syracuse et al. 2010). We find that, while diapir growth depends strongly on the temperature of the subducting slab and mantle wedge, sediments can form diapirs that detach from the slab at locations corresponding to the location of arc volcanism over a wide range of slab thermal structures. In 'hot' subduction zones (young slabs and/or slow convergence rates, for example, Cascadia), effective viscosities are relatively small, enabling instabilities to form over a broad range of sediment thicknesses and mantle-wedge thermal and strain rate structures. In colder subduction zones (old slabs and/or fast convergence rates, for example, Izu-Bonin), effective viscosities are greater, slowing instability growth, and secondary controls such as the ratio of sediment to mantle viscosities and the length scale of viscous decay in the mantle play a more significant role in the development of sediment diapirs.

\section{METHODS}

We modelled the growth of metasedimentary diapirs in subduction zones as Rayleigh-Taylor-type instabilities forming in a buoyant, water-rich, quartz layer that underlies a dense, hydrous, olivine halfspace (Fig. 1). We first used a 2-D, particle-in-cell, finite- difference method (Gerya 2010) to calculate diapir growth rates for Newtonian and non-Newtonian viscosities at a range of temperatures and strain

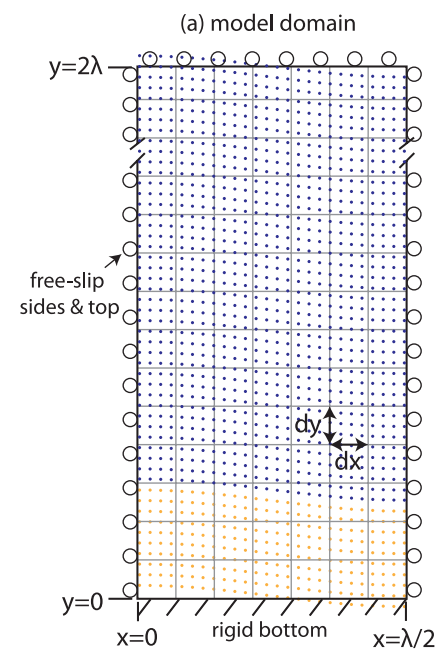

(b) instability parameters

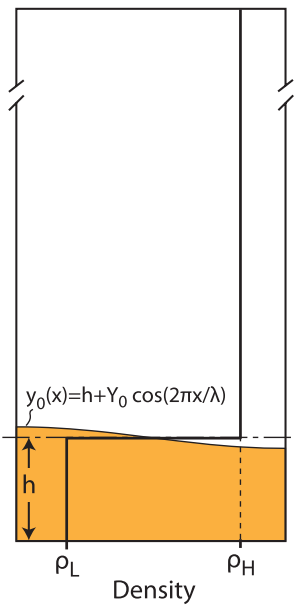

(c) rheologic parameters

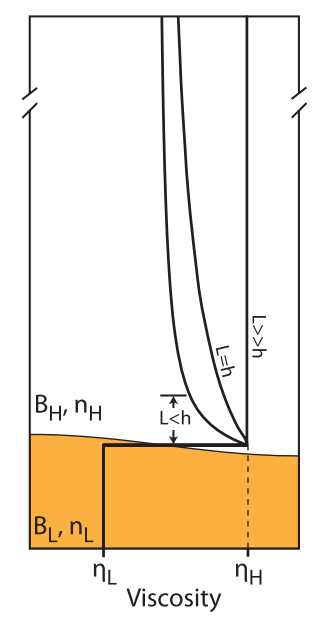

Figure 1. Schematic diagrams showing the initial model setup and parametrization. (a) Model domain, boundary conditions, and initial particle layout. (b) Density structure and initial layer geometry. (c) Initial viscosity structure. 
rates. From these growth rates, we calculated timescales for diapir formation, which we quantified through the 'instability time' (defined below for Newtonian and non-Newtonian rheologies). Next, we exploited previously derived scaling relationships found by linear analysis and numerical experiments (e.g. Rayleigh 1883; Taylor 1950; Chandrasekhar 1961; Whitehead \& Luther 1975; Conrad \& Molnar 1997; Houseman \& Molnar 1997; Molnar et al. 1998) to scale instability times for the range of temperature and strain rate conditions in subduction-zone thermal models (Wada \& Wang 2009; Syracuse et al. 2010). Finally, we integrated these instability times over the history of subduction to estimate the timescales for diapir formation in individual thermal models. Comparing calculated timescales from a range of subduction zone settings reveals the sensitivity of sediment-diapir growth to key parameters such as sediment-layer thickness, slab temperature (slab age and subduction rate) and the strength of the slab/mantle interface (e.g. Wada \& Wang 2009; Syracuse et al. 2010). The symbols and scaling terms defined below and used throughout this paper are listed in Table 1.

Table 1. Symbols.

\begin{tabular}{|c|c|}
\hline$x, y$ & $\begin{array}{l}\text { Horizontal, vertical Cartesian } \\
\text { coordinates in diapir models }\end{array}$ \\
\hline $\mathrm{z}$ & $\begin{array}{l}\text { Depth coordinate in subduction zone } \\
\text { thermal models }\end{array}$ \\
\hline $\mathbb{T}_{h \Delta \rho}=\left(\frac{B_{L}}{\Delta \rho g h}\right)^{n_{L}}$ & Timescale \\
\hline $\mathbb{T}_{h \Delta \rho \dot{E}}=\left(\frac{B_{L}}{\Delta \rho g h}\right) \dot{E}_{L}^{\left(1-n_{L}\right) / n_{L}}$ & Timescale \\
\hline$w=w^{\prime} h / \mathbb{T}_{h \Delta \rho}$ & Maximum vertical velocity \\
\hline$q^{\prime}=q \mathbb{T}_{h \Delta \rho}$ & $\begin{array}{l}\text { Exponential growth rate scaled by layer } \\
\text { thickness and density contrast }\end{array}$ \\
\hline$q^{\prime \prime}=q \mathbb{T}_{h \Delta \rho E}$ & $\begin{array}{l}\text { Exponential growth rate scaled by layer } \\
\text { thickness, density contrast, and } \\
\text { background strain rate }\end{array}$ \\
\hline$C^{\prime}=C \mathbb{T}_{h \Delta \rho}$ & $\begin{array}{l}\text { Super exponential growth rate scaled by } \\
\text { layer thickness and density contrast }\end{array}$ \\
\hline$t^{\prime}=t / \mathbb{T}_{h \Delta \rho}, t_{b}^{\prime}=t_{b} / \mathbb{T}_{h \Delta \rho}$ & $\begin{array}{l}\text { Elapsed time, instability time rate scaled } \\
\text { by layer thickness and density contrast }\end{array}$ \\
\hline$\dot{E}=\sqrt{1 / 2\left(\dot{\varepsilon}_{x x} \dot{\varepsilon}_{y y}-\dot{\varepsilon}_{x y}^{2}\right)}$ & $\begin{array}{l}\text { Second invariant of the strain rate tensor } \\
\dot{\varepsilon}\end{array}$ \\
\hline$\dot{E}_{L}, \dot{E}_{H}$ & Layer, half-space strain rate invariant. \\
\hline$h$ & Layer thickness \\
\hline$Y_{0}=Y_{0}^{\prime} h$ & Initial perturbation size \\
\hline$k=k^{\prime} / h$ & Wavenumber of initial perturbation \\
\hline$\lambda=2 \pi / k=\lambda^{\prime} h$ & Wavelength of initial perturbation \\
\hline$y_{0}(x)=h+Y_{0} \cos (2 \pi x / \lambda)$ & Initial layer boundary position \\
\hline$y_{\max }$ & Maximum height of material interface \\
\hline$Y=\left(y_{\max }-h\right) / h$ & Maximum fractional displacement \\
\hline$\rho, \Delta \rho=\left(\rho_{L}-\rho_{H}\right)$ & Density, layer-half-space density contrast \\
\hline$R$ & Universal gas constant \\
\hline$A ; A_{L}, A_{H}$ & $\begin{array}{l}\text { Empirical rheologic constant; rheologic } \\
\text { constant in layer, half-space }\end{array}$ \\
\hline$n ; n_{L}, n_{H}$ & $\begin{array}{l}\text { Stress exponent; stress exponent in layer, } \\
\text { half-space }\end{array}$ \\
\hline$Q ; Q_{H}$ & $\begin{array}{l}\text { Activation energy; activation energy in } \\
\text { half-space }\end{array}$ \\
\hline$B=\frac{A^{-1 / n}}{2} \exp \left(\frac{Q}{n R T_{0}}\right) ; B_{L}, B_{H}$ & $\begin{array}{l}\text { Rheologic parameter; rheologic } \\
\text { parameter in layer, half-space }\end{array}$ \\
\hline$r=B_{L} / B_{H}$ & $\begin{array}{l}\text { Ratio of layer to half-space rheologic } \\
\text { parameters }\end{array}$ \\
\hline$T_{0}$ & Layer and boundary temperature \\
\hline$\beta_{H}$ & $\begin{array}{l}\text { Slope of linear geothermal gradient in } \\
\text { mantle wedge }\end{array}$ \\
\hline$L=\frac{n_{H} R T_{0}^{2}}{Q_{H} \beta_{H}}$ & $\begin{array}{l}\text { e-folding length of mantle-wedge } \\
\text { viscosity }\end{array}$ \\
\hline
\end{tabular}

(c) 2012 The Authors, GJI, 190, 1361-1377

Geophysical Journal International (C) 2012 RAS

\subsection{Rheologic flow law}

The absolute and relative viscosities of the sediments and overlying mantle determine how easily a buoyant sediment layer can flow upward into the dense mantle. In most rock-forming minerals, viscosity decreases with increasing strain rate and temperature (e.g. Hirth \& Kohlstedt 2003). To model deformation with this behaviour, we use the flow law (e.g. Kirby 1983)

$\dot{\varepsilon}=A \sigma^{n} \exp \left(-\frac{Q}{R T}\right)$,

where $A$ is an empirical constant, $\sigma=\sigma_{\max }-\sigma_{\min }$ is the differential stress, $n$ is the stress exponent, $Q$ is the activation energy, $R$ is the gas constant $\left(=8.31 \mathrm{~J} \mathrm{~K}^{-1} \mathrm{~mole}^{-1}\right)$ and $T$ is temperature. Assuming that deviatoric stress $\tau_{i j}$ is related to strain rate $\dot{\varepsilon}_{i j}$ by the constitutive relationship

$\tau_{i j}=\eta_{\mathrm{eff}} \varepsilon_{i j}^{\prime}$

we define an effective viscosity $\eta_{\text {eff }}$ as

$\eta_{\mathrm{eff}}=\frac{B}{2} \dot{E}^{(1-n) / n}$,

where $\dot{E}=\sqrt{1 / 2\left(\dot{\varepsilon}_{x x} \dot{\varepsilon}_{y y}-\dot{\varepsilon}_{x y}^{2}\right)}$ is the second invariant of the strainrate tensor $\dot{\varepsilon}$. The rheologic parameter $B$ describes the sensitivity of viscosity to changes in strain rate and temperature and is defined (Molnar et al. 1998):

$B=3^{-(n+1) / 2 n}\left(\frac{A}{2}\right)^{-1 / n} \exp \left(\frac{Q}{n R T}\right)$.

For $n=1$ (Newtonian), $\eta_{\text {eff }}=B / 2$, viscosity varies with temperature alone, and strain rate is a linear function of stress. For $n>1$ (non-Newtonian), viscosity depends on strain rate and temperature, causing strain rate to vary nonlinearly with stress.

\subsection{Theoretical model: scaling relationships and non-dimensionalization}

Solutions found by linear analysis of the Stokes equation (i.e. the Navier-Stokes equations with inertial terms ignored) can describe the growth of infinitesimal-amplitude instabilities in a buoyant layer underlying a half-space with Newtonian or non-Newtonian viscosities in each. For instabilities to form, the layer boundary must be initially perturbed. In prior analytic solutions and in our models, the height of this initial boundary is defined by

$y_{0}(x)=h+Y_{0} \cos (2 \pi x / \lambda)$,

where $Y_{0}$ is the perturbation amplitude and $\lambda=2 \pi / k$ is the wavelength of the perturbation.

For Newtonian materials, Chandrasekhar (1961) showed that maximum instability displacement $Y$ increases exponentially from this initial deflection according to

$Y=Y_{0} \exp (q t)$,

where $t$ is time and $q$ is a growth rate. Here, maximum vertical velocity $w$ is given by

$w=w_{0} \exp (q t)$

where $w_{0}=q Y_{0}$ is the initial velocity.

To quantify the timescale for instability formation, we used the 'instability time' (e.g. Houseman \& Molnar 1997), which we refer to by the symbol $t_{b}$. For the Newtonian (i.e. exponential growth) case, we define $t_{b}$ as the time at which diapir displacement reaches 
a height equal to the initial layer thickness $h$, and setting $Y=h$ in eq. (6) yields

$t_{b}(q)=-\frac{1}{q} \ln \left(\frac{Y_{0}}{h}\right)$.

Non-dimensionalization reveals the sensitivity of diapir growth to changes in layer buoyancy, initial perturbation wavelength and viscosities. By choosing the initial layer thickness $(h)$, the density contrast between the layer and half-space $\left(\Delta \rho=\rho_{L}-\rho_{H}\right)$, and the rheologic parameter and stress exponent in the sediment layer ( $B_{L}$ and $n_{L}$, respectively) as characteristic scales, we can define a characteristic timescale (Houseman \& Molnar 1997)

$\mathbb{T}_{h \Delta \rho}=\left(\frac{B_{L}}{\Delta \rho g h}\right)^{n_{L}}$

and the following non-dimensional (primed) quantities

$Y^{\prime}=Y / h ; \quad Y_{0}^{\prime}=Y_{0} / h ;$

$t^{\prime}=t / \mathbb{T}_{h \Delta \rho} ; w^{\prime}=\frac{w}{h} \mathbb{T}_{h \Delta \rho} ;$ and

$k^{\prime}=k h=2 \pi / \lambda^{\prime}$.

The exponential growth rate from eqs (6) and (7) is then

$q=q^{\prime}\left(k^{\prime}, r\right) / \mathbb{T}_{h \Delta \rho}$,

where $r=B_{L} / B_{H}$ is the ratio of the layer to half-space $\left(B_{H}\right)$ rheologic parameters.

For cases with non-Newtonian rheologies in which $B_{L}$ and $B_{H}$ are constant throughout each layer, Houseman \& Molnar (1997) showed that the maximum vertical displacement of the layer and the velocity change with time according to the superexponential functions:

$(Y / h)^{1-n_{L}}=\left(n_{L}-1\right)\left(\frac{C^{\prime} \Delta \rho g h}{n_{L} B_{L}}\right)^{n_{L}}\left(t_{b}-t\right)$

and

$w=\left[C^{\prime}\left(\frac{n_{L}-1}{n_{L}}\right) \frac{\Delta \rho}{B_{L}} h^{1 / n_{L}}\left(t_{b}-t\right)\right]^{n_{L} /\left(1-n_{L}\right)}$,

respectively, where $C^{\prime}\left(k^{\prime}, r\right)=C \mathbb{T}_{h \Delta \rho}$ is a growth rate analogous to $q^{\prime}$. In this case, the instability time $t_{b}$ is defined as the time at which maximum vertical velocity accelerates to infinity (Houseman \& Molnar 1997), given by

$t_{b}\left(C^{\prime}\right)=\left(\frac{n_{L} B_{L}}{C^{\prime} \Delta \rho g h}\right)^{n_{L}} \frac{\left(Y_{0} / h\right)^{1-n_{L}}}{\left(n_{L}-1\right)}$.

As the velocity accelerates to infinity, $Y$ rapidly approaches $h$, and the instability time given by eq. (14) can thus be compared directly to the instability time defined by eq. (8).

At depth in subduction zones, temperature increases with distance from the slab surface (e.g. Wada \& Wang 2009), causing viscosities to decay exponentially (eq. 3) into the mantle wedge. This viscous decay can be quantified in terms of the $e$-folding length scale $L$ (Fletcher \& Hallet 1983; Conrad \& Molnar 1997), defined by

$L=\frac{n_{H} R T_{0}^{2}}{Q_{H} \beta_{H}}$,

where $T_{0}$ and $\beta_{H}$ describe a linear, mantle-wedge geotherm, $T(y)=$ $T_{0}+\beta_{H} y$. The ratio of $L$ to the layer thickness $h$ also controls instability growth (Conrad \& Molnar 1997; Houseman \& Molnar 1997). If $L / h$ is small, the half-space weakens rapidly with distance from the interface and the layer 'senses' the lower viscosity within the half-space, shortening instability times. For such cases, Molnar et al. (1998) showed that the relationships in eqs (6-14) still apply, although $L$ replaces $h$ as the controlling length scale.

In settings with strong background strain rates, such as those associated with corner flow in the mantle wedge, Molnar et al. (1998) showed that diapirs first grow exponentially according to eq. (6), but with viscosities given by eq. (3) with $\dot{E}$ defined by the background strain rate. For this initial growth stage, Molnar et al. (1998) defined a second timescale

$\mathbb{T}_{h \Delta \rho \dot{E}}=\left(\frac{B_{L}}{\Delta \rho g h}\right) \dot{E}_{L}^{\left(1-n_{L}\right) / n_{L}}$,

where $\dot{E}_{L}$ is the second invariant of the background strain rate tensor in the layer. The initial, exponential growth rate is then:

$q=q^{\prime \prime}\left(k^{\prime}, r, n_{L}\right) / \mathbb{T}_{h \Delta \rho \dot{E}}$.

As long as the background strain rate is much faster than strain rates from local, diapiric flow, instability growth remains exponential. If local strain rates never exceed the background strain rate, the final instability time is simply

$t_{b}\left(q^{\prime \prime}\right)=-\left(\mathbb{T}_{h \Delta \rho \dot{E}} / q^{\prime \prime}\right) \ln \left(\frac{Y_{0}}{h}\right)$.

If, however, local strain rates become sufficiently large, growth will become super exponential and displacement will follow the form of eq. (12).

\subsection{Model parameters for subduction zones}

We calculated growth rates and instability times for the range of thermal and background strain rate conditions in the subductionzone modelling results of Wada \& Wang (2009) and Syracuse et al. (2010). To calculate viscosities, we assume that the subducting sediments and overlying mantle are both hydrated (Hacker 2008). We apply values for rheologic parameters $(A, n$ and $Q)$ reported for hydrous quartz (Hirth et al. 2001) to the metasediment layer and those for hydrous olivine (Hirth \& Kohlstedt 2003) to the overlying mantle wedge (Table 2). While slab-top conditions can exceed the fluid-saturated solidus for metasediments (Nichols et al. 1994;

Table 2. Rheologic parameters.

\begin{tabular}{lcccl}
\hline Material & $\ln (A)\left[\mathrm{MPa}^{-\mathrm{n}} \mathrm{s}^{-1}\right]$ & $n$ & $Q\left[\mathrm{~kJ} \mathrm{~mol}^{-1}\right]$ & Reference \\
\hline Metasediments & & & & \\
Ruby Gap quartzite (wet) & $-11.2 \pm 0.6$ & 4 & $135 \pm 15$ & Hirth et al. (2001) \\
Synthetic coesite (dry) $^{a}$ & $-3.7 \pm 4.3$ & $3 \pm 1$ & $275 \pm 50$ & Renner et al. (2001) \\
Mica schist (weak $T$ and $E$ dependence) $^{a}$ & -910 & $171 \pm 6$ & $98 \pm 9$ & Shea \& Kronenberg (1992) \\
Mica schist (strong $T$ and $E$ dependence) $^{a}$ & -154 & $31 \pm 1$ & $98 \pm 9$ & Shea \& Kronenberg (1992) \\
Mantle wedge $_{\text {Olivine (wet) }}^{b}$ & 13.6 & $3.5 \pm 0.3$ & $480 \pm 40$ & Hirth \& Kohlstedt (2003) \\
\hline
\end{tabular}

${ }^{a}$ Shown for comparison. The Hirth et al. (2001) rheology for wet quartz is used for metasediments in all models.

${ }^{b} A$ calculated using $A=\alpha\left(C_{O H}\right)^{r}$ where $C_{O H}=5000 \mathrm{H} / 10^{6} \mathrm{Si}, r=1.2$ and $\alpha=30$. 


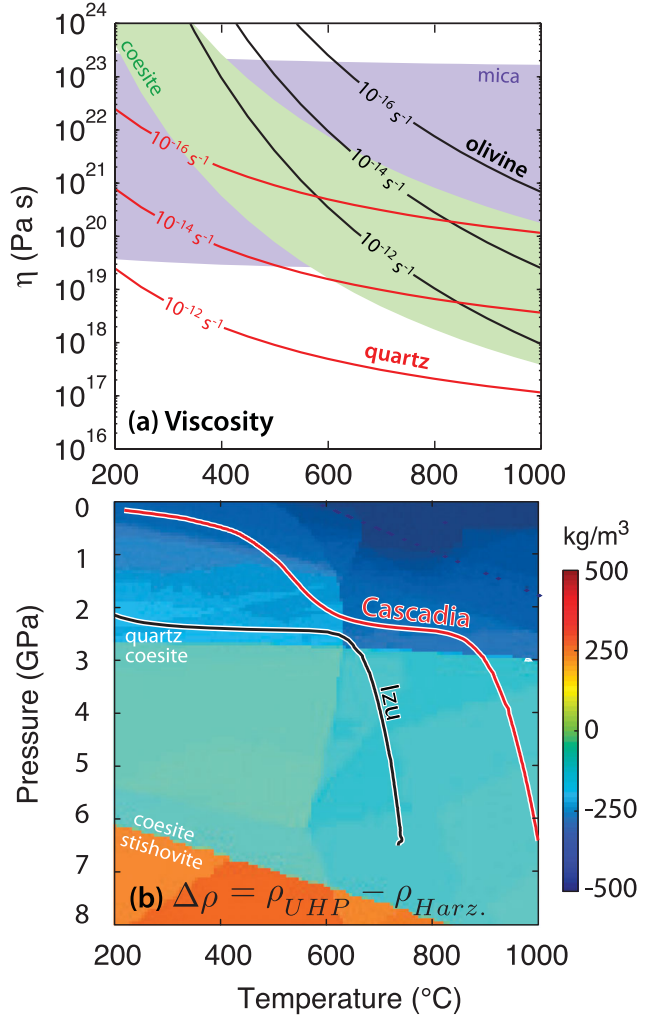

Figure 2. (a) Effective viscosity as a function of temperature for hydrous quartz (Hirth et al. 2001) and olivine (Hirth \& Kohlstedt 2003) at different strain rates. For comparison, shaded regions indicate the viscosity range of mica shist (strong $T$ and $\dot{E}$ dependent rheology of Shea \& Kronenberg 1992) and dry coesite (Renner et al. 2001). In subduction zone thermal models, both slab-surface and mantle wedge temperatures and strain rates vary from $\sim 200$ to $\sim 1000{ }^{\circ} \mathrm{C}$ and from $\sim 10^{-16}$ to $\sim 10^{-12} \mathrm{~s}^{-1}$, respectively. (b) Density contrast between UHP rocks (sediments) and harzburgite (mantle wedge) with $2 \mathrm{wt} \% \mathrm{H}_{2} \mathrm{O}$ as a function of temperature and pressure (Behn et al. 2011). Lines show the pressure-temperature trajectory of the slab surface in the Cascadia (red) and Izu (black) subduction zone models of Wada \& Wang (2009).

Schmidt et al. 2004), we assume that any melting has a negligible effect on viscosity. If melt migration is rapid compared to the timescale of the matrix flow, only a small amount ( $\leqslant 3$ per cent) of melt is likely to be retained in the sediment layer and/or overlying mantle (McKenzie 1984), reducing viscosities by at most an order of magnitude (Zimmerman \& Kohlstedt 2004).

Subducted metasediments are likely similar in composition to ultrahigh pressure (UHP) metapelites (Behn et al. 2011). These rocks have between 47 and $76 \mathrm{wt} \% \mathrm{SiO}_{2}$ and, at pressures less than $\sim 2.5 \mathrm{GPa}$, would be composed of $\sim 35$ per cent quartz by volume, with smaller volumes of phengite and plagioclase (Behn et al. 2011). Of these minerals, quartz is the weakest phase (Fig. 2a). Multiphase rocks have been shown to deform according to the rheology of the weakest phase when even small amounts $(<15$ per cent $)$ of that mineral are present (Dell'Angello \& Tullis 1996), and we thus model deformation in the sediment layer with a quartz rheology. At pressures greater than $\sim 2.5 \mathrm{GPa}$, quartz undergoes a phase change to coesite (Fig. 2b), which is stronger than quartz (Fig. 2a). As discussed below in Section 4, this viscosity change will have only a small effect on instability times for diapirs forming in subduction zones, and thus we ignore the quartz-to-coesite transition in our calculations of layer viscosity.

Hirth et al. (2001) used microstructures and thermochronology in naturally deformed quartzite samples, along with laboratory experiments, to constrain the rheologic parameters of quartz at strain rates of $\sim 10^{-14} \mathrm{~s}^{-1}$ and over a temperature range of $\sim 600-1200{ }^{\circ} \mathrm{C}$. For strain rates typical of active deformation $\left(10^{-15}\right.$ to $\left.10^{-12} \mathrm{~s}^{-1}\right)$, this flow law has been shown to fit stress profiles inferred from naturally deformed, metamorphosed rocks from the mid-crust (Behr $\&$ Platt 2011). These conditions are similar to the strain rates and temperatures for diapir formation in our models, suggesting that this flow law can accurately describe deformation in subducted metasediments. For olivine, Hirth \& Kohlstedt (2003) used experimental results to determine rheologic parameters for temperatures of $\sim 1100-1300^{\circ} \mathrm{C}$ and strain rates of $\sim 10^{-4}-10^{-6}$. Viscosity profiles extrapolated from these experimental conditions to upper mantle conditions agree well with constraints on viscosities from geophysical observations (Hirth \& Kohlstedt 2003), indicating that these parameters accurately describe the rheology of the bulk upper mantle over the range of conditions in the mantle wedge at subduction zones.

For our calculations of instability times for exponential growth, we imposed a constant background strain rate in the mantle wedge $\left(\dot{E}_{H}\right)$ based on average values in the Wada \& Wang (2009) thermal models. Strain rates in the sediments depend on assumptions about the nature of mantle-wedge flow and strain localization at the slab surface. Both the Wada \& Wang (2009) and Syracuse et al. (2010) models include a shallow $(<50-90 \mathrm{~km})$ region in which the subducting slab descends faster than the overall flow in the mantle wedge, requiring that strain be accommodated within a weak zone at the slab surface. This shallow 'decoupling' creates a stagnant, cold, mantle-wedge nose beneath the forearc, a feature needed to explain surface heat flow and seismic attenuation measurements (e.g. Kneller et al. 2005, 2007; Abers et al. 2006; Wada \& Wang 2009). At shallow depths, we assume that strain is accommodated within the sediment layer, and we set the background strain rate in the sediments based on the layer thickness and the slab/arc convergence velocity. At greater depths, we set the background strain rate in the sediment layer to be equal to the strain rate in the mantle wedge $\left(\dot{E}_{H}\right)$. That is,

$\dot{E}_{L}=\left\{\begin{array}{cc}\theta V_{\mathrm{slab}} /(2 h) & z \leq z_{\mathrm{DC}} \\ \dot{E}_{H} & z>z_{\mathrm{DC}}\end{array}\right.$,

where $z$ is depth in the subduction zone model, $V_{\text {slab }}$ is the slab velocity, and $z_{\mathrm{DC}}$ is the depth of the decoupling/coupling transition in the thermal models. In this way, the strain rate in the sediment layer can differ from the strain rate governing the non-Newtonian viscosity of the overlying mantle wedge. $\theta$ is a value less than one that determines how much of the relative motion between the slab and mantle wedge is accommodated within sediments on the slab surface. For consistency with the parametrization of the thermal models, we set $\theta$ to 1.0 (full decoupling) in the Wada \& Wang (2009) models and 0.98 (partial decoupling) in the Syracuse et al. (2010) models.

The absolute and relative viscosities of hydrous quartz and olivine vary by several orders of magnitude over the range of subduction zone temperatures $\left(\sim 200-1000{ }^{\circ} \mathrm{C}\right)$ and background strain rates $\left(\sim 10^{-16}-10^{-12} \mathrm{~s}^{-1}\right)$ predicted by thermal models (Fig. 2a), suggesting that growth rates for sediment diapirs may vary 
significantly. While quartz and olivine are brittle at low temperatures $\left(<280-350{ }^{\circ} \mathrm{C}\right.$ for quartz, Stöckert et al. $1999 ;<600{ }^{\circ} \mathrm{C}$ for olivine, Boettcher et al. 2007), we are interested in the formation of sediment diapirs at depths greater than $\sim 50 \mathrm{~km}$ in subduction zones, where diapirs would be incorporated into arc magma systems. At these depths, temperatures are near or above the temperature of the brittle/ductile transition for quartz and olivine, and we thus only consider deformation by viscous flow. At $\sim 600^{\circ} \mathrm{C}$, olivine viscosities are high $\left(10^{20}-10^{23} \mathrm{~Pa} \mathrm{~s}\right.$ for strain rates of $\left.10^{-12}-10^{-16} \mathrm{~s}^{-1}\right)$ and the viscosity ratio of quartz to olivine (i.e. $r=B_{\mathrm{qtz}} / B_{\mathrm{ol}}$ ) at a given strain rate is $<10^{-3}$. As temperature increases to $\sim 1000{ }^{\circ} \mathrm{C}$, olivine viscosities decrease to $\sim 10^{18}-10^{21} \mathrm{~Pa}$ s for strain rates of $10^{-12}-10^{-16} \mathrm{~s}^{-1}$, approaching the viscosity of quartz and causing $r$ to increase to $\gtrsim 0.1$. This decrease in absolute viscosities with increasing temperature promotes diapir growth, shortening instability times. Further, the relative weakening of olivine with respect to quartz (i.e. larger $r$ ) with temperature allows quartz diapirs to more readily ascend into the overlying olivine half-space, decreasing instability times (e.g. Houseman \& Molnar 1997; Conrad \& Molnar 1997).

The effect of the viscous decay length on the growth of sediment diapirs depends on the ratio of $L$ to the layer thickness $h$. In subduction zone thermal models, $L$ is typically minimal at depths of $\sim 80 \mathrm{~km}$ (Fig. 3e) and acts to weaken the mantle with respect to the sediment layer, promoting diapir growth. This decrease in $L$ is a consequence of steepening, inverted geotherms near the slab/mantle decoupling/coupling transition (e.g. Wada \& Wang 2009). The abruptness of the transition determines both the shape of the mantle geotherms and the depth and magnitude of the minimum in $L$ (Syracuse et al. 2010), which in turn influences the time it takes sediment instabilities to form.

Diapirism is driven by the buoyancy of the sediment layer, which depends on the density contrast between the sediments and the overlying mantle and the thickness of the sediment layer. We assign a density contrast $\Delta \rho$ between the sediments and mantle wedge based on Behn et al.'s (2011) calculations of temperature- and pressure-dependent densities for metasediments and mantle-wedge harzburgite along a slab-top geotherm (Fig. 2b). These densities assume $2 \mathrm{wt} \% \mathrm{H}_{2} \mathrm{O}$ in both compositions, which is representative of the amount of $\mathrm{H}_{2} \mathrm{O}$ retained by subducting sediments at $700{ }^{\circ} \mathrm{C}$ and $3 \mathrm{GPa}$ (Hacker 2008). The resulting density contrast varies from -340 to $-80 \mathrm{~kg} \mathrm{~m}^{-3}$ at depths $<100 \mathrm{~km}$, but is nearly constant at $\sim-200 \mathrm{~kg} \mathrm{~m}^{-3}$ at depths $>100 \mathrm{~km}$ (Fig. $3 \mathrm{c}$ ).

The geometry and thickness of the subducting sediment layer is largely unconstrained at depth, and we therefore calculate timescales for diapirism over a range of layer thicknesses and initial perturbation sizes. The average thickness of the sediment layer on the incoming plate at trenches varies from $\sim 100$ to $\sim 4000 \mathrm{~m}$ globally (Plank \& Langmuir 1998), although much of this of sediment is scraped off the slab at the trench, leaving at most $\sim 1000 \mathrm{~m}$ that is transported to depths beyond the forearc (von Huene \& Scholl 1991; Clift \& Vannucchi 2004). For completeness, we consider instabilities forming in 10-2000-m-thick layers, given that sediment layers could be $>1000 \mathrm{~m}$ locally.

Deposition over rough topography and deformation during subduction likely cause sediments to vary in thickness across the slab, with undulations that are potentially similar in amplitude and wavelength to abyssal hill topography on the subducting plate. These variations in thickness would provide the initial perturbations in the layer surface (i.e. $Y_{0}^{\prime}$ ) that are required for diapirism. While large portions of the sediment layer may be removed at the trench during subduction, sediments are deposited in lows on the abyssal hill topography and erosion from the top of the layer would leave significant variations in sediment thickness. Folding and faulting during shallow subduction would also create variations in sediment thickness. Abyssal hills can be 100 s of meters tall (e.g. Goff \& Jordan 1988) and shallowly deformed slabtop sediments have fold amplitudes of up to $\sim 500 \mathrm{~m}$ (Chauhan et al. 2009), leading us to conservatively (instability time decreases with increasing $Y_{0}^{\prime}$ ) consider instability growth from initial perturbations of 10 and 30 per cent of the layer thickness $\left(Y_{0}^{\prime}=[0.1,0.3]\right)$.

Diapirs grow fastest at a preferred wavelength that depends on the viscosities of the layer and half-space (e.g. Whitehead \& Luther 1975), and this wavelength of fastest growth may vary significantly from the initial perturbation wavelength (Schmeling 1987). In our models and scaling for the growth of sediment diapirs in subduction zones, we find that a majority of instability growth occurs at temperatures greater than $\sim 800^{\circ} \mathrm{C}$ and that, at these temperatures, diapirs grow fastest at wavelengths near $\lambda=2 \pi h$ or $k^{\prime}=1$. For the
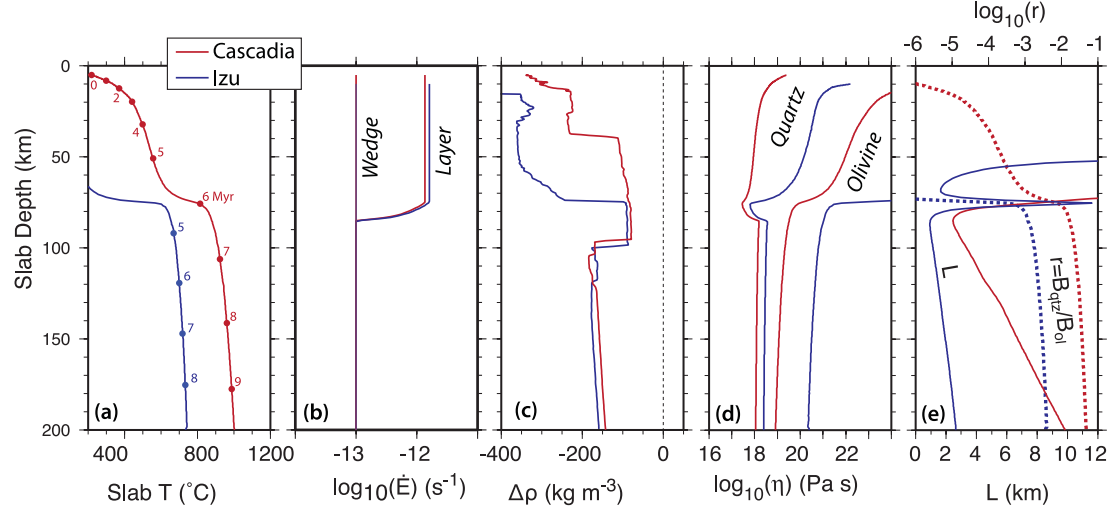

Figure 3. Key parameters controlling instability growth from models of the Cascadia (red) and Izu (blue) subduction zones (Wada \& Wang 2009) plotted as a function of slab depth. (a) Slab-surface temperature. Circles indicate increments of $1 \mathrm{Myr}$ in subduction time from an arbitrary reference point. (b) Strain rate in the sediment layer and mantle wedge. (c) Density constrast of UHP rocks (sediments) and harzburgite (mantle wedge) (Behn et al. 2011). (d) Effective viscosity of quartz and olivine. (e) e-folding length scale for viscous decay in the mantle wedge (solid lines) and ratio of quartz-to-olivine rheologic parameters (dashed lines). 
sediment thicknesses that we consider (10-2000 m), wavelengths corresponding to $k^{\prime}=1$ are within the spectra of typical, largely stochastic, abyssal hill topography (Goff \& Jordan 1988), suggesting that diapirs forming in subducted, abyssal sediments may initiate at this preferred spacing. In predicting timescales and detachment depths for instabilities forming in subduction zones, we therefore focus on diapir growth at $k^{\prime}=1$.

\subsection{Numerical model}

To calculate instability times $t_{b}\left(q^{\prime \prime}\right)$ and $t_{b}\left(C^{\prime}\right)$ (eqs (18) and (14)), we first calculated the growth rates $q^{\prime \prime}$ and $C^{\prime}$. Since no analytic growth rate solution exists for the case of non-Newtonian rheologies and an exponentially decaying half-space viscosity (i.e. finite $L$ ), we calculated these growth rates using a particle-in-cell, finite-difference method (Gerya 2010). The code assumes plane strain and solves equations for two-dimensional Stokes flow and continuity on a fixed (Eulerian) grid with regularly spaced, advecting (Lagrangian) tracer points (particles). Material properties (i.e. density and rheologic parameters) are carried by the particles and transferred to the grid by bilinear interpolation. The particles are advected over small time steps by first-order Runge-Kutta integration of the gridded velocities.

We setup the initial material geometry by defining a buoyant layer beneath a dense half-space (Fig. 1). The layer and half-space were distinguished by assigning particle densities $\rho_{L}$ and $\rho_{H}$, rheologic parameters $\mathrm{B}_{L}$ and $\mathrm{B}_{H}$ and stress exponents $\mathrm{n}_{L}$ and $\mathrm{n}_{H}$, respectively. The material boundary was defined by eq. (5). We assigned a tem- perature $T_{0}$ to particles within the layer, and imposed a temperature profile $T=T_{0}+\beta_{H}(y-h)$ in the half-space. Our models do not explicitly include the effects of thermal diffusion, a simplification that does not significantly alter the accuracy of the model results. The subduction zone models of Wada \& Wang (2009) and Syracuse et al. (2010) include heating of the subducting slab by thermal diffusion, and, by assigning values for $T_{0}$ and $\beta_{H}$ from these subduction zone models, we implicitly include this effect as a starting condition in our diapir models.

We set the width of the model domain to $\lambda / 2$, ignoring possible interactions between adjacent perturbation peaks. We numerically simulated a half-space by setting the model height to be four times this width - the minimum height found to prevent interaction of the layer with the top boundary during initial instability growth in our models. For mechanical boundary conditions, we assumed that the sediment layer is rigidly coupled to deeper slab rocks (i.e. $\mathrm{u}=w=0$ at $y=0$ ) and imposed free-slip side and top boundaries (i.e. $u=\sigma_{x y}=0$ at $x=\left[0, x_{2}\right]$ and $y=y_{2}$ ).

In all of our models, we used a $64 \times 256$-node grid (resolution of $\lambda / 128$ in the horizontal and vertical) with 25 particles in each grid cell, resolutions that we found to produce accurate results as compared to predictions of growth rates from analytic solutions. We determined growth rates by tracking the maximum vertical velocity of the layer particles as a function of time. For a layer and halfspace with homogenous, Newtonian viscosities, plotting $\ln \left(w^{\prime}\right)$ as a function of $t^{\prime}$ produces a linear relationship with a slope of $q^{\prime}$, verifying that the numerical instabilities grow according to eq. (7) (Fig. 4a). Similarly, plotting $w^{\left(1-n_{L}\right) / n_{L}}$ versus $t^{\prime}$ for models with non-Newtonian rheologies yields a linear relationship with slope
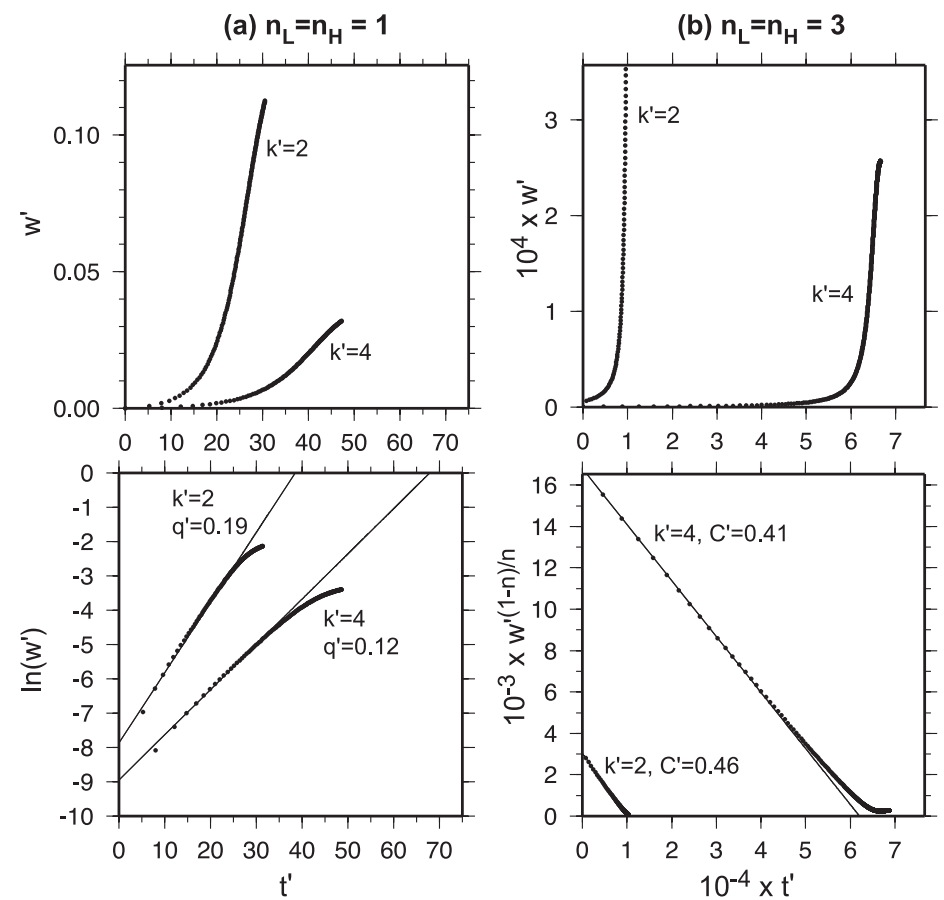

Figure 4. Plots of non-dimensionaled, maximum vertical velocity $w^{\prime}$ as function of non-dimensional time $t^{\prime}$ (top panels) in numerical models with (a) Newtonian and (b) non-Newtonian rheologies and different initial perturbation wavenumbers $k^{\prime}$. In the Newtonian case, velocity increases exponentially and plotting $\ln \left(w^{\prime}\right)$ versus $t^{\prime}$ (lower panel) produces a linear function (thin line). Similarly for the non-Newtonian case, velocity evolves according to a power law and can be linearized by plotting $w^{\prime(1-n) / n}$ versus $t^{\prime}$. In both cases, the slope of linearized velocities is proportional to the growth rate factor (i.e. $q^{\prime}$ or $\mathrm{C}^{\prime}$ ). 


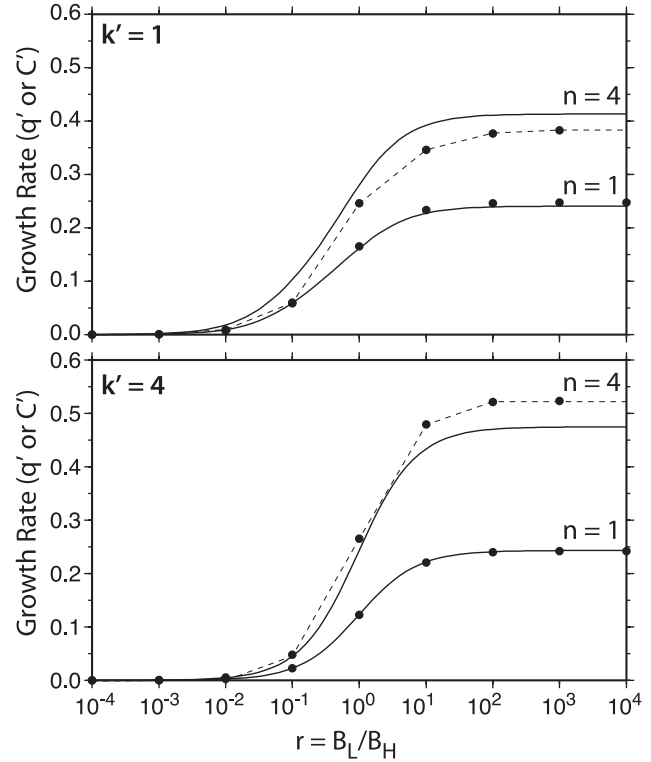

Figure 5. Comparison of non-dimensional growth rates plotted as a function of the ratio of rheologic parameters $r$ found numerically (dots) and analytically (lines) for Newtonian $(n=1)$ and non-Newtonian $(n=4)$ rheologies and different initial perturbation wavenumbers $\left(k^{\prime}\right)$

$q^{\prime}\left(n_{L}-1\right) / n_{L}$, indicating that the code can model the superexponential growth predicted by eq. (13) (Fig. 4b).

The effective viscosities of metasediments and the mantle vary by several orders of magnitude over the range of temperatures and strain rates in subduction zone thermal models (Fig. 2a), requiring that the models be able to handle significant viscosity contrasts (i.e. $r$ ). A comparison of $q^{\prime}$ predicted by analytic solutions (eq (33) in Conrad \& Molnar 1997) to maximum values found numerically (Fig. 5) shows that we can calculate growth rates for $r<$ 0.1 (i.e. the range for quartz and olivine under subduction conditions) to within $\sim 0.03$ of the analytic solutions. In the scaling for subduction zone conditions that follows, this $O\left(10^{-2}\right)$ uncertainty in non-dimensional growth rate translates to a $<1 \mathrm{Myr}$ uncertainty in instability time or a $<25 \mathrm{~km}$ uncertainty in the depth for diapir detachment for typical subduction rates.

\subsection{Calculating instability times for sediment diapirs in subduction zones}

To evaluate the likelihood of sediment diapir growth in subduction zones, we first calculated non-dimensional exponential $\left(q^{\prime \prime}\right)$ and superexponential $\left(C^{\prime}\right)$ growth rates for quartz diapirs in an olivine halfspace over a range of temperatures $\left(T_{0}=200-1200{ }^{\circ} \mathrm{C}\right)$, thermal gradients $(L / h=1-1000)$ and perturbation wavenumbers $\left(k^{\prime}=\right.$ 0.5-5). Examples of these growth rates are shown in Fig. 6 at 600 and $1000{ }^{\circ} \mathrm{C}$ and all values are reported in Table 3 .

We then used these growth rates to calculate dimensional instability times $t_{b}\left(q^{\prime \prime}\right)$ and $t_{b}\left(C^{\prime}\right)$ using eqs (18) and (14), respectively, for a range of thermal conditions $\left(T_{0}\right.$ and $\left.\beta\right)$ and, for $t_{b}\left(q^{\prime \prime}\right)$, a range of background strain rates $\left(\dot{E}_{L}\right.$ and $\left.\dot{E}_{H}\right)$. In the calculations of exponential growth (eq. 18), $\dot{E}_{L}$ enters only through the timescale $\mathbb{T}_{h \Delta \rho \dot{E}}$ (eq. 16). For a constant value of $\dot{E}_{L}$, increasing $\dot{E}_{H}$ reduces the effective viscosity of the mantle wedge with respect to the vis- (a) Exponential Growth
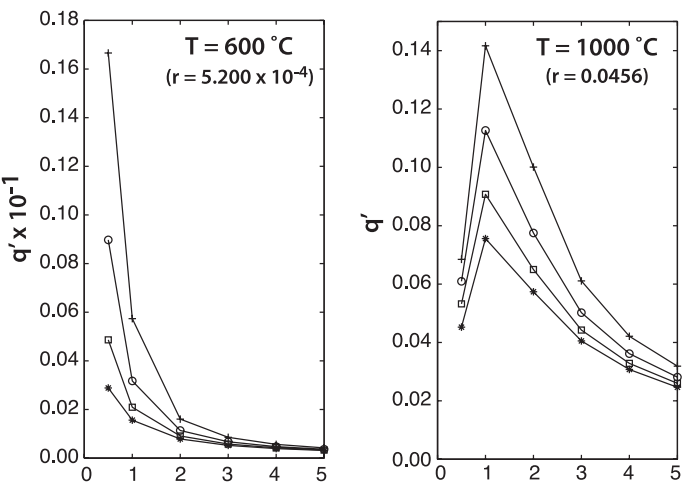

(b) Super Exponential Growth
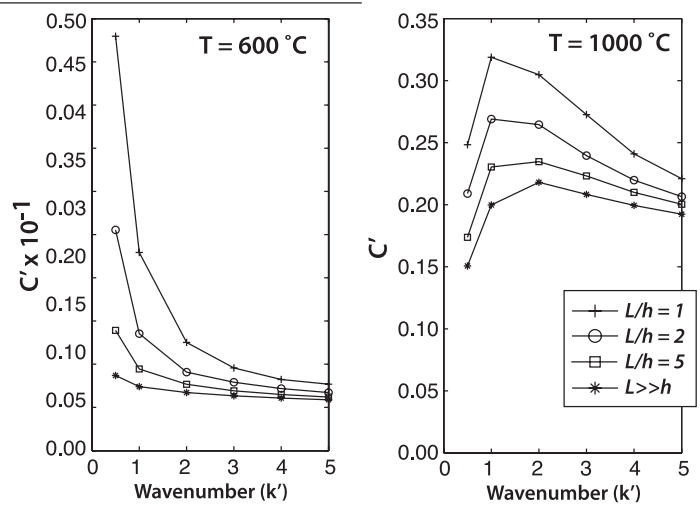

Figure 6. Numerically calculated growth rate factors as a function of wavenumber $k^{\prime}=2 \pi / \lambda^{\prime}$ for quartz diapirs in an olivine half-space with a homogenous layer temperature of 600 and $1000{ }^{\circ} \mathrm{C}$ for different length scales for viscous decay in the half-space $(L / h)$. In (a), viscosities are held constant, and the diapirs grow exponentially. In (b), viscosities decay with increasing strain rate and diapir growth is super-exponential. If $L / h$ is small, the half-space viscosity decays rapidly with distance from the layer boundary, while if $L \gg h$, viscosity in the half-space is nearly homogenous. Changes in $L / h$ have a much stronger effect at low temperatures where quartz is weak with respect to olivine (i.e. small $r$ ) than at higher temperatures where quartz and olivine viscosities are comparable.

cosity of the layer, increasing the viscosity ratio $r=B_{L} / B_{H}$, and we thus included $\dot{E}_{H}$ via the scaling for $r$. We found that $t_{b}\left(q^{\prime \prime}\right)$ and $t_{b}\left(C^{\prime}\right)$ differ by several orders of magnitude over the range of temperatures predicted along the slab top, implying that, at low temperature, instability times would be controlled by exponential growth, but, at higher temperatures, would be dominated by superexponential growth (Fig. 7). We thus approximate instability times for diapirs forming in the presence of a background strain rate by writing:

$t_{b}=\min \left[t_{b}\left(q^{\prime \prime}\right), t_{b}\left(C^{\prime}\right)\right]$.

We then scaled these instability times for different layer thicknesses, initial perturbation amplitudes, and density contrasts (Fig. 8). From eq. (14), it can be shown that differences in $h, Y_{0}^{\prime}$ and $\Delta \rho$ are related to a difference in instability time by

$t_{b 2}=t_{b 1}\left[\left(\frac{\Delta \rho_{1} h_{1}}{\Delta \rho_{2} h_{2}}\right)^{n}\left(\frac{Y_{01}^{\prime}}{Y_{02}^{\prime}}\right)^{n-1}\right]$ 
Table 3. Non-dimensional, exponential and superexponential growth rates for quartz diapirs in an olivine half-space for various initial perturbation wavenumbers $\left(k^{\prime}\right)$. Models were run with fixed temperatures $(T)$ and fixed relative length scales for viscous decay in the half-space $(L / h)$.

\begin{tabular}{|c|c|c|c|c|c|c|c|c|c|}
\hline & \multicolumn{4}{|c|}{ Exponential growth rate $\left(q^{\prime}\right)$} & \multicolumn{5}{|c|}{ Superexponential growth rate $\left(C^{\prime}\right)$} \\
\hline & $k^{\prime}$ & $L / h=1$ & $L / h=2$ & $L / h=5$ & $L / h=1000$ & $L / h=1$ & $L / h=2$ & $L / h=5$ & $L / h=1000$ \\
\hline \multirow[t]{6}{*}{$T=200^{\circ} \mathrm{C}$} & 0.5 & $1.920 \mathrm{E}-07$ & $7.240 \mathrm{E}-08$ & $3.350 \mathrm{E}-08$ & $1.860 \mathrm{E}-08$ & $1.090 \mathrm{E}-06$ & $3.730 \mathrm{E}-07$ & $1.530 \mathrm{E}-07$ & $8.980 \mathrm{E}-08$ \\
\hline & 1 & $3.670 \mathrm{E}-08$ & $1.940 \mathrm{E}-08$ & $1.260 \mathrm{E}-08$ & $9.320 \mathrm{E}-09$ & $3.160 \mathrm{E}-07$ & $1.490 \mathrm{E}-07$ & $9.410 \mathrm{E}-08$ & $7.750 \mathrm{E}-08$ \\
\hline & 2 & $9.670 \mathrm{E}-09$ & $6.770 \mathrm{E}-09$ & $5.410 \mathrm{E}-09$ & $4.660 \mathrm{E}-09$ & $1.150 \mathrm{E}-07$ & $9.190 \mathrm{E}-08$ & $8.580 \mathrm{E}-08$ & $8.410 \mathrm{E}-08$ \\
\hline & 3 & $5.110 \mathrm{E}-09$ & $3.990 \mathrm{E}-09$ & $3.430 \mathrm{E}-09$ & $3.110 \mathrm{E}-09$ & $1.220 \mathrm{E}-07$ & $1.100 \mathrm{E}-07$ & $1.060 \mathrm{E}-07$ & $1.030 \mathrm{E}-07$ \\
\hline & 4 & $3.380 \mathrm{E}-09$ & $2.810 \mathrm{E}-09$ & $2.510 \mathrm{E}-09$ & $2.330 \mathrm{E}-09$ & $1.240 \mathrm{E}-07$ & $1.250 \mathrm{E}-07$ & $1.250 \mathrm{E}-07$ & $1.230 \mathrm{E}-07$ \\
\hline & 5 & $2.520 \mathrm{E}-09$ & $2.170 \mathrm{E}-09$ & $1.980 \mathrm{E}-09$ & $1.860 \mathrm{E}-09$ & $1.510 \mathrm{E}-07$ & $1.440 \mathrm{E}-07$ & $1.430 \mathrm{E}-07$ & $1.410 \mathrm{E}-07$ \\
\hline \multirow[t]{6}{*}{$T=300^{\circ} \mathrm{C}$} & 0.5 & $1.830 \mathrm{E}-05$ & $7.020 \mathrm{E}-06$ & $3.280 \mathrm{E}-06$ & $1.830 \mathrm{E}-06$ & $1.050 \mathrm{E}-04$ & $4.610 \mathrm{E}-05$ & $1.820 \mathrm{E}-05$ & $1.010 \mathrm{E}-05$ \\
\hline & 1 & $3.550 \mathrm{E}-06$ & $1.900 \mathrm{E}-06$ & $1.230 \mathrm{E}-06$ & $9.140 \mathrm{E}-07$ & $3.910 \mathrm{E}-05$ & $2.220 \mathrm{E}-05$ & $1.470 \mathrm{E}-05$ & $1.100 \mathrm{E}-05$ \\
\hline & 2 & $9.450 \mathrm{E}-07$ & $6.630 \mathrm{E}-07$ & $5.310 \mathrm{E}-07$ & $4.570 \mathrm{E}-07$ & $1.920 \mathrm{E}-05$ & $1.370 \mathrm{E}-05$ & $1.120 \mathrm{E}-05$ & $9.710 \mathrm{E}-06$ \\
\hline & 3 & $5.000 \mathrm{E}-07$ & $3.910 \mathrm{E}-07$ & $3.370 \mathrm{E}-07$ & $3.050 \mathrm{E}-07$ & $1.410 \mathrm{E}-05$ & $1.130 \mathrm{E}-05$ & $8.190 \mathrm{E}-06$ & $8.950 \mathrm{E}-06$ \\
\hline & 4 & $3.310 \mathrm{E}-07$ & $2.750 \mathrm{E}-07$ & $2.460 \mathrm{E}-07$ & $2.280 \mathrm{E}-07$ & $9.570 \mathrm{E}-06$ & $8.190 \mathrm{E}-06$ & $7.300 \mathrm{E}-06$ & $6.940 \mathrm{E}-06$ \\
\hline & 5 & $2.470 \mathrm{E}-07$ & $2.120 \mathrm{E}-07$ & $1.940 \mathrm{E}-07$ & $1.830 \mathrm{E}-07$ & $8.320 \mathrm{E}-06$ & $7.450 \mathrm{E}-06$ & $6.970 \mathrm{E}-06$ & $6.860 \mathrm{E}-06$ \\
\hline \multirow[t]{6}{*}{$T=400^{\circ} \mathrm{C}$} & 0.5 & $4.440 \mathrm{E}-04$ & $1.740 \mathrm{E}-04$ & $8.190 \mathrm{E}-05$ & $4.580 \mathrm{E}-05$ & $1.710 \mathrm{E}-03$ & $7.820 \mathrm{E}-04$ & $3.880 \mathrm{E}-04$ & $2.270 \mathrm{E}-04$ \\
\hline & 1 & $8.820 \mathrm{E}-05$ & $4.740 \mathrm{E}-05$ & $3.090 \mathrm{E}-05$ & $2.290 \mathrm{E}-05$ & $6.560 \mathrm{E}-04$ & $3.710 \mathrm{E}-04$ & $2.480 \mathrm{E}-04$ & $1.920 \mathrm{E}-04$ \\
\hline & 2 & $2.360 \mathrm{E}-05$ & $1.660 \mathrm{E}-05$ & $1.330 \mathrm{E}-05$ & $1.150 \mathrm{E}-05$ & $3.320 \mathrm{E}-04$ & $2.370 \mathrm{E}-04$ & $1.970 \mathrm{E}-04$ & $1.730 \mathrm{E}-04$ \\
\hline & 3 & $1.250 \mathrm{E}-05$ & $9.820 \mathrm{E}-06$ & $8.450 \mathrm{E}-06$ & $7.650 \mathrm{E}-06$ & $2.500 \mathrm{E}-04$ & $2.040 \mathrm{E}-04$ & $1.780 \mathrm{E}-04$ & $1.630 \mathrm{E}-04$ \\
\hline & 4 & $8.310 \mathrm{E}-06$ & $6.910 \mathrm{E}-06$ & $6.180 \mathrm{E}-06$ & $5.740 \mathrm{E}-06$ & $2.150 \mathrm{E}-04$ & $1.850 \mathrm{E}-04$ & $1.670 \mathrm{E}-04$ & $1.560 \mathrm{E}-04$ \\
\hline & 5 & $6.190 \mathrm{E}-06$ & $5.330 \mathrm{E}-06$ & $4.870 \mathrm{E}-06$ & $4.590 \mathrm{E}-06$ & $1.980 \mathrm{E}-04$ & $1.730 \mathrm{E}-04$ & $1.600 \mathrm{E}-04$ & $1.540 \mathrm{E}-04$ \\
\hline \multirow[t]{6}{*}{$T=500^{\circ} \mathrm{C}$} & 0.5 & $4.240 \mathrm{E}-03$ & $1.790 \mathrm{E}-03$ & $8.710 \mathrm{E}-04$ & $4.930 \mathrm{E}-04$ & $1.230 \mathrm{E}-02$ & $5.960 \mathrm{E}-03$ & $3.050 \mathrm{E}-03$ & $1.810 \mathrm{E}-03$ \\
\hline & 1 & $9.460 \mathrm{E}-04$ & $5.140 \mathrm{E}-04$ & $3.360 \mathrm{E}-04$ & $2.500 \mathrm{E}-04$ & $5.040 \mathrm{E}-03$ & $2.930 \mathrm{E}-03$ & $1.970 \mathrm{E}-03$ & $1.530 \mathrm{E}-03$ \\
\hline & 2 & $2.570 \mathrm{E}-04$ & $1.810 \mathrm{E}-04$ & $1.450 \mathrm{E}-04$ & $1.250 \mathrm{E}-04$ & $2.610 \mathrm{E}-03$ & $1.940 \mathrm{E}-03$ & $1.580 \mathrm{E}-03$ & $1.430 \mathrm{E}-03$ \\
\hline & 3 & $1.360 \mathrm{E}-04$ & $1.070 \mathrm{E}-04$ & $9.220 \mathrm{E}-05$ & $8.340 \mathrm{E}-05$ & $2.040 \mathrm{E}-03$ & $1.630 \mathrm{E}-03$ & $1.420 \mathrm{E}-03$ & $1.340 \mathrm{E}-03$ \\
\hline & 4 & $9.050 \mathrm{E}-05$ & $7.530 \mathrm{E}-05$ & $6.740 \mathrm{E}-05$ & $6.260 \mathrm{E}-05$ & $1.750 \mathrm{E}-03$ & $1.480 \mathrm{E}-03$ & $1.380 \mathrm{E}-03$ & $1.290 \mathrm{E}-03$ \\
\hline & 5 & $6.740 \mathrm{E}-05$ & $5.810 \mathrm{E}-05$ & $5.310 \mathrm{E}-05$ & $5.000 \mathrm{E}-05$ & $1.580 \mathrm{E}-03$ & $1.380 \mathrm{E}-03$ & $1.310 \mathrm{E}-03$ & $1.250 \mathrm{E}-03$ \\
\hline \multirow[t]{6}{*}{$T=600^{\circ} \mathrm{C}$} & 0.5 & $1.670 \mathrm{E}-02$ & $8.980 \mathrm{E}-03$ & $4.870 \mathrm{E}-03$ & $2.890 \mathrm{E}-03$ & $4.800 \mathrm{E}-02$ & $2.550 \mathrm{E}-02$ & $1.390 \mathrm{E}-02$ & $8.700 \mathrm{E}-03$ \\
\hline & 1 & $5.740 \mathrm{E}-03$ & $3.180 \mathrm{E}-03$ & $2.100 \mathrm{E}-03$ & $1.560 \mathrm{E}-03$ & $2.290 \mathrm{E}-02$ & $1.350 \mathrm{E}-02$ & $9.450 \mathrm{E}-03$ & $7.400 \mathrm{E}-03$ \\
\hline & 2 & $1.610 \mathrm{E}-03$ & $1.140 \mathrm{E}-03$ & $9.140 \mathrm{E}-04$ & $7.880 \mathrm{E}-04$ & $1.250 \mathrm{E}-02$ & $9.090 \mathrm{E}-03$ & $7.670 \mathrm{E}-03$ & $6.720 \mathrm{E}-03$ \\
\hline & 3 & $8.570 \mathrm{E}-04$ & $6.740 \mathrm{E}-04$ & $5.810 \mathrm{E}-04$ & $5.260 \mathrm{E}-04$ & $9.570 \mathrm{E}-03$ & $7.910 \mathrm{E}-03$ & $6.920 \mathrm{E}-03$ & $6.330 \mathrm{E}-03$ \\
\hline & 4 & $5.690 \mathrm{E}-04$ & $4.750 \mathrm{E}-04$ & $4.250 \mathrm{E}-04$ & $3.940 \mathrm{E}-04$ & $8.240 \mathrm{E}-03$ & $7.180 \mathrm{E}-03$ & $6.500 \mathrm{E}-03$ & $6.080 \mathrm{E}-03$ \\
\hline & 5 & $4.250 \mathrm{E}-04$ & $3.660 \mathrm{E}-04$ & $3.350 \mathrm{E}-04$ & $3.150 \mathrm{E}-04$ & $7.680 \mathrm{E}-03$ & $6.720 \mathrm{E}-03$ & $6.200 \mathrm{E}-03$ & $5.890 \mathrm{E}-03$ \\
\hline \multirow{6}{*}{$T=700^{\circ} \mathrm{C}$} & 0.5 & $3.030 \mathrm{E}-02$ & $2.210 \mathrm{E}-02$ & $1.470 \mathrm{E}-02$ & $9.770 \mathrm{E}-03$ & $1.070 \mathrm{E}-01$ & $6.920 \mathrm{E}-02$ & $4.190 \mathrm{E}-02$ & $2.810 \mathrm{E}-02$ \\
\hline & 1 & $2.210 \mathrm{E}-02$ & $1.280 \mathrm{E}-02$ & $8.650 \mathrm{E}-03$ & $6.510 \mathrm{E}-03$ & $7.230 \mathrm{E}-02$ & $4.540 \mathrm{E}-02$ & $3.110 \mathrm{E}-02$ & $2.460 \mathrm{E}-02$ \\
\hline & 2 & $6.810 \mathrm{E}-03$ & $4.860 \mathrm{E}-03$ & $3.920 \mathrm{E}-03$ & $3.380 \mathrm{E}-03$ & $4.120 \mathrm{E}-02$ & $3.130 \mathrm{E}-02$ & $2.580 \mathrm{E}-02$ & $2.330 \mathrm{E}-02$ \\
\hline & 3 & $3.660 \mathrm{E}-03$ & $2.890 \mathrm{E}-03$ & $2.490 \mathrm{E}-03$ & $2.260 \mathrm{E}-03$ & $3.280 \mathrm{E}-02$ & $2.640 \mathrm{E}-02$ & $2.400 \mathrm{E}-02$ & $2.200 \mathrm{E}-02$ \\
\hline & 4 & $2.440 \mathrm{E}-03$ & $2.040 \mathrm{E}-03$ & $1.830 \mathrm{E}-03$ & $1.700 \mathrm{E}-03$ & $2.830 \mathrm{E}-02$ & $2.400 \mathrm{E}-02$ & $2.250 \mathrm{E}-02$ & $2.110 \mathrm{E}-02$ \\
\hline & 5 & $1.820 \mathrm{E}-03$ & $1.570 \mathrm{E}-03$ & $1.440 \mathrm{E}-03$ & $1.360 \mathrm{E}-03$ & $2.570 \mathrm{E}-02$ & $2.250 \mathrm{E}-02$ & $2.150 \mathrm{E}-02$ & $2.050 \mathrm{E}-02$ \\
\hline \multirow[t]{6}{*}{$T=800^{\circ} \mathrm{C}$} & 0.5 & $4.010 \mathrm{E}-02$ & $3.410 \mathrm{E}-02$ & $2.690 \mathrm{E}-02$ & $2.030 \mathrm{E}-02$ & $1.610 \mathrm{E}-01$ & $1.220 \mathrm{E}-01$ & $9.060 \mathrm{E}-02$ & $6.470 \mathrm{E}-02$ \\
\hline & 1 & $5.600 \mathrm{E}-02$ & $3.580 \mathrm{E}-02$ & $2.520 \mathrm{E}-02$ & $1.940 \mathrm{E}-02$ & $1.560 \mathrm{E}-01$ & $1.070 \mathrm{E}-01$ & $7.820 \mathrm{E}-02$ & $6.250 \mathrm{E}-02$ \\
\hline & 2 & $2.140 \mathrm{E}-02$ & $1.550 \mathrm{E}-02$ & $1.250 \mathrm{E}-02$ & $1.090 \mathrm{E}-02$ & $1.040 \mathrm{E}-01$ & $7.990 \mathrm{E}-02$ & $6.880 \mathrm{E}-02$ & $6.060 \mathrm{E}-02$ \\
\hline & 3 & $1.170 \mathrm{E}-02$ & $9.320 \mathrm{E}-03$ & $8.070 \mathrm{E}-03$ & $7.320 \mathrm{E}-03$ & $8.370 \mathrm{E}-02$ & $6.810 \mathrm{E}-02$ & $6.230 \mathrm{E}-02$ & $5.730 \mathrm{E}-02$ \\
\hline & 4 & $7.860 \mathrm{E}-03$ & $6.590 \mathrm{E}-03$ & $5.910 \mathrm{E}-03$ & $5.500 \mathrm{E}-03$ & $7.260 \mathrm{E}-02$ & $6.440 \mathrm{E}-02$ & $5.860 \mathrm{E}-02$ & $5.500 \mathrm{E}-02$ \\
\hline & 5 & $5.880 \mathrm{E}-03$ & $5.090 \mathrm{E}-03$ & 4.670E-03 & $4.400 \mathrm{E}-03$ & $6.590 \mathrm{E}-02$ & $6.030 \mathrm{E}-02$ & $5.590 \mathrm{E}-02$ & $5.320 \mathrm{E}-02$ \\
\hline \multirow[t]{6}{*}{$T=900^{\circ} \mathrm{C}$} & 0.5 & $5.210 \mathrm{E}-02$ & $4.600 \mathrm{E}-02$ & $3.900 \mathrm{E}-02$ & $3.180 \mathrm{E}-02$ & $1.970 \mathrm{E}-01$ & $1.750 \mathrm{E}-01$ & $1.410 \mathrm{E}-01$ & $1.090 \mathrm{E}-01$ \\
\hline & 1 & $9.990 \mathrm{E}-02$ & $7.190 \mathrm{E}-02$ & $5.410 \mathrm{E}-02$ & $4.320 \mathrm{E}-02$ & $2.450 \mathrm{E}-01$ & $1.920 \mathrm{E}-01$ & $1.500 \mathrm{E}-01$ & $1.270 \mathrm{E}-01$ \\
\hline & 2 & $5.200 \mathrm{E}-02$ & $3.860 \mathrm{E}-02$ & $3.170 \mathrm{E}-02$ & $2.760 \mathrm{E}-02$ & $2.010 \mathrm{E}-01$ & $1.590 \mathrm{E}-01$ & $1.390 \mathrm{E}-01$ & $1.280 \mathrm{E}-01$ \\
\hline & 3 & $2.970 \mathrm{E}-02$ & $2.390 \mathrm{E}-02$ & $2.080 \mathrm{E}-02$ & $1.890 \mathrm{E}-02$ & $1.660 \mathrm{E}-01$ & $1.420 \mathrm{E}-01$ & $1.310 \mathrm{E}-01$ & $1.210 \mathrm{E}-01$ \\
\hline & 4 & $2.010 \mathrm{E}-02$ & $1.700 \mathrm{E}-02$ & $1.530 \mathrm{E}-02$ & $1.430 \mathrm{E}-02$ & $1.450 \mathrm{E}-01$ & $1.300 \mathrm{E}-01$ & $1.230 \mathrm{E}-01$ & $1.160 \mathrm{E}-01$ \\
\hline & 5 & $1.510 \mathrm{E}-02$ & $1.320 \mathrm{E}-02$ & $1.210 \mathrm{E}-02$ & $1.140 \mathrm{E}-02$ & $1.370 \mathrm{E}-01$ & $1.220 \mathrm{E}-01$ & $1.180 \mathrm{E}-01$ & $1.120 \mathrm{E}-01$ \\
\hline \multirow[t]{6}{*}{$T=1000^{\circ} \mathrm{C}$} & 0.5 & $6.850 \mathrm{E}-02$ & $6.100 \mathrm{E}-02$ & $5.320 \mathrm{E}-02$ & $4.520 \mathrm{E}-02$ & $2.480 \mathrm{E}-01$ & $2.090 \mathrm{E}-01$ & $1.740 \mathrm{E}-01$ & $1.510 \mathrm{E}-01$ \\
\hline & 1 & $1.420 \mathrm{E}-01$ & $1.130 \mathrm{E}-01$ & $9.080 \mathrm{E}-02$ & $7.560 \mathrm{E}-02$ & $3.190 \mathrm{E}-01$ & $2.690 \mathrm{E}-01$ & $2.300 \mathrm{E}-01$ & $2.000 \mathrm{E}-01$ \\
\hline & 2 & $1.000 \mathrm{E}-01$ & $7.750 \mathrm{E}-02$ & $6.500 \mathrm{E}-02$ & $5.740 \mathrm{E}-02$ & $3.050 \mathrm{E}-01$ & $2.650 \mathrm{E}-01$ & $2.350 \mathrm{E}-01$ & $2.180 \mathrm{E}-01$ \\
\hline & 3 & $6.110 \mathrm{E}-02$ & $5.020 \mathrm{E}-02$ & $4.420 \mathrm{E}-02$ & $4.050 \mathrm{E}-02$ & $2.730 \mathrm{E}-01$ & $2.400 \mathrm{E}-01$ & $2.230 \mathrm{E}-01$ & $2.080 \mathrm{E}-01$ \\
\hline & 4 & $4.210 \mathrm{E}-02$ & $3.620 \mathrm{E}-02$ & $3.280 \mathrm{E}-02$ & $3.080 \mathrm{E}-02$ & $2.410 \mathrm{E}-01$ & $2.200 \mathrm{E}-01$ & $2.100 \mathrm{E}-01$ & $1.990 \mathrm{E}-01$ \\
\hline & 5 & $3.190 \mathrm{E}-02$ & $2.810 \mathrm{E}-02$ & $2.600 \mathrm{E}-02$ & $2.470 \mathrm{E}-02$ & $2.210 \mathrm{E}-01$ & $2.060 \mathrm{E}-01$ & $2.000 \mathrm{E}-01$ & $1.920 \mathrm{E}-01$ \\
\hline
\end{tabular}


Table 3. (Continued.)

\begin{tabular}{|c|c|c|c|c|c|c|c|c|c|}
\hline & \multicolumn{4}{|c|}{ Exponential growth rate $\left(q^{\prime}\right)$} & \multicolumn{4}{|c|}{ Superexponential growth rate $\left(C^{\prime}\right)$} & \multirow[b]{2}{*}{$L / h=1000$} \\
\hline & $k^{\prime}$ & $L / h=1$ & $L / h=2$ & $L / h=5$ & $L / h=1000$ & $L / h=1$ & $L / h=2$ & $L / h=5$ & \\
\hline \multirow[t]{6}{*}{$T=1100^{\circ} \mathrm{C}$} & 0.5 & $8.430 \mathrm{E}-02$ & $7.690 \mathrm{E}-02$ & $6.910 \mathrm{E}-02$ & $6.060 \mathrm{E}-02$ & $2.920 \mathrm{E}-01$ & $2.670 \mathrm{E}-01$ & $2.130 \mathrm{E}-01$ & $1.880 \mathrm{E}-01$ \\
\hline & 1 & $1.770 \mathrm{E}-01$ & $1.510 \mathrm{E}-01$ & $1.280 \mathrm{E}-01$ & $1.110 \mathrm{E}-01$ & $3.770 \mathrm{E}-01$ & $3.290 \mathrm{E}-01$ & $2.990 \mathrm{E}-01$ & $2.580 \mathrm{E}-01$ \\
\hline & 2 & $1.580 \mathrm{E}-01$ & $1.280 \mathrm{E}-01$ & $1.110 \mathrm{E}-01$ & $9.950 \mathrm{E}-02$ & $3.850 \mathrm{E}-01$ & $3.450 \mathrm{E}-01$ & $3.290 \mathrm{E}-01$ & $3.100 \mathrm{E}-01$ \\
\hline & 3 & $1.040 \mathrm{E}-01$ & $8.840 \mathrm{E}-02$ & $7.920 \mathrm{E}-02$ & $7.330 \mathrm{E}-02$ & $3.480 \mathrm{E}-01$ & $3.240 \mathrm{E}-01$ & $3.110 \mathrm{E}-01$ & $3.070 \mathrm{E}-01$ \\
\hline & 4 & $7.390 \mathrm{E}-02$ & $6.480 \mathrm{E}-02$ & $5.950 \mathrm{E}-02$ & $5.610 \mathrm{E}-02$ & $3.190 \mathrm{E}-01$ & $3.010 \mathrm{E}-01$ & $2.920 \mathrm{E}-01$ & $2.890 \mathrm{E}-01$ \\
\hline & 5 & $5.660 \mathrm{E}-02$ & $5.070 \mathrm{E}-02$ & $4.730 \mathrm{E}-02$ & $4.510 \mathrm{E}-02$ & $2.960 \mathrm{E}-01$ & $2.880 \mathrm{E}-01$ & $2.780 \mathrm{E}-01$ & $2.710 \mathrm{E}-01$ \\
\hline \multirow[t]{6}{*}{$T=1200^{\circ} \mathrm{C}$} & 0.5 & $9.650 \mathrm{E}-02$ & $9.050 \mathrm{E}-02$ & $8.340 \mathrm{E}-02$ & $7.510 \mathrm{E}-02$ & $3.670 \mathrm{E}-01$ & $3.140 \mathrm{E}-01$ & $2.560 \mathrm{E}-01$ & $2.230 \mathrm{E}-01$ \\
\hline & 1 & $2.040 \mathrm{E}-01$ & $1.830 \mathrm{E}-01$ & $1.620 \mathrm{E}-01$ & $1.450 \mathrm{E}-01$ & $4.140 \mathrm{E}-01$ & $3.720 \mathrm{E}-01$ & $3.370 \mathrm{E}-01$ & $3.120 \mathrm{E}-01$ \\
\hline & 2 & $2.120 \mathrm{E}-01$ & $1.810 \mathrm{E}-01$ & $1.620 \mathrm{E}-01$ & $1.480 \mathrm{E}-01$ & $4.560 \mathrm{E}-01$ & $4.170 \mathrm{E}-01$ & $3.900 \mathrm{E}-01$ & $3.780 \mathrm{E}-01$ \\
\hline & 3 & $1.520 \mathrm{E}-01$ & $1.330 \mathrm{E}-01$ & $1.220 \mathrm{E}-01$ & $1.140 \mathrm{E}-01$ & $4.210 \mathrm{E}-01$ & $3.950 \mathrm{E}-01$ & $3.760 \mathrm{E}-01$ & $3.660 \mathrm{E}-01$ \\
\hline & 4 & $1.110 \mathrm{E}-01$ & $9.970 \mathrm{E}-02$ & $9.290 \mathrm{E}-02$ & $8.840 \mathrm{E}-02$ & $3.890 \mathrm{E}-01$ & $3.730 \mathrm{E}-01$ & $3.620 \mathrm{E}-01$ & $3.500 \mathrm{E}-01$ \\
\hline & 5 & $8.600 \mathrm{E}-02$ & $7.860 \mathrm{E}-02$ & $7.410 \mathrm{E}-02$ & $7.120 \mathrm{E}-02$ & $3.670 \mathrm{E}-01$ & $3.520 \mathrm{E}-01$ & $3.450 \mathrm{E}-01$ & $3.350 \mathrm{E}-01$ \\
\hline
\end{tabular}

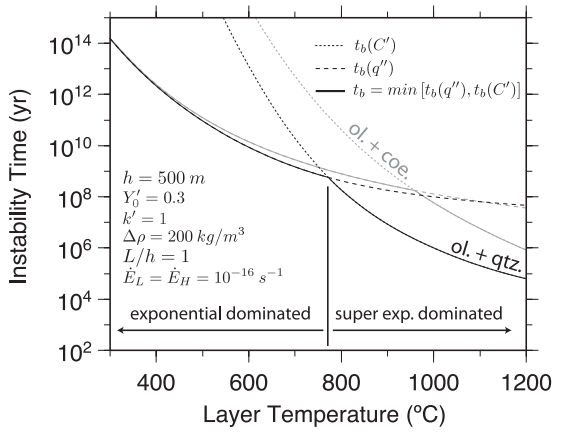

Figure 7. Example determination of diapir instability time. At low temperatures, diapirs grow fastest when Newtonian viscosities are calculated for a finite background strain rate $\left(\dot{E}_{L}=\dot{E}_{H}=10^{-16} \mathrm{~s}^{-1}\right)$ (dashed line). At higher temperatures, diapirs grow faster when viscosities are non-Newtonian and decay with increasing local strain rates (dotted line). To determine an instability time as a function of temperature, we choose the minimum of these two curves (solid line). Instability times are shown for wet-quartz (black lines) and dry-coesite (grey lines) layers underlying a wet-olivine half-space.

where $n=1$ (exponential growth) or $n=n_{L}$ (superexponential growth) and the subscripts 1 and 2 refer to the original and scaled values, respectively.

Finally, to determine the point at which diapirs will detach from the downgoing slab for specific subduction zone models, we integrated the scaled instability times calculated for slab-surface conditions as a function of depth. If instability time as a function of time elapsed during subduction (i.e. 'subduction time', $\left.t_{s}\right)$ is $t_{b}\left(t_{s}\right)$, then the time at which diapir displacement approaches the initial layer thickness is found by solving for when the sum of fractional displacement

$\sum_{i=1}^{n} \frac{t_{s}(i)}{t_{b}(i)}$

is $\geq 1$, where $n$ is the total number of time (depth) intervals along the slab surface and $i$ is the index of a discrete subduction time. After reaching this doubling height, diapirs ascend vertically at a nearly constant velocity, effectively detaching from the downgoing slab and the depth of detachment can thus be inferred from $t_{s}$.

\section{SENSITIVITY OF DIAPIR GROWTH TO TEMPERATURE AND STRAIN RATE}

\subsection{Effect of temperature and half-space thermal structure}

Calculated dimensional instability times show the strong dependence of diapir growth on temperature (Fig. 8). At low temperatures $\left(\leqslant 800^{\circ} \mathrm{C}\right)$, diapir growth is slow, viscosities are dominated by background strain rates, and superexponetial growth does not occur until after displacement reaches the doubling height (i.e. $Y=h$ ). At temperatures greater than $\sim 800^{\circ} \mathrm{C}$, lower viscosities enable faster instability growth, causing local strain rates (from the diapiric flow) to exceed background strain rates and enabling superexponential growth to initiate before diapir displacement reaches the doubling height, thereby reducing instability times.

Non-dimensionalizing growth rates by $\mathbb{T}_{h \Delta \rho}$ shows that diapir growth is also sensitive to secondary controls such as the ratio of the sediment-to-mantle viscosity, $r$, which is a function of temperature and the length scale of viscous decay in the mantle wedge, $L$ (Fig. 6). At low temperatures $\left(\sim 600^{\circ} \mathrm{C}\right)$, olivine is much more viscous than quartz $\left(r=5.2 \times 10^{-4}\right)$ and the ascent of weak quartz diapirs into the strong, overlying olivine half-space is slow $\left(\left[q^{\prime}, C^{\prime}\right]=O\left(10^{-2}\right)\right)$. At these low temperatures, diapirs grow fastest at small wavenumbers $\left(k^{\prime}<0.5\right)$ (Fig. 6). As temperature increases, olivine weakens with respect to quartz $\left(r=4.6 \times 10^{-2}\right.$ at $\left.1000{ }^{\circ} \mathrm{C}\right)$, enabling faster diapir growth $\left(\left[q^{\prime}, C^{\prime}\right]=O\left(10^{-1}\right)\right)$. By $800^{\circ} \mathrm{C}$, the preferred wavenumber for diapir growth begins to converge on $k^{\prime} \approx 1$ (Table 3 ).

The thermal gradient in the mantle wedge also influences the relative viscosities of the sediment layer and mantle wedge and has the strongest effect on diapir growth at lower temperatures and longer wavelengths. For example, decreasing $L$ from $L \gg h$ to $L=$ $h$ increases $q^{\prime}$ by a factor of $\sim 3$ at $600{ }^{\circ} \mathrm{C}$ and $k^{\prime}=1$ (Fig. 6); this same change in the decay length has only a minimal effect at hotter temperatures and/or short wavelengths $\left(k^{\prime}>3\right)$. In terms of dimensional instability time, this same change in $L / h$ results in a shortening of $t_{b}\left(q^{\prime \prime}\right)$ by two orders of magnitude at $600^{\circ} \mathrm{C}$, but only one order of magnitude at $1000{ }^{\circ} \mathrm{C}$ (Fig. 8).

\subsection{Effect of background strain rate}

Finite background strain rates reduce effective viscosities, shortening diapir instability times and effectively reducing the temperature and/or sediment layer thickness required to produce diapirs. The 
(a) $Y_{0}^{\prime}=0.1$
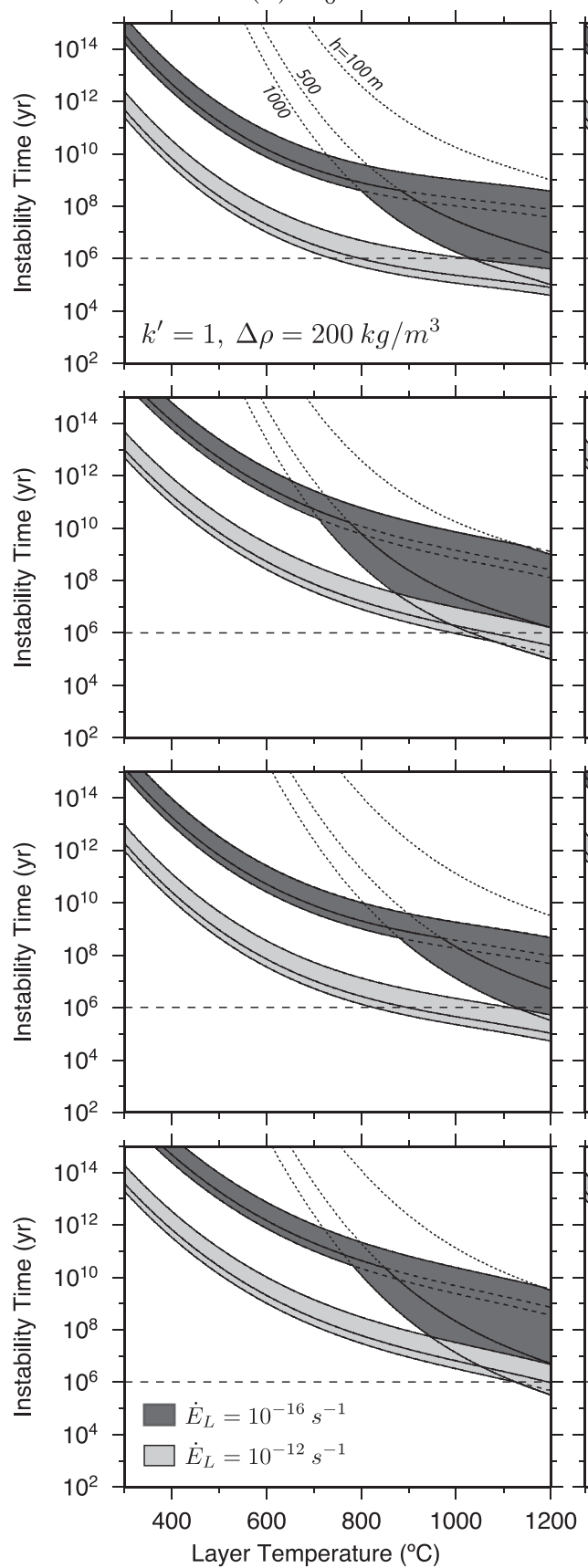

(b) $Y_{0}^{\prime}=0.3$

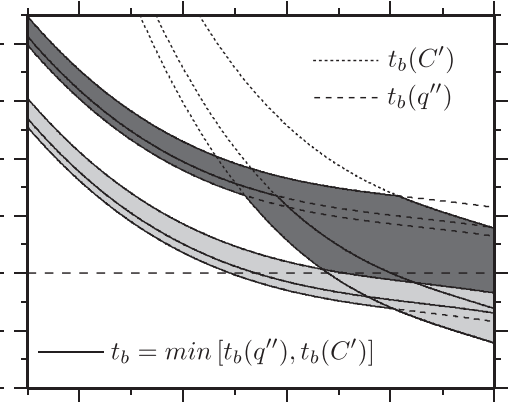

tr
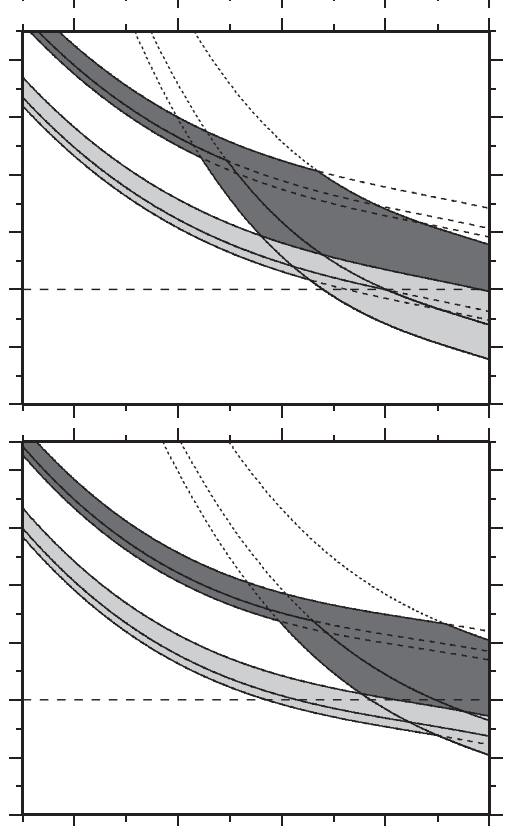

$\checkmark$

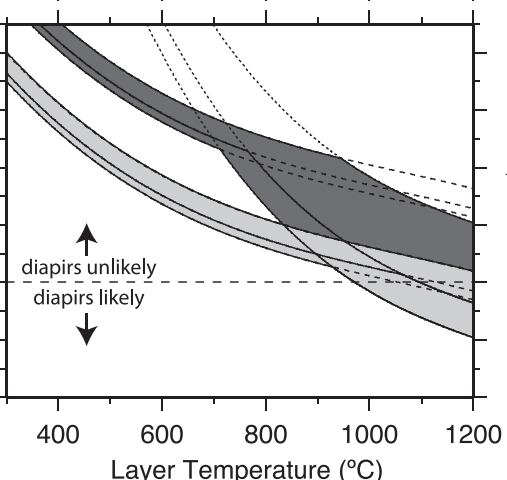

Figure 8. Scaled instability times as function of temperature for initial perturbation sizes of (a) 10 per cent and (b) 30 per cent for different layer thicknesses, background strain rates and half-space viscous decay length scales. Shaded regions show the range of instability times calculated as in Fig. 7 for background strain rates of $10^{-16}$ and $10^{-16} \mathrm{~s}^{-1}$. In most arcs, sediments are subducted in a few million years, and thus diapirs are only likely to form and detach from the slab when $t_{b}<O\left(10^{6}\right) \mathrm{yr}$. 
scaled instability times in Fig. 8 show that increasing the background strain rate from $10^{-16}$ to $10^{-12} \mathrm{~s}^{-1}$ can reduce the time required to form an instability by up to three orders of magnitude $\left(\sim 10^{9}\right.$ to $\left.10^{6} \mathrm{yr}\right)$ at temperatures of $600-800{ }^{\circ} \mathrm{C}$. Similarly, for $Y_{0}^{\prime}=0.3$ and a temperature of $900{ }^{\circ} \mathrm{C}$, a background strain rate of $10^{-12} \mathrm{~s}^{-1}$ allows a $100-\mathrm{m}$-thick sediment layer to reach a doubling height in approximately the same time it takes a 500-m-thick layer to grow by the same amount with $10^{-16} \mathrm{~s}^{-1}$. The relative value of the layer and mantle background strain rates also has an effect on instability times, with a factor of 100 increase in $\dot{E}_{L} / \dot{E}_{H}$ slowing instability times by up to half an order of magnitude (Fig. 8). As shown above in instability times for variable $L / h$ and $T_{0}$, these results demonstrate the importance of the relative viscosities of the sediment layer and the mantle half-space in diapir formation.

\section{TIMESCALES FOR SEDIMENT DIAPIRS IN SUBDUCTION ZONES}

\subsection{Instability times for subduction zone thermal models}

The sensitivity of sediment diapir growth to the thermal and strain rate structure of the slab and mantle wedge is revealed by scaling instability times to the conditions found in a range of subduction zone thermal models (Fig. 9). Diapir growth is principally controlled by the viscosity-reducing effect of temperature, with instabilities initiating when slab-surface temperatures reach $\sim 500{ }^{\circ} \mathrm{C}\left(\eta_{\text {eff }} \approx\right.$ $10^{18}-10^{24} \mathrm{~Pa} \mathrm{~s}$ ) and detaching (i.e. growing to a height equal to the initial layer thickness) within $\sim 1-3$ Myr. The depth of initiation depends on the temperature of the incoming slab, which is a function of plate age and, at depth in subduction zones, subduction rate (Molnar \& England 1990; Molnar \& England 1995). In arcs with young slabs subducting at moderate rates, such as Cascadia, the slab reaches $\sim 500{ }^{\circ} \mathrm{C}$ at $\sim 30 \mathrm{~km}$ and diapirs begin to grow. Here, instabilities forming in a 1500-m-thick sediment layer, for example, would detach at a depth of $\sim 90 \mathrm{~km}$. By contrast, sediments on older, faster subducting slabs, such as Izu, do not reach $\sim 500{ }^{\circ} \mathrm{C}$ until a depth of $\sim 70 \mathrm{~km}$. At this depth, diapirs forming in the same 1500 $\mathrm{m}$-thick layer would begin to grow rapidly and detach from the slab at a depth of $\sim 140-170 \mathrm{~km}$.

The maximum depth of full or partial mechanical decoupling between the slab and mantle wedge significantly influences the thermal structure of subduction zone models, and thus affects viscosities and the growth of sediment diapirs in our calculations of instability times. The decoupling/coupling transition marks an abrupt onset of mantle-wedge flow that brings heat from the back arc to the slab (e.g. van Keken et al. 2002; Wada et al. 2008). The shallower the depth of this transition, the sooner subducting sediments heat up, leading to lower absolute viscosities and faster diapir growth. This effect can be seen in instability times scaled for subduction zone thermal models that make different assumptions about what controls the depth of the decoupling/coupling transition (e.g. D80: prescribed $80 \mathrm{~km}$ depth, X25: distance from arc, T550: depth of the brittle/ductile transition, W1300: subarc mantle temperatures; see Syracuse et al. 2010 for full discussion; Fig. 9). The change in temperature across the transition, and therefore the effect of the transition depth on diapir growth, is most pronounced in subduction zones with colder ambient temperatures. In models of diapirs forming on a cold slab such as that subducting at Izu, increasing the depth of the decoupling/coupling transition from 80 to $120 \mathrm{~km}$ delays the onset of hotter slab-surface temperatures and produces a similar difference in the predicted depth of diapir detachment. By contrast, a
$30 \mathrm{~km}$ difference in the depth of the decoupling/coupling transition in models of the hotter Cascadia arc produces only small differences in slab temperatures, and thus diapir detachment depths are similar in these models. Changes in the degree of slab/mantle coupling also have strong effects on the thermal structure of the mantle wedge, with partial coupling in the D80 Syracuse et al. (2010) models enabling mantle flow to reach further into the mantle-wedge nose than in the Wada \& Wang (2009) models, which assume full slab/mantle decoupling at depths less than $80 \mathrm{~km}$. This enhanced mantle flow produces hotter slab-top and mantle temperatures, promoting diapirism (Fig. 10).

A shortening of the viscous decay length in the mantle wedge near the depth of the decoupling/coupling transition promotes the development of instabilities, enabling diapir growth in even the coldest subduction systems. In the mantle wedge, the decoupling/coupling transition is marked by a zone of steep, inverted geotherms (i.e. short $L$ ) at depths of $\sim 50-180 \mathrm{~km}$ in both hot and cold subduction systems (Wada \& Wang 2009; Syracuse et al. 2010). In colder subduction systems, olivine is stronger with respect to quartz (i.e. small $r$ ) and diapir growth is more sensitive to these changes in $L$ (Fig. 6). At depths of $\sim 70 \mathrm{~km}$ in thermal models of Izu, $L$ shortens rapidly as $r$ increases with temperature (Fig. 9). This short-lived zone where both $L / h$ and $r$ are small enables rapid diapir growth while quartz and olivine viscosities are still relatively large, promoting diapirism on cold slabs.

Variability in sediment-layer geometry can produce large differences in diapir detachment depths (Fig. 10). As with other parameters influencing diapirism, instability growth is most sensitive to changes in these parameters in colder subduction systems where absolute viscosities are larger. For diapirs growing from a 30 per cent initial perturbation $\left(Y_{0}=0.3\right)$ in the Izu model of Syracuse et al. (2010), reducing the sediment layer thickness from 2000 to $1000 \mathrm{~m}$ deepens the depth for diapir detachment from $\sim 130$ to $\sim 190 \mathrm{~km}$. In the Cascadia models, the same reduction in layer thickness only produces a $\sim 20 \mathrm{~km}$ change in the depth of detachment. Because diapirs grow significantly in the exponential (background-strainrate dominated) regime (Fig. 8), increasing the initial perturbation amplitude has a similar effect as increasing the layer thickness (eq. 19).

\subsection{Sensitivity of instability times to variability in viscosity}

The growth of sediment diapirs is sensitive to uncertainties in rheologic parameters and background strain rates. Varying these parameters changes effective viscosity, and thus we assessed the sensitivity of instability times to uncertainty in viscosity by calculating timescales for different background strain rates in the mantle wedge (Fig. 11). As with other instability parameters, diapir growth is most sensitive to changes in viscosity in colder subduction systems, such as Izu, where changing $\dot{E}_{H}$ from $10^{-13}$ to $10^{-12} \mathrm{~s}^{-1}$ reduces the minimum thickness required for diapir formation by up to $\sim 550 \mathrm{~m}$. In the hot Cascadia models, changing $\dot{E}_{H}$ by the same amount reduces this minimum thickness by only $\sim 100 \mathrm{~m}$. This one order of magnitude change in background strain rate is equivalent to a one order of magnitude change in effective viscosity (Fig. 2).

We assessed the effect of the quartz-to-coesite transition on sediment rheology in our instability calculations. This phase change occurs at a pressure of $\sim 2.5 \mathrm{GPa}\left(\sim 700{ }^{\circ} \mathrm{C}\right.$ for Izu and $\sim 900$ ${ }^{\circ} \mathrm{C}$ for Cascadia) (Fig. 2b) and would increase viscosity by up to two orders of magnitude at low temperatures $\left(700^{\circ} \mathrm{C}\right)$ (Fig 2a). To 


\section{Cascadia}

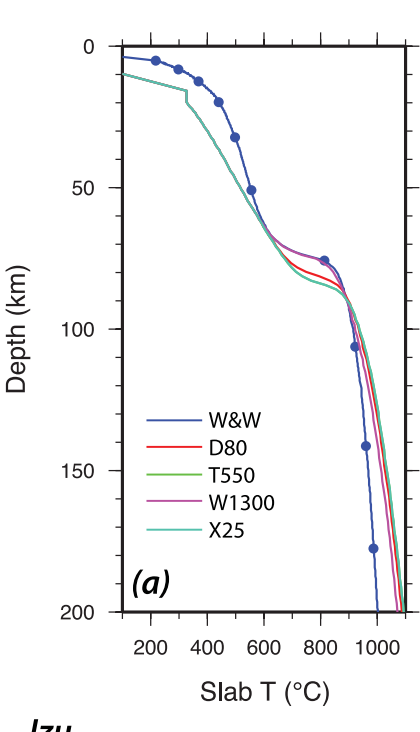

Izu

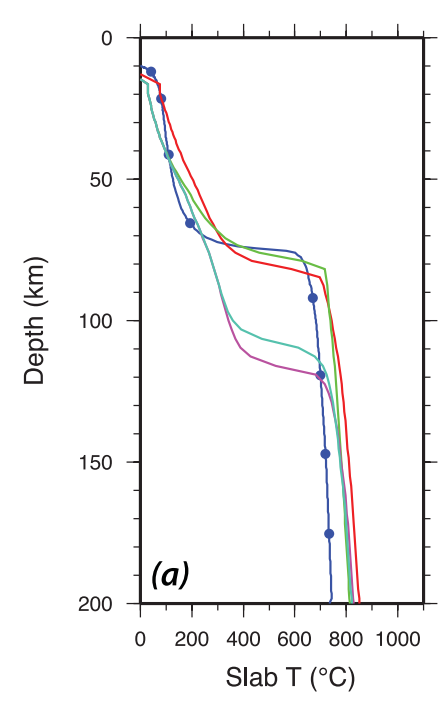

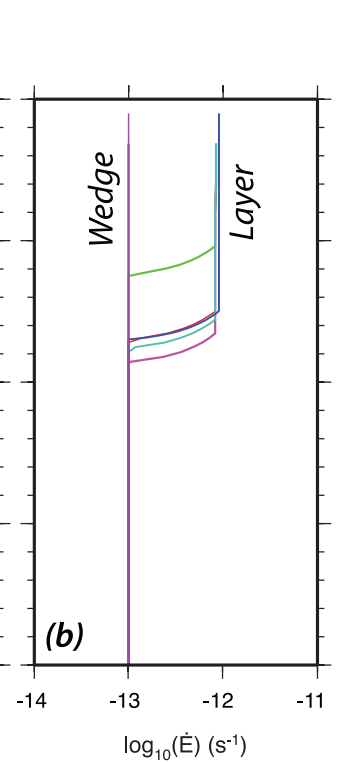

$\log _{10}(r)$

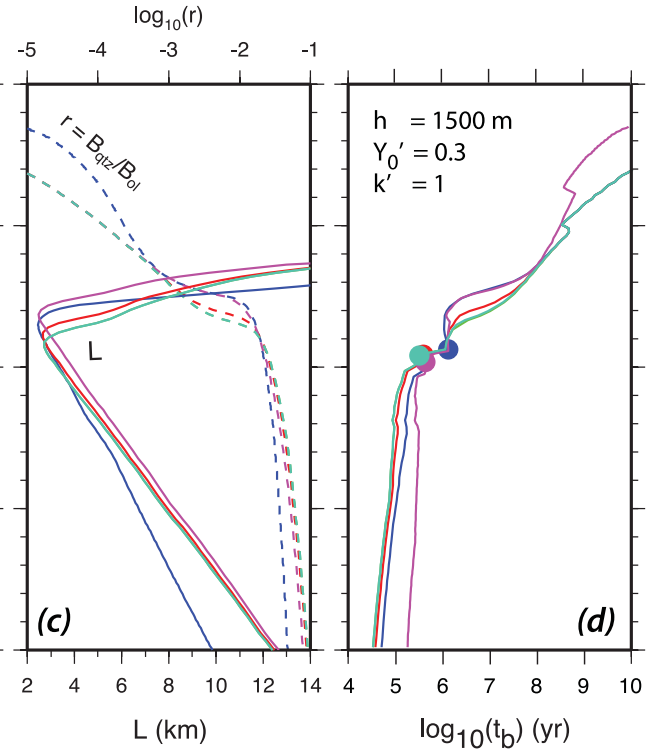

$\begin{array}{lll}-3 & -2 & -1\end{array}$

$\log _{10}(r)$

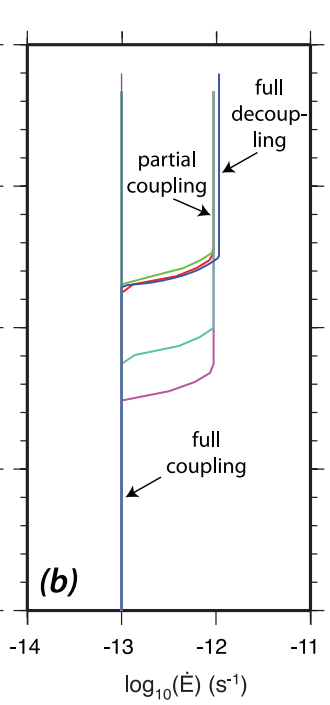

$\begin{array}{lllll}-5 & -4 & -3 & -2 & -1\end{array}$

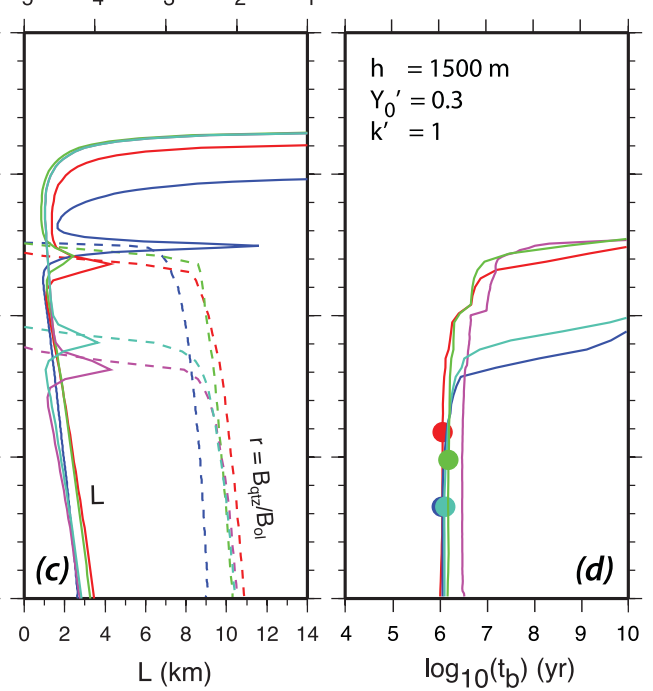

Figure 9. (a-c) Subset of the model parameters shown in Fig. 3. (d) Instability times scaled for conditions at depth (lines) and depths for diapir detachment found by integrating these instability times (circles) for Cascadia (top) and Izu (bottom). W\&W refers to models from Wada \& Wang (2009) in which the decoupling/coupling transition is set to $80 \mathrm{~km}$ and the mantle-wedge temperature is allowed to evolve to steady state. Other models are from Syracuse et al. (2010) and have the following prescribed parameters: (D80) Depth of decoupling/coupling transition is set to $80 \mathrm{~km}$. (T550) The decoupling/coupling transition occurs where the slab surface reaches the brittle/ductile transition at $550^{\circ} \mathrm{C}$. (W1300) The minimum temperature in the mantle wedge beneath the arc is held fixed at $1300^{\circ} \mathrm{C}$. (X25) The decoupling/coupling transition is placed $25 \mathrm{~km}$ from the arc. See references for additional model details.

determine the maximum effect of this viscosity change on diapir growth, we calculated instability times for a dry-coesite layer underlying a wet-olivine half-space (Fig. 7). For exponential growth, instability times are similar to those for wet quartz, while for superexponential growth, instability times are up to an order of magnitude slower. Consequently, including the quartz-to-coesite transition would delay the onset of superexponential growth from $\sim 700^{\circ} \mathrm{C}$ (for a quartz layer) to $>950{ }^{\circ} \mathrm{C}$ (for a coesite layer). In both hot and cold subduction zones, however, a significant portion of diapir growth occurs in the exponential regime (i.e. at temperatures $<700-950{ }^{\circ} \mathrm{C}$ ) (Figs 8 and 9). Further, because vertical velocity increases either exponentially or superexponentially with time, this late-stage change in growth rate will have a minimal effect on the timeintegrated instability times. 

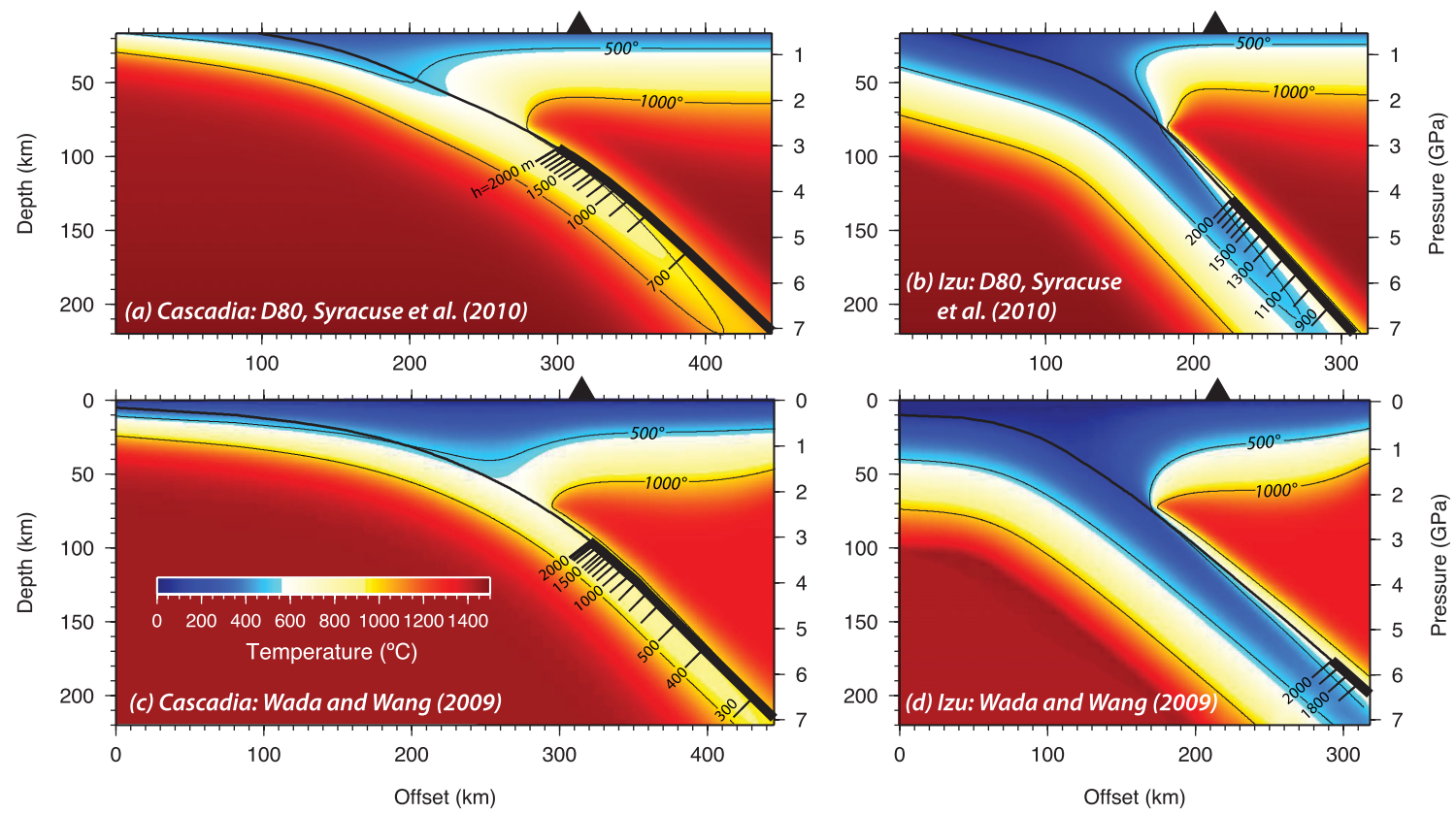

Figure 10. Locations of sediment diapir detachment in the D80 Syracuse et al. (2010) and the Wada \& Wang (2009) models of the Cascadia and Izu subduction zones. Scale on slab surface indicates the location of diapir detachment for different layer thicknesses and a 30 per cent initial perturbation.

\section{DISCUSSION}

Growth rates calculated from numerical models predict that, for sufficiently thick sediment layers and/or large enough initial perturbations, sediment diapirs will form in a broad range of subduction zone settings (Fig. 10). For initial perturbations that are larger than $\sim 30$ per cent of the layer thickness, diapirs form and detach from the slab within the mantle wedge (i.e. within $\sim 100 \mathrm{~km}$ of the slab depth below the arc) when sediment layers are as thin as $200 \mathrm{~m}$ in hot subduction systems (young slabs and/or slow subduction rates, for example, Cascadia) or $\sim 800 \mathrm{~m}$ in cold systems (old slabs and/or fast subduction rates, for example, Izu) (Fig. 11). Globally, estimates for the thickness of subducted sediment layers range from 150 to $>1000 \mathrm{~m}$ (e.g. Clift \& Vannucchi 2004), suggesting that subducted sediments commonly form diapirs. Our predicted minimum layer thickness for diapirism at the Izu arc is similar to the result of Currie et al. (2007), who found that, in trenches with old $(>70 \mathrm{Ma})$, cold subducting slabs, diapirs forming in sediment layers $>350 \mathrm{~m}$ will detach within the mantle wedge. However, Currie et al. (2007) required a much larger density contrast $\left(<-400 \mathrm{~kg} \mathrm{~m}^{-3}\right)$ than the $\sim-200 \mathrm{~kg} \mathrm{~m}^{-3}$ density contrast at which diapirs grow in our models.

Our calculations of instability times suggest that sediment diapir growth depends strongly on subduction zone thermal structure, which is largely influenced by the depth of the decoupling/coupling transition (e.g. Wada \& Wang 2009; Syracuse et al. 2010). In general, the deeper the depth of this transition, the longer it takes subducting sediments to be heated by mantle flow from the back arc, resulting in absolute viscosities that remain larger to greater depths, increasing instability times (Fig. 9). At the decoupling/coupling transition, rapidly increasing temperatures and steepening mantle geotherms create a narrow zone in which the viscosity ratio be- tween the sediments and mantle increases sharply and the length scale for viscous decay in the mantle shortens - both conditions that promote instability growth. These effects are strongest in cold subduction zones where the contrast in slab and mantle temperatures is more pronounced and diapir growth is most sensitive to changes in secondary controls (i.e. $r$ and $L$ ).

A key result of our study is that that the $\sim-200 \mathrm{~kg} \mathrm{~m}^{-3}$ density contrast between subducted sediments and the mantle wedge alone is sufficient to drive diapirism. This contrasts with previous studies in which sediments are entrained in cold diapirs that arise from hydration of the mantle above the subducting slab (Gerya \& Yuen 2003; Gerya et al. 2006; Gorczyk et al. 2006, 2007). In such models, fluids supplied to the mantle wedge by slab dehydration at depth may serpentinize the mantle, reducing the mantle density by $100-300 \mathrm{~kg} \mathrm{~m}^{-3}$ in a thick ( $\left.\sim 20 \mathrm{~km}\right)$ layer above the slab (e.g. Gerya \& Yuen 2003). Hydration would also drive partial melting of the mantle, further reducing mantle density. These reductions in mantle density would inhibit the growth of sediment diapirs into the serpentine layer (by reducing the density contrast between the sediment layer and overlying mantle), but may result in the development of mixed plumes that rise off the top of the slab and entrain the underlying sediment layer. Numerical models have suggested that these hydrous, cold plumes initiate at depths of $\sim 50-200 \mathrm{~km}$ (Gerya \& Yuen 2003), similar to the depths predicted for the detachment of sediment diapirs. However, because these plumes originate from a much thicker buoyant layer, they are typically larger than diapirs arising from the sediment layer alone, and thus have a much greater effect on the dynamics and thermal structure of the mantle wedge than the sediment diapirs that we consider here. In our models, sediment diapirs typically form at temperatures and pressures exceeding the stability field for serpentinite (e.g. Wada \& Wang 2009), implying that the density reduction by serpentinization of 
(a) Cascadia
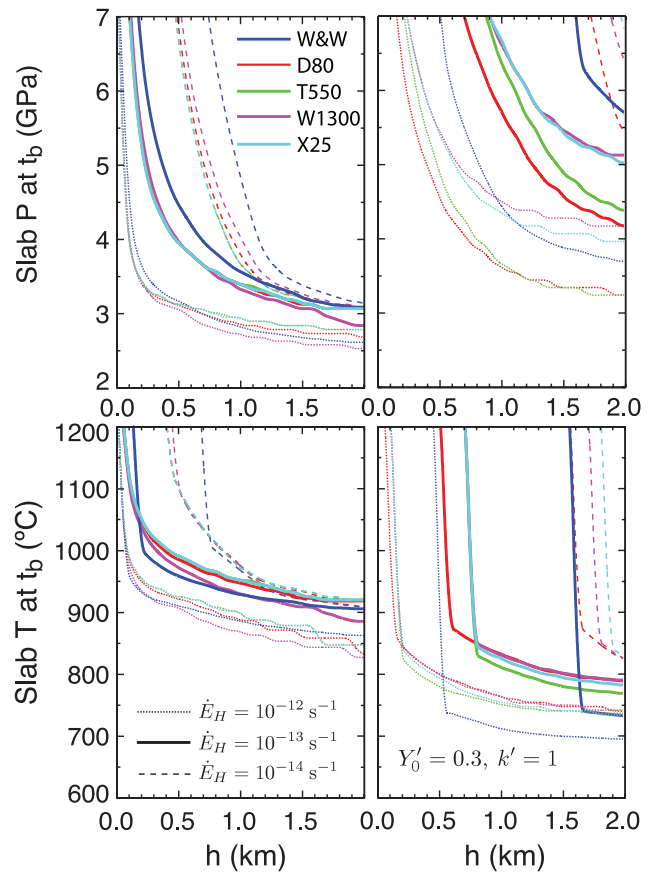

Figure 11. Slab-surface pressures (top) and temperatures (bottom) at the location of diapir detachment plotted as a function of sediment layer thickness in thermal models for the (a) Cascadia and (b) Izu subduction zones. Values are for a 30 per cent initial perturbation with wavenumber $k^{\prime}=1$. Colour coding is the same as in Fig. 9.

the mantle would not strongly influence the growth of sediment diapirs.

In hot subduction zones, diapirs detach from the slab at temperatures between $\sim 850$ and $1000{ }^{\circ} \mathrm{C}$ and at pressures between $\sim 2.5$ and 5.5 GPa (Fig. 11). In cold subduction zones, diapirs detach from the slab at greater depths (pressures of $\sim 4-6 \mathrm{GPa}$ ), but at slab-top temperatures as low as $\sim 700{ }^{\circ} \mathrm{C}$. Sediments at these temperatures and pressures are near the fluid-saturated solidus (Nichols et al. 1994; Schmidt et al. 2004), but still below $1050{ }^{\circ} \mathrm{C}$ - the temperature threshold associated with the depletion of key trace elements forming the sediment melt signature in high- and ultra-high pressure metasediments that have undergone subduction (Behn et al. 2011). Thus, our results support the hypothesis that the sediment-melt signature observed in many arc magmas is generated when subducting sediments detach from the slab as diapirs and rapidly rise into the mantle wedge, where they would undergo melting (Gerya \& Yuen 2003). Both sediment-derived melts and sediment diapirs would rapidly $\left(\mathrm{cm} \mathrm{yr}^{-1}\right.$ to $\mathrm{m} \mathrm{yr}^{-1}$ ) traverse the mantle wedge (Kelemen et al. 1997 and references therein; Hall \& Kincaid 2001; Gerya \& Yuen 2003), satisfying U/Th isotope measurements from arc magmas that imply slab-to-surface transfer times on the order of a million years (e.g. Hawkesworth et al. 1997). Ascending sediments may also be re-laminated to the base of the upper plate (Hacker et al. 2011).

To assess how efficiently sediment diapirs transport sediments into the mantle wedge, we allowed several models to run past the instability time (Fig. 12). We found that diapirs form plume heads

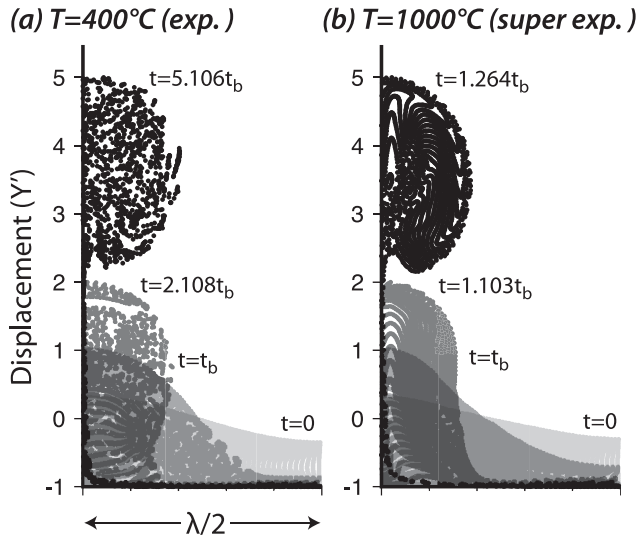

Figure 12. Snapshots of quartz diapirs in an olivine half-space for an initial perturbation wavenumber $k^{\prime}=1$ and amplitude $Y_{0}^{\prime}=0.3$. In (a), viscosities are held constant but are calculated for a temperature of $400{ }^{\circ} \mathrm{C}$ and a background strain rate of $10^{-13} \mathrm{~s}^{-1}$, and growth is exponential. In (b), temperature is set to $1000^{\circ} \mathrm{C}$, viscosities are allowed to change with increasing local strain rates, and growth is superexponential.

by $\sim 2.1 t_{b}$ at lower temperatures $\left(400{ }^{\circ} \mathrm{C}\right)$, where instability growth is exponential. At higher temperatures $\left(1000^{\circ} \mathrm{C}\right)$, where superexponential growth dominates, plume heads are nearly fully formed at $t_{b}$. In both cases, plume heads have a width of $\sim 0.2 \lambda$. Since diapir accent rates eventually reach $\mathrm{m} \mathrm{yr}^{-1}$, greater than the $\mathrm{cm} \mathrm{yr}^{-1}$ rate of mantle corner flow, these instabilities can efficiently transport sediments into the core of the mantle wedge near the location of detachment from the slab. We also note that, in both cases, the rigid bottom boundary condition causes a thin veneer of sediment to remain attached to the slab, which implies that diapir formation may not be 100 per cent efficient in recycling sediments into the mantle wedge.

The models considered here are 2-D with a horizontal bottom boundary, and thus our instability timescales correspond to diapirs forming in trench-parallel sheets. An important question for future work is how sediment diaper growth rates will change for the case of a 3-D, dipping slab. Theoretical and observational studies suggest that both finger-like and sheet-like instabilities form in three dimensions (Ribe 1998; Zhu et al. 2009) and have growth rates that are similar to those for 2-D diapirs (Kaus \& Podladchikov 2001). Nonetheless, understanding the morphology of such instabilities in three dimensions will be important for determining how sediments released from the slab will eventually be incorporated into the melting region beneath the arc.

\section{CONCLUSIONS}

Using instability growth rates calculated from numerical models of quartz diapirs forming in an olivine half-space, we predict that sediment diapirs detach from the downgoing slab and ascend into the mantle wedge in a broad range of subduction zone settings. The growth of sediment diapirs is largely controlled by layer buoyancy and the absolute viscosities of the sediments and mantle wedge. In hot subduction zones (young slabs and/or slow subduction rates), lower absolute viscosities enable rapid diapir growth and instabilities can form and detach from the slab in layers as thin as $\sim 200 \mathrm{~m}$. Diapirs also form in arcs with cold subducting slabs, although larger sediment layer thicknesses $(\geq 800 \mathrm{~m})$ are required. These values are 
similar to estimates of the subducted sediment-layer thickness in a majority of subduction zones, suggesting that sediment diapirism is a common feature of arcs and may be responsible for the 'sediment signature' in the chemistry of many arc magmas. The growth of diapirs is sensitive to the thermal structure of the mantle wedge, which, in subduction zone thermal models, is largely controlled by the depth of the transition from a mechanically decoupled slab and mantle to full slab/mantle coupling at depth. In models with a deeper decoupling/coupling transition, the advection of heat from the back arc to the slab by mantle flow is suppressed, lowering mantle wedge viscosities and slowing the growth of diapirs. This effect is most pronounced in cold subduction zones where the contrast between the cold slab and hot ambient mantle is more extreme and where cold quartz sediments are weaker with respect to mantle olivine. In both hot and cold subduction systems, we predict that sediment diapirs detach from the slab at temperatures below $1050{ }^{\circ} \mathrm{C}$, the temperature associated with depletions in key trace elements in UHP rocks that endured subduction. This supports a hypothesis in which sediments are transported into the mantle wedge by viscous flow before they undergo significant degrees of melting.

\section{ACKNOWLEDGMENTS}

We thank Ikuko Wada and Ellen Syracuse for generously sharing their subduction-zone models, Daniel Lizarralde for his insights during development of the numerical model, and Taras Gerya for making his finite-difference codes freely available. We are also grateful to Peter Molnar, William Landuyt and two anonymous reviewers for their critiques of this manuscript, as well as to John Whitehead and Ikuko Wada for comments on an earlier version of this paper. This work was supported by NSF Grant EAR-0652707 and a WHOI Deep Ocean Exploration Institute Fellowship to MB.

\section{REFERENCES}

Abers, G.A., van Keken, P.E., Kneller, E.A., Ferris, A. \& Stachnik, J.C., 2006. The thermal structure of subduction zones constrained by seismic imaging: implications for slab dehydration and wedge flow, Earth planet. Sci. Lett., 241, 387-397.

Arcay, D., Tric, E. \& Doin, M.P., 2007. Slab surface temperature in subduction zones: influence of the interplate decoupling depth and upper plate thinning processes, Earth planet. Sci. Lett., 255, 324-338.

Armstrong, R.L., 1968. A model for the evolution of strontium and lead isotopes in a dynamic earth, Rev. Geophys., 6, 175-199.

Armstrong, R.L., 1991. The persistent myth of crustal growth, Aust. J. Earth Sci., 38, 613-630.

Behn, M.D., Kelemen, P.B., Hirth, G., Hacker, B.R. \& Massone, H., 2011.

Diapirs as the source of the sediment signature in arc lavas, Nature Geosci., 4, 641-646.

Behr, W.M. \& Platt, J.P., 2011. A naturally constrained stress profile through the middle crust in an extensional terrane, Earth planet. Sci. Lett., $\mathbf{3 0 3}$, 181-192, doi:10.1016/j.eps1.2010.11.044.

Boettcher, M.S., Hirth, G. \& Evans, B., 2007. Olivine friction at the base of oceanic seismogenic zones, J. geophys. Res., 112, B01205, doi:10.1029/2006JB004301.

Castro, A. \& Gerya, T.V., 2008. Magmatic implications of mantle wedge plumes: experimental study, Lithos, 103, 138-148.

Chandrasekhar, S., 1961. Hydrodynamic and hydromagnetic stability, illustrated edn, Courier Dover Publications, New York, NY, 652pp.

Chauhan, A.P.S., Singh, S.C., Hananto, N.D., Carton, H., Klingelhoefer, F., Dessa, J.-X., Permana, H., White, N.J., Graindorge, D., Sumatra OBS Scientific Team, 2009. Seismic imaging of forearc backthrusts at northern Sumatra subduction zone, Geophys. J. Int., 179, 1772-1780.
Clift, P.D. \& Vannucchi, P., 2004 Controls on tectonic accretion versus erosion in subduction zones: implications for the origin and recycling of the continental crust, Rev. Geophys., 42, RG2001, doi:10.1029/2003RG000127.

Conder, J.A., 2005. A case for hot slab surface temperatures in numerical viscous flow models of subduction zones with an improved fault zone parameterization, Phys. Earth planet. Inter., 149, 155164.

Conrad, C.P. \& Molnar, P., 1997. The growth of Rayleigh-Taylor-type instabilities in the lithosphere for various rheological and density structures, Geophys. J. Int., 129, 95-112.

Currie, C.A., Beaumont, C. \& Huismans, R.S., 2007. The fate of subducted sediments: a case for backarc intrusion and underplating, Geology, 35, 1111-1114, doi:10.1130/G24098A.1.

de Bremond d'Ars, J., Jaupart, C. \& Sparks, R.S.J., 1995. Distribution of volcanoes in active margins, J. geophys. Res., 100, 20 421-20 432.

Dell'Angelo, L.N. \& Tullis, J., 1996. Textural and mechanical evolution with progressive strain in experimentally deformed aplite, Tectonophysics, 256, 57-82, doi:10.1016/0040-1951(95)00166-2.

Elliott, T., Plank, T., Zindler, A., White, W. \& Bourdon, B., 1997. Element transport from slab to volcanic front at the Mariana arc, J. geophys. Res., 102, 14991-15019, doi:10.1029/97JB00788.

England, P.C. \& Katz, R.F., 2010. Melting above the anhydrous solidus controls the location of volcanic arcs, Nature, 467, 700-703.

Fletcher, R.C. \& Hallet, B., 1983. Unstable extension of the lithosphere: a mechanical model for Basin-and-Range structure, J. geophys. Res., $\mathbf{8 8}$, 7457-7466.

Gerya, T., 2010. Introduction to Numerical Geodynamic Modelling, illustrated edn, Cambridge University Press, Cambridge, 358pp.

Gerya, T.V. \& Yuen, D.A., 2003. Rayleigh-Taylor instabilities from hydration and melting propel cold plumes' at subduction zones, Earth planet. Sci. Lett., 212, 47-62.

Gerya, T.V., Connolly, J.A.D., Yuen, D.A., Gorczyk, W. \& Capel, A.M., 2006. Seismic implications of mantle wedge plumes, Phys. Earth planet Inter, 156, 59-74.

Goff, J.A. \& Jordan, T.H., 1988. Stochastic modeling of seafloor morphology: inversion of sea beam data for second-order statistics, J. geophys. Res., 93, 13589-13513.

Gorczyk, W., Gerya, T.V., Connolly, J.A.D. \& Yuen, D.A., 2007. Growth and mixing dynamics of mantle wedge plumes, Geology, 35, 587-590, doi:10.1130/G23485A.1.

Gorczyk, W., Gerya, T.V., Connolly, J.A.D., Yuen, D.A. \& Rudolph, M., 2006. Large-scale rigid-body rotation in the mantle wedge and its implications for seismic tomography, Geochem. Geophys. Geosys., 7, Q05018, doi:10.1029/2005GC001075.

Hacker, B.R., 2008. $\mathrm{H}_{2} \mathrm{O}$ subduction beyond arcs, Geochem. Geophys. Geosys., 9, Q03001, doi:10.1029/2007GC001707.

Hacker, B.R., Kelemen, P.B. \& Behn, M.D., 2011. Differentiation of the continental crust by relamination, Earth planet. Sci. Lett., 307, 501-516, doi:10.1016/j.eps1.2011.05.024.

Hall, P.S. \& Kincaid, C., 2001. Diapiric flow at subduction zones: a recipe for rapid transport, Science, 292, 2472-2475, doi:10.1126/science.1060488.

Hawkesworth, C.J., Turner, S.P., McDermott, F., Peate, D.W. \& Van Calsteren, P., 1997. U-Th isotopes in arc magmas: implications for element transfer from the subducted crust, Science, 276, 551-555, doi: $10.1126 /$ science. 276.5312 .551 .

Hirth, G. \& Kohlstedt, D., 2003. Rheology of the upper mantle and the mantle wedge: a view from the experimentalists, in Inside the Subduction Factory, Geophys. Monogr. Vol. 138, pp. 83-105, American Geophysical Union, Washington, DC.

Hirth, G., Teyssier, C. \& Dunlap, J.W., 2001. An evaluation of quartzite flow laws based on comparisons between experimentally and naturally deformed rocks, Int. J. Earth Sci., 90, 77-87.

Houseman, G.A. \& Molnar, P., 1997. Gravitational (Rayleigh-Taylor) instability of a layer with non-linear viscosity and convective thinning of continental lithosphere, Geophys. J. Int., 128, 125-150.

Jull, M. \& Kelemen, P.B., 2001. On the conditions for lower crustal convective instability, J. geophys. Res., 106, 6423-6446.

(C) 2012 The Authors, GJI, 190, 1361-1377 Geophysical Journal International (C) 2012 RAS 
Karig, D.E., Kay, R.W., Brown, G.C. \& Armstrong, R.L., 1981. Fate of sediments on the descending plate at convergent margins, Phil. Trans. $R$. Soc. Lond. A., 301, 233-251.

Kaus, B.J.P. \& Podladchikov, Y.Y., 2001. Forward and reverse modeling of the three-dimensional viscous Rayleigh-Taylor instability, Geophys. Res Lett, 28, 1095-1098.

Kelemen, P.B., Hirth, G., Shimizu, N., Spiegelman, M. \& Dick, H.J., 1997. A review of melt migration processes in the adiabatically upwelling mantle beneath oceanic spreading ridges, Phil. Trans. R. Soc. Lond. A, $\mathbf{3 5 5}$, 283-318, doi:10.1098/rsta 1997.0010

Kelemen, P.B., Rilling, J.L., Parmentier, E.M., Mehl, L. \& Hacker, B.R., 2003. Thermal structure due to solid-state flow in the mantle wedge beneath arcs, in Inside the Subduction Factory, Geophys. Monogr. Vol. 138, pp. 293-311, American Geophysical Union, Washington, DC.

Kirby, S.H., 1983. Rheology of the lithosphere, Rev. Geophys., 21, 1458-1487, doi:10.1029/RG021i006p01458

Kneller, E.A., Van Keken, P.E., Karato, S. \& Park, J., 2005. B-type olivine fabric in the mantle wedge: insights from high-resolution non-Newtonian subduction zone models, Earth planet. Sci. Lett., 237, 781-797.

Kneller, E.A., Van Keken, P.E., Katayama, I. \& Karato, S., 2007. Stress, strain, and B-type olivine fabric in the fore-arc mantle: sensitivity test using high-resolution steady-state subduction zone models, J. geophys Res, 112, B04406, doi:10.1029/2006JB004544.

Marsh, B.D., 1979. Island arc development: some observations, experiments, and speculations, J. Geol., 87, 687-713.

McKenzie, D.P., 1984. The generation and compaction of partially molten rock, J. Petrol., 25, 713-765.

Molnar, P. \& England, P., 1990. Temperatures, heat flux, and frictional stress near major thrust faults, J. geophys. Res., 95, 4833-485.

Molnar, P. \& England, P., 1995. Temperatures in zones of steady-state underthrusting of young oceanic lithosphere, Earth planet. Sci. Lett, 131, $57-70$

Molnar, P., Houseman, G.A. \& Conrad, C.P., 1998. Rayleigh-Taylor instability and convective thinning of mechanically thickened lithosphere: effects of non-linear viscosity decreasing exponentially with depth and of horizontal shortening of the layer, Geophys. J. Int., 133, 568-584, doi:10.1111/j.1365-246X.1998.00510.x.

Nichols, G.T., Wyllie, P.J. \& Stern, C.R., 1994. Subduction zone melting of pelagic sediments constrained by melting experiments, Nature, $\mathbf{3 7 1}$, $785-788$

Plank, T. \& Langmuir, C.H., 1993. Tracing trace elements from sediment input to volcanic output at subduction zones, Nature, 362, 739-743.

Plank, T. \& Langmuir, C.H., 1998. The chemical composition of subducting sediment and its consequences for the crust and mantle, Chem. Geol., 145, 325-394.

Plank, T., Cooper, L.B. \& Manning, C.E., 2009. Emerging geothermometers for estimating slab surface temperatures, Nature Geosci., 2, 611-615.

Rayleigh, L., 1883. Investigation of the character of the equilibrium of an incompressible heavy fluid of variable density, Proc. Lond. Math. Soc, 14, 170-177.

Renner, J., Stöckhert, B., Zerbian, A., Röller, K. \& Rummel, F., 2001. An experimental study into the rheology of synthetic polycrystalline coesite aggregates, J. geophys. Res., 106, 411-419.

Ribe, N.M., 1998. Spouting and planform selection in the Rayleigh-Taylor instability of miscible viscous fluids, J. Fluid Mech., 377, 27-45.
Schmeling, H., 1987. On the relation between initial conditions and late stages of Rayleigh-Taylor instabilities, Tectonophysics, $\mathbf{1 3 3}$, 65-80.

Schmidt, M.W., Vielzeuf, D. \& Auzanneau, E., 2004. Melting and dissolution of subducting crust at high pressures: the key role of white mica, Earth planet. Sci. Lett., 228, 65-84.

Shea, W.T. \& Kronenberg, A.K., 1992. Rheology and deformation mechanisms of an isotropic mica schist, J. geophys. Res, 97, 152015237.

Spiegelman, M. \& McKenzie, D., 1987. Simple 2-D models for melt extraction at mid-ocean ridges and island arcs, Earth planet. Sci. Lett., 83, $137-152$.

Stöckert, B., Brix, M.R., Kleinschrodt, R., Hurford, A.J. \& Wirth, R., 1999. Thermochronometry and microstructures of quartz - a compariwith experimental flow laws and predictions on the temperature of the brittle-plastic transition, J. Struct. Geol., 21, 351-369.

Sun, S.S., 1980. Lead isotopic study of young volcanic rocks from midocean ridges, ocean islands and island arcs, Phil. Trans. R. Soc. Lond. A. 297, 409-445.

Syracuse, E.M., van Keken, P.E. \& Abers, G.A., 2010. The global range of subduction zone thermal models, Phys. Earth planet. Inter, 183, 73-90, doi:10.1016/j.pepi.2010.02.004

Taylor, G., 1950. The instability of liquid surfaces when accelerated in a direction perpendicular to their planes. I, Phil. Trans. R. Soc. Lond. A., 201, 192-196.

Tera, F., Brown, L., Morris, J., Sacks, I.S., Klein, J. \& Middleton, R., 1986. Sediment incorporation in island-arc magmas: inferences from $10 \mathrm{Be}$ Geochim. Cosmochim. Acta., 50, 535-550.

van Keken, P.E., Kiefer, B. \& Peacock, S.M., 2002. High-resolution models of subduction zones: implications for mineral dehydration reactions and the transport of water into the deep mantle, Geochem. Geophys. Geosyst., 3, 1056, doi:10.1029/2001GC000256.

Vogt, P.R., 1974. Volcano spacing, fractures, and thickness of the lithosphere, Earth planet. Sci. Lett., 21, 235-252.

von Huene, R. \& Scholl, D.W., 1991. Observations at convergent margins concerning sediment subduction, subduction erosion, and the growth of continental crust, Rev. Geophys., 29, 279-316.

Wada, I. \& Wang, K., 2009. Common depth of slab-mantle decoupling: reconciling diversity and uniformity of subduction zones, Geochem. Geophys. Geosyst., 10, 10009, doi:10.1029/2009GC002570.

Wada, I., Wang, K. \& Hyndman, R.D., 2008. Weakening of the subduction interface and its effects on surface heat flow, slab dehydration, and mantle wedge serpentinization, J. geophys. Res., 113, B04402, doi: 10.1029/2007JB00519.

White, W.M., Dupré, B. \& Vidal, P., 1985. Isotope and trace element geochemistry of sediments from the Barbados Ridge-Demerara Plain region, Atlantic Ocean, Geochim. Cosmochim. Acta., 49, 1875-1886.

Whitehead, J.A. \& Luther, D.S., 1975. Dynamics of laboratory diapir and plume models, J. geophys. Res, 80, 705-717.

Zhu, G., Gerya, T.V., Yuen, D.A., Honda, S., Yoshida, T. \& Connolly, J.A.D. 2009. Three-dimensional dynamics of hydrous thermal-chemical plumes in oceanic subduction zones, Geochem. Geophys. Geosyst., 10, Q11006, doi: 10.1029/2009GC002625.

Zimmerman, M.E. \& Kohlstedt, D.L., 2004. Rheological properties of partially molten lherzolite, J. Petrol., 45, 275-298. 


\title{
Chapter 4:
}

\section{Upper-mantle anisotropy and hydration at the Middle America Trench}

\begin{abstract}
This chapter presents measurements of upper mantle anisotropy that constrain the extent of bending-induced faulting and upper-mantle hydration at the outer rise of the Middle America Trench. Water carried to depth by a hydrated, subducting oceanic upper mantle is the primary source of mantle hydration, an essential component of many arc- and global-scale processes. The upper mantle is often assumed to be efficiently dehydrated by melting at ridges, but recent seismic-reflection images of bending-induced normal faults extending into the upper mantle, and reduced uppermantle seismic velocities under the outer rise near trenches, have been interpreted as evidence that the subducting mantle is pervasively hydrated via serpentinization by seawater penetrating through the crust along plate-bending-induced faults. This seawater may fill cracks in the upper mantle and react strongly with olivine in upper mantle peridotite, filling cracks and fault zones with serpentinite; or it may diffuse between fault zones, pervasively serpentinizing the upper mantle. The seismic velocity of serpentinized rocks is much slower than that of unaltered mantle rocks, and much of the support for the hypothesis that subducting mantle is hydrated near the outer-rise comes from isotropic seismic velocity analyses that assume observed slow velocity anomalies can be attributed entirely to the presence of serpentine. However, the outerrise normal faults themselves, as well as inherited crystal-preferred orientation of mineral grains in the upper mantle can produce azimuthally dependent seismic wave speeds that are up to $\sim 0.5 \mathrm{~km} / \mathrm{s}$ slower in one direction than in another, an effect comparable to the change in velocity due to $\sim 20 \%$ pervasive serpentinization.

Wavespeed models fit to delay-times from wide-angle, active-source seismic data indicate that the upper mantle is between $\sim 1.57$ and $6.89 \%$ anisotropic beneath the outer rise at the Middle America Trench. This anisotropy can be explained by combining wavespeed variations in a relic mantle fabric with anisotropy from cracks and/or joints aligned along the strike of bending-related normal faults. Measurements made using rays that turn at different depths indicate that anisotropy varies with depth in the mantle, with anisotropy from aligned cracks composing a larger portion of the wavespeed variations in the upper-most mantle. Anisotropy in both the upper-most mantle and over depths up to $24 \mathrm{~km}$ below the Moho appears to include a component attributable to large joints aligned with the bending-induced faults, although it is unclear how much of this signal can be explained by crustal, as opposed to mantle, faulting. Wavespeeds along raypaths that are dominated by propagation through the deeper mantle are up to $2.29 \%$ anisotropic. Accounting for this anisotropy in seismicvelocity-based measurements of serpentinization reduces current estimates for the water content of the upper mantle offshore of Nicaragua from $\sim 2.5$ to $1.5 \mathrm{wt} \%$, a significant difference in the water input to the mantle at subduction zones.
\end{abstract}




\section{Introduction}

Water in the mantle has a significant effect on rock rheology and geochemistry and plays an important role in geodynamic and geochemical processes on Earth. At subduction zones, water supplied to the mantle wedge from the subducting lithosphere drives mantle melting and the production of arc crust (Davies and Stevenson, 1992; Iwamori, 1998). Over-pressuring and weakening caused by the presence of water at the slab interface enables the lower plate to subduct (Wang et al., 1995), and water fluxing through the down-going slab may force the transition from gabbro to eclogite at depth (John and Schenk, 2003), increasing slab density and promoting subduction. Globally, rheologic weakening caused by widespread hydration of the upper mantle allows for the movement of tectonic plates (Hirth and Kohlstedt, 1996). Without this weakening, plate tectonics may be impossible, with mantle convection on Earth resembling the "stagnant-lid" convection thought to occur on other terrestrial planets (Solomatov and Moresi, 1996). Together, arc volcanism and mantle convection enable global biogeochemical cycles, and thus sustaining these processes through rehydration of the mantle is essential for life on Earth. Subduction zones are the primary location where water is cycled into the mantle, and understanding the mechanisms for hydration of the subducting oceanic lithosphere, along with quantitative estimates for the input flux of water into arcs, are critical components in our understanding of the role of water in subduction systems and in global-scale mantle dynamics.

Water carried to depth by subducting oceanic lithosphere is the primary source of mantle hydration (Figure 1). Subducting sediments and oceanic crust can contain large quantities of water (Staudigel et al., 1995; Plank and Langmuir, 1998; Kerrick and 
Connolly, 2001), however much of this crustal water may be expelled through the forearc before reaching the mantle wedge in some subduction systems (Klaucke et al., 2008; Ranero et al., 2008). Water bound in hydrous upper mantle minerals is more likely to be released at depth during subduction (Hacker, 2008), driving processes within the wedge and hydrating the deeper mantle. The upper mantle is a volumetrically much larger component of the subducting lithosphere than the crust and may account for a majority of water fluxing into arcs, yet there are few constraints on the degree of hydration of subducting oceanic upper mantle (Rüpke et al., 2004).

The mantle is generally assumed to be efficiently dehydrated by melting at ridges. However, recent seismic-reflection images of bending-induced normal faults that extend into the upper-mantle (Ranero et al., 2003; Nedimović et al., 2009), as well as significantly reduced upper-mantle seismic velocities under the outer-rise and trenches of arcs (Ivandic et al., 2008; Contreras-Reyes and Grevemeyer, 2008; Van Avendonk et al., 2011; Lefeldt et al., 2012), have been interpreted as evidence that the subducting mantle is hydrated by seawater penetrating through the crust along plate-bendinginduced faults (Faccenda et al., 2009). This seawater may fill cracks in the upper mantle with free water, react strongly with olivine in upper mantle peridotite, filling cracks and fault zones with serpentinite, and/or diffuse between fault zones, pervasively serpentinizing the upper mantle (Ranero and Sallares, 2004; Faccenda et al., 2009).

The hypothesis that seawater flowing along outer-rise faults commonly hydrates the upper mantle is largely based on isotropic seismic velocity analyses that assume observed slow velocity anomalies can be attributed entirely to serpentinization (Van Avendonk et al., 2011). Seismic velocities in serpentinized rocks are much slower than 
in unaltered rocks (Christensen, 1966), enabling seismic-travel-time-based estimates of mantle serpentinization and thus the flux of water carried into subduction zones by serpentinite. However, the outer-rise normal faults themselves, as well as an inherited, strain-induced alignment of mineral grains along a crystal-preferred orientation (CPO) in the upper mantle can produce azimuthally dependent seismic wave speeds that are up to $\sim 0.5 \mathrm{~km} / \mathrm{s}$ slower in one direction than in another (Shearer and Orcutt, 1986; Hudson, 1981), an effect comparable to the change in velocity due to $\sim 20 \%$ pervasive serpentinization (Christensen, 1966) (Figure 2). To accurately estimate the degree of serpentinization at the outer rise using seismic travel times, the azimuthal variation of seismic wave speed must be determined. Separating the competing effects of CPO, cracks, joints, and hydration, which each have their own azimuthal dependence, can also provide an additional constraint on the depth extent of outer-rise faulting and the degree and distribution of hydration in the mantle (Figure 3).

This chapter presents preliminary models of azimuthal anisotropy in the upper mantle beneath the outer rise of the Middle America Trench offshore of Nicaragua (Figure 4). The models come from delay-time inversions of active-source, marineseismic data. Solutions for rays bottoming within different depth ranges show a clear progression in the phase and polarity of wavespeeds from the upper-most mantle to up to $24 \mathrm{~km}$ into the mantle. In the upper $100 \mathrm{~m}$ of the mantle, wavespeeds appear to be affected by anisotropy from cracks and joints aligned along bending-induced normal faults. At greater depths, the contribution to effective anisotropy from cracks is minimal, yet wavespeeds for these depths also appear to be affected by jointing. Although the anisotropy from jointing is likely, at least in part, a crustal signal, the 
change in anisotropy with depth suggests that these data may help constrain the depth extent of faulting and hydration in the upper mantle.

\section{Geophysical properties of a hydrated, subducting upper mantle}

Evidence that the upper mantle is serpentinized by seawater moving along outerrise faults comes largely from seismic reflection images and tomographic velocity models, as well as heat flow surveys. Slow upper-mantle seismic velocities at the PeruChile, Kuril, and Middle America trenches have been observed and interpreted as evidence for a serpentinized mantle (Walther et al., 2000; Ranero and Sallares, 2004; Grevemeyer et al., 2007; Ivandic et al., 2010; Van Avendonk et al., 2011; Ivandic et al., 2008; Fujie et al., 2013; Lefeldt et al., 2012). Offshore Nicaragua where the outer rise is densely faulted, measured velocities range from $7.8 \mathrm{~km} / \mathrm{s}$ (Walther et al., 2000) and 7.5 $\mathrm{km} / \mathrm{s}$ (Ivandic et al., 2010; Ivandic et al., 2008) to as low as $6.9 \mathrm{~km} / \mathrm{s}$ (Van Avendonk et al., 2011) (Figure 5). If this velocity reduction is due to serpentinization alone, these values imply that the upper mantle subducting at the Middle America Trench is between about 10 and 30\% serpentinized (Christensen, 1966), giving an average water content of up to $\sim 3.5 \mathrm{wt} \%$ (Carlson, 2003; Van Avendonk et al., 2011). To the south and offshore of Costa Rica, outer-rise faulting is not as extreme and upper-mantle velocities are $\sim 8.0 \mathrm{~km} / \mathrm{s}$ (Van Avendonk et al., 2011), closer to the ridge-parallel wavespeed of the unaltered upper mantle in the Pacific (Kawasaki and Kon'no, 1984; Shearer and Orcutt, 1986). The hypothesis that slow observed seismic wave speeds are due to serpentinite is supported by heat flow data from Costa Rica and Nicaragua. There, measured heat flow is lower than expected, suggesting that the crust is perhaps cooled by hydrothermal circulation through newly opened fault zones (Grevemeyer et 
al., 2005). However, these heat-flow values could also be explained by efficient hydrothermal circulation through permeable seamounts and basaltic outcrops (Fisher et al., 2003). Similarly, decreased seismic velocities could be explained as due to anisotropy from cracking or other effects unrelated to serpentinization.

At the outer rise, upper-mantle seismic velocities may be slowed by pervasive serpentinization, but relic, strain-induced anisotropy and/or anisotropy created by bending-related faulting may also significantly affect mantle wave speeds (Figure 2 ). In the Pacific upper mantle, azimuth-dependent delay times of upper-mantle refractions (Pn) indicate that compressional wave speeds vary from $\sim 7.9 \mathrm{~km} / \mathrm{s}$ to as fast as 8.4 km/s (Kawasaki and Kon'no, 1984; Shearer and Orcutt, 1986). This $\sim 7 \%$ anisotropy could result from a $\mathrm{CPO}$ in which $\sim 22 \%$ alignment of individually anisotropic olivine grains creates a bulk anisotropy (Morris et al., 1969; Shearer and Orcutt, 1986). CPO can result from strain-induced grain rotation and recrystallization (Kaminski and Ribe, 2001; Kaminski and Ribe, 2002) that occurs during, for example, flow at mid-ocean ridges (Marquart et al., 2007). In the absence of continued strain, such an inherited anisotropic fabric may be progressively erased by pervasive serpentinization at the outer rise (Horen et al., 2012; Wallis et al., 2011).

Changes in seismic wave speed and corresponding delay times from both CPO in the upper-mantle and cracking are on the order of the effect that a $\sim 10-20 \%$ change in the degree of pervasive serpentinization has on isotropic upper mantle velocities (Figure 2), a value similar to isotropic-velocity-based estimates of upper-mantle serpentinization at the Middle America Trench (Walther et al., 2000; Grevemeyer et al., 2007; Ivandic et al., 2010; Van Avendonk et al., 2011; Ivandic et al., 2008). There, isotropic mantle 
velocities on two-dimensional tomograms are systematically slower in the trenchparallel direction than in the trench-perpendicular direction (Figure 5). These velocities suggest the presence of azimuthal anisotropy with a fast direction oriented in the relic plate spreading direction, consistent with measured anisotropy in the Pacific upper mantle (Kawasaki, 1986; Shearer and Orcutt, 1986).

In faulted rocks with aligned cracks or joints, anisotropy depends on the geometry and spacing of the cracks/joints and the stiffness of the un-faulted rocks and any voidfilling materials (Anderson et al., 1974; Hudson, 1981; Crampin, 1984; Thomsen, 1995; Hudson et al., 1996; Hudson et al., 2001; Gurevich, 2003). For example, effective media theory (Hudson, 1981) predicts that dilation of closed, but wet, disk-shaped cracks in dunite $\left(\mathrm{V}_{\mathrm{p}}=8.55 \mathrm{~km} / \mathrm{s}\right)$ that have a radius of $10 \mathrm{~m}$ and an average spacing of $100 \mathrm{~m}$ cause P-wave speeds to vary from a minimum of $8.24 \mathrm{~km} / \mathrm{s}$ along azimuths oriented $45^{\circ}$ with respect to the cracks to maxima of $8.55 \mathrm{~km} / \mathrm{s}$ in crack-normal and crack-parallel directions, a 3.6\% difference. Expanding these same cracks with $10 \mathrm{~cm}$ of serpentinite $(\mathrm{Vp}=5.5 \mathrm{~km} / \mathrm{s})$ would increase their stiffness and reduce the anisotropy to $1.5 \%$ $(\mathrm{Vp}=8.42-8.55 \mathrm{~km} / \mathrm{s})$. Waves traveling $50 \mathrm{~km}$ through such rocks would show delay times of up to $\sim 100$ to $200 \mathrm{~ms}$. The geometrical effect of seismic waves crossing large joints (i.e., joints with a width that is on the order of the seismic wavelength) filled with slow, isotropic material - a model that could represent wide zones of serpentinization along major fault zones - at variable azimuths would also produce anisotropy. For example, 100-m-thick, serpentinite-filled joints spaced every $2 \mathrm{~km}$ would produce $1.8 \%$ anisotropy with average P-wave velocities varying from $8.40 \mathrm{~km} / \mathrm{s}$ in the jointperpendicular direction to $8.55 \mathrm{~km} / \mathrm{s}$ in the joint-parallel direction. At $50 \mathrm{~km}$, delay 
times through this jointed media would be as large as $100 \mathrm{~ms}$. (Equations for wavespeeds in materials containing cracks and joints are given in Section 3.3.2.)

Controlled-source electromagnetic data collected offshore of Nicaragua suggest that bending-induced faulting produces an anisotropy in the electrical resistivity of the crust (Key et al., 2012). There, crustal resistivity decreases by up to a factor of five with the onset of outer-rise faulting. Furthermore, resistivity in the incoming, un-faulted crust is isotropic, while the crust at the outer rise is strongly anisotropic with a conductive direction oriented parallel to the bending-induced faults. This observed decrease in resistivity and corresponding increase in anisotropy can be explained by an increase in porosity along parallel fault planes, supporting the hypothesis that these faults provide pathways for seawater to penetrate into the lithosphere. This electrical anisotropy and inferred fault-controlled-porosity structure corresponds to a seismic anisotropy in which wavespeeds are slower in the fault-normal direction than in the fault-parallel direction, opposite the orientation of anisotropy from a relic CPO in the incoming upper mantle. Thus, a transition between these two modes of anisotropy is expected to occur across the maximum depth extent of bending-induced faulting, and isolating these effects provides to a means for testing models of mantle hydration.

Cracks, joints, and a relic CPO may all be present in the upper mantle beneath the outer rise of subduction zones, and we expect that effective wavespeeds through such a composite material would include wavespeed variations from the different sources of anisotropy. Each of these potential sources of anisotropy has a unique azimuthal dependence (Figure 2), and measurements of effective wavespeeds should help constrain 
the distribution and extent of jointing, cracking, and/or pervasive serpentinization in the upper mantle (Figure 3).

\section{Measurements of upper-mantle anisotropy}

We measured upper mantle anisotropy under the outer rise of the Middle America Trench using a delay-time approach (Morris et al., 1969; Shearer and Orcutt, 1986; Gaherty et al., 2004). In this method, the difference (i.e., residual or delay-time) between traveltimes for rays traced through a reference isotropic velocity model and traveltimes picked on seismic data are calculated as a function of source/receiver azimuth. The amplitude, orientation, and source of anisotropy (i.e., cracks/joints vs. $\mathrm{CPO}$ ) can be constrained by fitting these delay times with models of wavespeeds in anisotropic media.

\subsection{Seismic data and traveltime picking}

We used active-source seismic data collected as part of the 2008 TICO-CAVA2 experiment (Van Avendonk et al., 2011) to develop isotropic models and calculate delay times. We focused on ocean-bottom seismograph (OBS) data from 34 sites located every $\sim 15 \mathrm{~km}$ along the spokes of a wheel-shaped array centered on the outer rise offshore of central Nicaragua (Figure 4). The OBS were short-period instruments developed and deployed by the Scripps Institution of Oceanography (SIO) and the Woods Hole Oceanographic Institution (WHOI), which are part of the U.S. OBS Instrument Pool (OBSIP), and they were deployed from aboard the $R / V$ New Horizon. The $R / V$ Marcus G. Langseth's 36-element-, 108-L-airgun provided the sound source, and the array was 
towed at a depth of $6 \mathrm{~m}$. The OBS recorded shots fired at intervals of $\sim 50$ to $500 \mathrm{~m}$ along the spoke lines and circular lines along portions of the array's circumference.

We processed the OBS data for traveltime picking on common-receiver gathers (Figure 6). To minimize energy from previous shots at long source-receiver offsets, we ignored traces for shots fired on time intervals of less than 43 seconds, a threshold found to enable reliable identification of refraction phases at offsets up to $\sim 175 \mathrm{~km}$. To further minimize the impact of low-energy shots on trace-to-trace coherency, we also ignored traces for shots fired with less than 27 elements (i.e., 3 strings) of the airgun array.

We solved for OBS locations using the traveltimes of direct arrivals through the water $(\mathrm{Pw})$. We picked $\mathrm{Pw}$ traveltimes on common-receiver gathers of traces from shots fired along lines that cross instrument sites. In this case, we defined the arrival time of the direct wave as the first break from zero amplitude in data filtered with a minimum phase bandpass filter from 30 to $80 \mathrm{~Hz}$. We assumed that instruments were on the seafloor at depths known from multi-beam bathymetry data and found locations that minimize the misfit between the picked $\mathrm{Pw}$ times and traveltimes calculated for a constant $1500 \mathrm{~m} / \mathrm{s}$ water velocity.

We picked traveltimes for the following crustal and upper-mantle phases: refractions through sediments on the oceanic plate (i.e., abyssal sediments) or in the upper forearc $\left(\mathrm{P}_{1}\right)$, refractions through the lower forearc $\left(\mathrm{P}_{2}\right)$, refractions through crust $(\mathrm{Pg})$, slab-surface reflections $(\mathrm{PgP})$, Moho reflections $(\mathrm{PmP})$, and upper-mantle refractions $(\mathrm{Pn})$. We made picks on common-receiver gathers with data grouped by shot line, filtered with a minimum-phase bandpass filter from 3 to $15 \mathrm{~Hz}$, and reduced at 
$8.55 \mathrm{~km} / \mathrm{s}$. To maintain consistency in picks between crossing shot lines, we used the open-source program OpendTect (dGB Earth Sciences, 2012) to visualize and pick traveltimes in three dimensions, with traces plotted at shot locations (Figure 6 inset, Figure 7).

The amplitude of delay times from anisotropy is expected to be at most $\sim 500 \mathrm{~ms}$, yet the period of the seismic wavelet for the lower crustal and upper mantle phases is $\sim 150 \mathrm{~ms}$ in the data. It was thus necessary to consistently pick traveltimes at the same phase (e.g., first-break, minimum, or maximum) of each wavelet. For data filtered with minimum phase filters, the first break from zero amplitude is considered a reliable reference for the arrival time of a wave (Scherbaum, 2007). The data are, however, somewhat noisy, especially at long offsets $(>50 \mathrm{~km})$, and the first break is difficult to identify. Thus, we defined the arrival time of lower crustal and upper mantle phases as the first minimum or maximum amplitude. OpendTects seeded-picking functionality was used to shift picks made manually to the nearest minimum or maximum amplitude within $30 \mathrm{~ms}$ of the pick, and, where permitted by trace-to-trace coherency, automatically pick traveltimes between these manual seeds.

The Langseth also recorded multi-channel seismic (MCS) data along all the shot lines using a 636-channel, $\sim 8-\mathrm{km}$-long hydrophone streamer, and we used these data to pick traveltimes to the basement reflector (Figure 8). These basement picks constrained sediment thickness in the isotropic models. We processed the MCS data using a standard sequence of common-mid-point (CMP) gathering, minimum-phase bandpass filtering from 21 to $120 \mathrm{~Hz}$, normal-move out (NMO) correction using a onedimensional velocity function hung from the seafloor, spherical divergence correction, 
trace editing, stacking, and Kirchhoff time migration using velocities based on the stacking velocities. Since this study is only interested in using basement structure to account for variations in sediment thickness in Pn traveltimes, we did not process these data beyond this brute stacking and time migration.

\subsection{Reference isotropic model}

We are interested in traveltime variations in the upper mantle beneath the outer rise as a function of propagation direction. However, waves passing through this region of the upper mantle must also pass through water, oceanic and/or forearc sediments, and oceanic crust. At subduction zones, the thickness and velocity structure of these layers varies in three dimensions (Moore et al., 2007; Walther et al., 2000; Van Avendonk et al., 2011; Ivandic et al., 2008), producing path-dependent variations in traveltimes that are unrelated to anisotropy. To account for these traveltime differences between different pairs of sources and receivers, we developed a $3 \mathrm{D}$ isotropic velocity model that includes these structures and calculated traveltimes through this model by raytracing. We then subtracted these isotropic traveltimes from the observed traveltimes to calculate delay times from anisotropy.

We calculated traveltimes through isotropic models using the shortest-path method described by Moser (1991) and implemented by Van Avendonk (1998), Van Avendonk et al. (1998; 2004), and A. Harding at SIO. This graph method approximates raypaths by first connecting straight-line segments between all nodes in a grid and calculating accumulated traveltime along this set of all possible paths. Raypaths are then found by choosing routes that minimize traveltime between unique combinations of source and receiver locations, which is consistent with Fermat's principle. Reflections or 
refractions in multi-layered media can be modeled by requiring that rays turn at or within a prescribed boundary or layer.

We based velocities in the $3 \mathrm{D}$ model on velocities found by fitting traveltimes in a 2D, trench-perpendicular model along Line NorthEast (Figure 9). We defined the overall slab geometry in the $2 \mathrm{D}$ model by fitting a polynomial to the seafloor from seaward of the trench and modifying the slab-dip angle at depth beneath the forearc to fit $\mathrm{PgP}$ and Pn. Seafloor depths in this model are from integrated multibeam and satellite-altimetry derived bathymetry data (Ryan et al., 2009). The basement structure came from converting two-way traveltimes for basement reflections in the MCS data to depth using sediment velocities measured by a sonic log in DSDP Hole 67-495 (Shipboard Scientific Party, 1982), which is located on the outer rise to the northwest of our experiment. Abyssal sediment velocities in the models also came from these borehole data. We modeled the thickness of the oceanic plate by fitting Pg, PmP, and Pn recorded by instruments deployed on the seaward end of the line. This crustal thickness is constant in all models.

We developed two 2D isotropic models: (1) NorthEast_v1d: a simple model in which a one-dimensional velocity-depth function is hung from the slab surface and (2) NorthEast_v2d: a model in which mantle velocities from NorthEast_v1d are slowed beneath the outer rise by a tomographic inversion. Velocities in NorthEast_v1d are bestfit solutions from a grid search over values for velocity at the top of each layer and velocity gradients with depth in the layers. In this model, we solved for velocities in the oceanic crust and mantle using Pg, PmP, and Pn from OBS instruments on the seaward end of the line, where the seafloor is unaffected by outer-rise faulting. These velocities 
are too fast to fit phases passing through the crust and upper mantle under the outer rise, but this model captures variations in sediment thickness and the overall shape of the subducting slab.

NorthEast_v2d is the result of a tomographic inversion that attempts to reduce the misfit in NorthEast_v1d along paths that cross through the crust and upper mantle under the outer rise. Forearc velocities were also allowed to change to match traveltimes for $\mathrm{P} 1, \mathrm{P}_{2}$, and $\mathrm{PgP}$. For this inversion, we used a traveltime tomography code developed by Van Avendonk (1998), Van Avendonk et al. (1998; 2004), and A. Harding at SIO. This code uses a damped least squares minimization of traveltime residuals with smoothness constraints to update an initial model along raypaths. These traveltime residuals and raypaths are calculated using the shortest-path method described above.

We created a 3D isotropic model for calculating delay times for all azimuths by extruding velocities from NorthEast_v2d along the orientation of magnetic reversals in the oceanic crust (azimuth of $312.9^{\circ}$ ), which is assumed to be normal to the relic spreading direction, and then shifting these velocities up or down in depth to account for changes in the 3D bathymetry and slab structure. The $3 \mathrm{D}$ slab geometry is based on a combination of large-scale trends in the bathymetry data, basement structure from the MCS lines, and, at depth, the slab dip in the 2D models. Extrusion of the slow velocities under the outer rise in NorthEast_v2d created a trench-parallel region of reduced velocities that generally agrees with the shape of a slow velocity anomaly attributed to upper mantle serpentinization in $3 \mathrm{D}$ isotropic tomography from the same region (Lefeldt et al., 2012). 


\subsection{Effective anisotropy from cracks, joints, and/or CPO}

We constrained the orientation and amplitude of upper-mantle anisotropy by fitting delay times calculated for Pn with models of wavespeeds (i.e., phase velocities) in transversely isotropic media. Materials are considered "transversely isotropic" if they have an axis of symmetry that is normal to a plane of isotropy. Although this form is one of the simplest models of anisotropy, it is applicable for modeling wavespeeds in mantle rocks. Olivine and pyroxene, the dominant minerals in the upper mantle, exhibit this kind of symmetry and are strongly anisotropic to the propagation of seismic waves. Since these minerals tend to align along a CPO in the presence of strain (Jung and Karato, 2001; Zhang and Karato, 1995; Karato, 2008), horizontal flow at seafloorspreading centers causes the upper mantle to be transversely isotropic with fastest wavespeeds in the direction of spreading (Ismail and Mainprice, 1998; Kaminski and Ribe, 2001; Kaminski and Ribe, 2002). As the plate cools and moves off axis, this fabric is retained (Backus, 1965; Shearer and Orcutt, 1986; Kawasaki and Kon'no, 1984), and thus the upper mantle under the outer rise may also be transversely isotropic. At the outer rise, faults slip along reactivated abyssal-hill fabric or break along new, trenchparallel orientations if the abyssal-hill fabric is oriented at a sufficient angle $\left(>25^{\circ}\right)$ to the trench (Delescluse and Montési, 2008; Billen et al., 2007; Masson, 1991), producing sets of parallel fault planes with an axis of symmetry that is approximately aligned in the trench-normal direction. This symmetry causes wavespeeds in rocks with cracks or joints aligned along fault planes to also be transversely isotropic with the slowest wavespeeds in the fault-normal direction (Anderson et al., 1974; Hudson, 1981). At the Middle America Trench, the relic plate spreading direction is also roughly normal to 
the trench and the trend of the bending-induced faults, and thus the slow direction from faulting is aligned with the fast direction from a relic, spreading-induced CPO fabric. Characterizing the effective anisotropy from these competing effects was a principal goal in this study.

\subsubsection{Wavespeeds in transversely isotropic media}

Expressions for seismic wavespeeds come from solutions to the equation of motion (Crampin, 1981; Thomsen, 1986), which, for small displacement caused by seismic waves traveling in anisotropic elastic media, is (Landau and Lifshiz, 1970):

$$
\rho \frac{\partial^{2} u_{i}}{\partial t^{2}}=\sum_{j, k, l} C_{i j k l} \frac{\partial^{2} u_{k}}{\partial x_{j} \partial x_{l}}
$$

where $\rho$ is density, $u_{i}$ is a displacement, $t$ is time, $x$ is the right-handed Cartesian coordinate, and $C_{i j k l}$ is the elastic stiffness tensor. Defining a plane wave as

$$
u_{i}=a_{i} \exp \left[i \omega\left(t-\sum_{k} q_{k} x_{k}\right)\right]
$$

where $\vec{a}$ is a vector defining the direction of the displacement and $\vec{q}$ is a slowness vector, and substituting Equation (2) into (1), yields (Karato, 2008)

$$
\rho a_{i}=\sum_{j, k, l} C_{i j k l} q_{j} q_{l} a_{k}
$$

Then, by defining slowness as

$$
q_{j}=\frac{1}{V} n_{j}
$$

where $V$ is the phase velocity of the seismic wave and $\vec{n}$ is a unit vector in the propagation direction, we have the Christoffel Equation (Crampin, 1981; Karato, 2008) 


$$
\sum_{k}\left(T_{i k}-\rho V^{2} \delta_{i k}\right) a_{k}=0
$$

where

$$
T_{i k}=\sum_{j, l} C_{i j k l} n_{j} n_{l}
$$

For the case of azimuthal anisotropy, we are interested in solving for phase velocity as function of angle in the horizontal plane, defined here as $x_{3}=0$. If $x_{3}=0$ is a plane of symmetry, and $\theta$ is the angle between the $x_{1}$ direction and the displacement direction, Equation (5) can be solved for $V(\theta)$ by rotating the stiffness tensor $C_{i j k l}$ into (Crampin, 1981; Karato, 2008)

$$
C_{i j k l}^{\prime}=\sum_{r, s, t, u=1}^{3} a_{i r} a_{j s} a_{k t} a_{l u} C_{r s t u}
$$

where $a_{i j}$ is the rotation matrix

$$
a_{i j}=\left[\begin{array}{ccc}
\cos \theta & \sin \theta & 0 \\
-\sin \theta & \cos \theta & 0 \\
0 & 0 & 1
\end{array}\right]
$$

This rotation is a multiplication of the fourth rank stiffness tensor with four matrices that each $\operatorname{contain} \sin \theta$ and $\cos \theta$ terms, and thus exact solutions for $V(\theta)$ are a combination of $\sin$ and $\cos$ functions of up to $4 \theta$ (Karato, 2008).

The stiffness tensor is symmetric such that $C_{i j k l}=C_{j i k l}$ and $C_{i j k l}=C_{i j l k}$, and the number of indices can be reduced from four to two using the Voigt notation where subscripts $11 \rightarrow 1,22 \rightarrow 2,33 \rightarrow 3,23 \rightarrow 4,32 \rightarrow 4,13 \rightarrow 5,31 \rightarrow 5,12 \rightarrow 6$, and $21 \rightarrow 6$. Then, 


$$
C_{i j}=\left[\begin{array}{llllll}
C_{11} & C_{12} & C_{13} & C_{14} & C_{15} & C_{16} \\
C_{12} & C_{22} & C_{23} & C_{24} & C_{25} & C_{26} \\
C_{13} & C_{23} & C_{33} & C_{34} & C_{35} & C_{36} \\
C_{14} & C_{24} & C_{34} & C_{44} & C_{45} & C_{46} \\
C_{15} & C_{25} & C_{35} & C_{45} & C_{55} & C_{56} \\
C_{16} & C_{26} & C_{36} & C_{46} & C_{56} & C_{66}
\end{array}\right]
$$

Phases in general anisotropic media propagate at an angle to the displacement front (i.e., wavefront). In weakly anisotropic media, however, such as a deformed and/or faulted upper mantle (Thomsen, 1986; Thomsen, 1987), the phase direction is approximately normal to the wavefront. Waves traveling in this quassi-normal direction are referred to as quassi-P waves (qP), and we define the phase velocity of this wave as $c=V_{2}=V\left(n_{2}\right)$. In transversely isotropic media with $x_{3}=0$ as the plane of symmetry, $C_{15}=C_{56}=0$, and the assumption of weak anisotropy implies that $C_{16} \ll C_{11}, C_{66}$ (Thomsen, 1986). Then, rotating $C_{i j}=C_{i j k l}$ about the $x_{3}$ axis, inserting the result into Equation (5), and solving for phase velocity yields (Crampin, 1981; Thomsen, 1986)

$$
c^{2} \approx A+B \cos 2 \theta+C \sin 2 \theta+D \cos 4 \theta+E \sin 4 \theta
$$

Here, the coefficients depend on five independent elastic constants and are defined by 


$$
\begin{aligned}
& A=\frac{3\left(C_{11}+C_{22}\right)+2\left(C_{12}+2 C_{66}\right)}{8 \rho} \\
& B=\frac{\left(C_{11}-C_{22}\right)}{2 \rho} \\
& C=\left(C_{16}+C_{26}\right) / \rho \\
& D=\frac{C_{11}+C_{22}-2\left(C_{12}+2 C_{66}\right)}{8 \rho} \\
& E=\frac{C_{16}-C_{26}}{2 \rho}
\end{aligned}
$$

Increasing levels of symmetry reduces the azimuthal dependence in wavespeed. If $x_{2}=0$ is also a plane of symmetry, $C_{16}=-C_{26}$, wavespeed only varies with angle in the horizontal plane, and Equation (10) can be reduced to (Crampin, 1981)

$$
c^{2} \approx A+B \cos 2 \theta+D \cos 4 \theta
$$

In isotropic media, $C_{11}=C_{22}$, and Equation (12) becomes simply

$$
c^{2}=A=\frac{C_{11}}{\rho}=\frac{\lambda+2 \mu}{\rho}
$$

where $\lambda=-5 C_{12} / 3$ is the Lamé parameter and $\mu=C_{44}=\left(C_{11}-C_{12}\right) / 2$ is the shear modulus.

\subsubsection{Transverse isotropy from aligned cracks and joints}

Hudson (1981) showed that isotropic solids containing a random distribution of aligned, ellipsoidal-shaped cracks (Figure 2) can be characterized as an effective transversely isotropic media. In this theory, the minor axis of the cracks $c$ is assumed to be much shorter than the seismic wavelength, and wavespeeds are calculated by deriving effective elastic constants for waves propagating through a set of randomly 
distributed, yet aligned, cracks. For a material with cracks with uniform major axes of radius $a$ and $v$ cracks per unit volume, a crack number density can be defined as

$$
e=v a^{3}
$$

The equations below are first-order solutions that assume a small crack density (i.e., $e \ll 1)$.

Cracks in the crust and upper mantle are likely to be filled with water and/or serpentinite (Faccenda et al., 2009). For cracks filled with a weak material such as serpentinite, wavespeed is given by (Hudson, 1981)

$$
c_{s}^{2} \approx A_{s}+B_{s} \cos 2 \theta+D_{s} \cos 4 \theta
$$

where $\theta$ is the angle of propagation measure from the symmetry axis and

$$
\begin{aligned}
& A_{s}=\left(\frac{\lambda+2 \mu}{\rho}\right)^{2}-\frac{4}{3} \alpha^{2} e\left(\frac{7}{2 \mu(\lambda+\mu)(1+K)}+\frac{\lambda^{2}}{\mu(\lambda+\mu)(1+K)}+\frac{2 \mu}{(3 \lambda+4 \mu)(1+M)}\right) \\
& B_{s}=-\frac{4}{3} \alpha^{2} e \frac{2 \lambda \mu+16 / 8 \mu^{2}}{\mu(\lambda+\mu)(1+K)} \\
& D_{s}=-\frac{4}{3} \alpha^{2} e\left(\frac{\mu^{2}}{2 \mu(\lambda+\mu)(1+K)}-\frac{2 \mu}{(3 \lambda+4 \mu)(1+M)}\right)
\end{aligned}
$$

$\lambda$ and $\mu$ is the Lamé parameter and shear modulus, respectively, of the un-cracked solid. $K$ and $M$ are constants that describe the relative elastic stiffness of the rock matrix and the crack-filling material. These terms are given by

$$
\begin{aligned}
& K=\frac{1}{\pi} \frac{a\left(\kappa^{\prime}+(4 / 3) \mu^{\prime}\right)}{c \mu}\left(\frac{\lambda+2 \mu}{\lambda+\mu}\right) \\
& M=\frac{4}{\pi}\left(\frac{a \mu^{\prime}}{c \mu}\right)\left(\frac{\lambda+2 \mu}{3 \lambda+4 \mu}\right)
\end{aligned}
$$


where $\mu^{\prime}$ and $\kappa^{\prime}=\lambda^{\prime}+2 / 3 \mu^{\prime}$ are the shear and bulk moduli of the crack-filling material, respectively.

If the cracks are closed and not wetted by a fluid, $\kappa^{\prime}=\mu^{\prime}=0$ and $K=M=0$. If the cracks are filled with a fluid, $\mu^{\prime}=0$, and

$$
\begin{aligned}
& K_{w}=K_{\mu^{\prime}=0}=\frac{1}{\pi} \frac{a}{c} \frac{\kappa^{\prime}}{\mu}\left(\frac{\lambda+2 \mu}{\lambda+\mu}\right) \\
& M_{w}=M_{\mu^{\prime}=0}=0
\end{aligned}
$$

Then, the coefficients in Equation (15) become

$$
\begin{aligned}
& A_{s}=\left(\frac{\lambda+2 \mu}{\rho}\right)^{2}-\frac{4}{3} \alpha^{2} e\left(\frac{7}{2 \mu(\lambda+\mu)(1+K)}+\frac{\lambda^{2}}{\mu(\lambda+\mu)(1+K)}+\frac{2 \mu}{(3 \lambda+4 \mu)}\right) \\
& B_{s}=-\frac{4}{3} \alpha^{2} e \frac{2 \lambda \mu+16 / 8 \mu^{2}}{\mu(\lambda+\mu)(1+K)} \\
& D_{s}=-\frac{4}{3} \alpha^{2} e\left(\frac{\mu^{2}}{2 \mu(\lambda+\mu)(1+K)}-\frac{2 \mu}{(3 \lambda+4 \mu)}\right)
\end{aligned}
$$

Zones of damage and/or alteration along planar faults zones can be characterized as cracks in which $a>>c$, and we refer to this geometry as "jointing." In materials with regularly spaced, parallel joints, the crack area per unit volume is $1 / d$, where $d$ is the spacing between the joints, and this area is equivalent to $v \pi a^{2}$ for circular cracks. Thus, Equation (15) is also valid for jointed materials, provided that the crack thickness $c$ in Equation (17) is replaced with $4 c / 3$. In general, for crustal and mantle rheologies, this factor of $4 / 3$ causes $B_{s}>D_{s}$, and anisotropy from jointing is dominated by the $2 \theta$ term. For cracks, $O\left(B_{s}\right)=O\left(D_{s}\right)$ and anisotropy is periodic to $4 \theta$. If the cracks are closed, but lubricated by a fluid, wavespeed variations are only a function of $4 \theta$, and Equation (15) becomes (Hudson, 1981) 


$$
c_{w}^{2} \approx A_{w}+D_{w} \cos 4 \theta
$$

where

$$
\begin{aligned}
& A_{w}=\frac{1}{\rho}\left(1-\frac{56}{3} e\right)\left(\frac{\mu}{\lambda+\mu}\right) \\
& D_{w}=-\frac{1}{8}\left(\frac{\lambda+2 \mu}{\rho}\right)\left(\frac{\mu}{3 \lambda+4 \mu}\right) e
\end{aligned}
$$

\subsubsection{Effective wavespeeds in composite fabrics}

At the outer rise, conjugate sets of trenchward- and seaward-dipping faults create two sets of cracks and/or joints with symmetry axes aligned in the dip direction. Hudson (1981) showed that wavespeeds in materials with sets of cracks aligned in different orientations can be found by rotating $C_{i j k l}$ for each set such that the $x_{3}$ axis is the axis of symmetry and summing the results to find the effective elastic stiffness tensor. If the different orientations are aligned at right angles to one another, wavespeeds are transversely isotropic with wavespeed given by Equation (10), but with the effective stiffness constants substituted for $C_{i j}$ in Equation (11). Aligned cracks are a particular case of transverse isotropy, and wavespeeds in rocks with an arbitrary combination of various sources (i.e., CPO, cracking, and jointing) of transverse isotropy oriented at right angles to one another would also yield effective wavespeeds in the form of Equation (10). At the outer rise offshore of Nicaragua, the relic spreading direction is approximately normal to the orientation of bending-induced faults, and we assume that the combination of a relic CPO fabric, aligned cracking and/or parallel jointing produces effective wavespeeds that are transversely isotropic. 


\subsection{Delay-time inversion for anisotropy}

We solved for parameters in models of transverse isotropy via least-squares inversions of delay-time data. Delay-time variations with azimuth are given by

$$
\tau(r, \theta)=\frac{r}{c_{0}+\delta c(\theta)}-\frac{r}{c_{0}}
$$

where $r$ is the propagation distance in the symmetry plane and $c_{0}=c-\delta c$ is a reference wavespeed. Delay time is thus a function of both wavespeed and propagation distance, which is different for each raypath, and including $r$ in inversions for wavespeed provides an additional constraint on anisotropy.

If we define $a_{0}=a_{0}^{0}+a_{0}^{1}$ and $c_{0}=\left(a_{0}^{0}\right)^{1 / 2}, \delta c$ is

$$
(\delta c)^{2}=a_{0}^{1}+a_{1} \cos 2 \theta+a_{2} \sin 2 \theta+a_{3} \cos 4 \theta+a_{4} \sin 4 \theta
$$

Then, we define $\tau$ for each unique raypath as

$$
\tau_{i j}=t_{i j}-t_{i j}^{0}-R_{i}-S_{j}-\epsilon_{i j}
$$

where the subscripts $i=[1,2, \ldots, N]$ and $j=[1,2, \ldots, M]$ refer to $N$ and $M$ receiver and source locations, respectively, $t_{i j}$ is the observed (picked) travel time, and $\tau_{i j}^{0}=r_{i j} /\left(a_{0}^{0}\right)^{1 / 2}$ is the travel time through the isotropic reference model. $R_{i}$ and $S_{j}$ are static corrections that account for errors in the isotropic model near individual receivers and sources, respectively, and $\epsilon_{i j}$ is the error from picking and remaining pathdependent misfit in the isotropic model. Then, setting Equation (22) equal to (24) yields

$$
t_{i j}-t_{i j}^{0}=\frac{r_{i j}}{\delta c\left(\theta_{i j}\right)}+R_{i}+S_{j}+\epsilon_{i j}
$$


To measure anisotropy, we seek solutions to Equation (25) that minimize $\epsilon_{i j}$. By setting $\epsilon_{i j}=0$ and defining

$$
\begin{aligned}
& \mathrm{T}_{i j}=t_{i j}-t_{i j}^{0} \\
& f_{i j}\left(r_{i j}, \theta_{i j}, \delta c\left(\theta_{i j}\right), R_{i}, S_{j}\right)=\frac{r_{i j}}{\delta c\left(\theta_{i j}\right)}+R_{i}+S_{j}
\end{aligned}
$$

Equation (25) becomes the objective function

$$
\mathrm{T}_{i j}=f_{i j}\left(r_{i j}, \theta_{i j}, \delta c\left(\theta_{i j}\right), R_{i}, S_{j}\right)
$$

or

$$
\mathrm{T}=A m
$$

where $A$ is a Jacobian matrix that relates model parameters in $m$ to delay times. $A$ is given by

$$
A=\left[\begin{array}{cccc}
\frac{\partial f_{11}}{d m_{0}} & \frac{\partial f_{11}}{d m_{1}} & \ldots & \frac{\partial f_{11}}{d m_{L}} \\
\frac{\partial f_{12}}{d m_{0}} & \frac{\partial f_{12}}{d m_{1}} & \ldots & \frac{\partial f_{12}}{d m_{L}} \\
\vdots & \vdots & \ddots & \vdots \\
\frac{\partial f_{N M}}{d m_{0}} & \frac{\partial f_{N M}}{d m_{1}} & \ldots & \frac{\partial f_{N M}}{d m_{L}}
\end{array}\right]
$$

where $L=5+N+M$ is the total number of parameters. The quotient $r / \delta c$ in Equation (26) causes derivatives in the Jacobian to be functions of wavespeed coefficients, and a joint inversion for wavespeeds and static corrections is thus nonlinear.

The Jacobian becomes linear if the problem is formulated in terms of slowness $q=c^{-1}$. To order $4 \theta$, slowness variations have the form 


$$
\delta q(\theta) \approx b_{0}+b_{1} \cos 2 \theta+b_{2} \sin 2 \theta+b_{3} \cos 4 \theta+b_{4} \sin 4 \theta
$$

and we rewrite Equation (27) as $\mathrm{T}_{i j}=f_{i j}^{\prime}$, where

$$
f_{i j}^{\prime}=r_{i j}\left(b_{0}+b_{1} \cos 2 \theta+b_{2} \sin 2 \theta+b_{3} \cos 4 \theta+b_{4} \sin 4 \theta\right)+R_{i}+S_{j}
$$

Then,

$$
\mathrm{T}=A^{\prime} m^{\prime}
$$

Non-zero terms in the Jacobian $A^{\prime}$ are

$$
\begin{gathered}
\frac{\partial f_{i j}^{\prime}}{\partial m_{0}^{\prime}}=r_{i j}, \quad \frac{\partial f_{i j}^{\prime}}{\partial m_{1}^{\prime}}=r_{i j} \cos \left(2 \theta_{i j}\right), \quad \frac{\partial f_{i j}^{\prime}}{\partial m_{2}^{\prime}}=r_{i j} \sin \left(2 \theta_{i j}\right), \\
\frac{\partial f_{i j}^{\prime}}{\partial m_{3}^{\prime}}=r_{i j} \cos \left(4 \theta_{i j}\right), \quad \frac{\partial f_{i j}^{\prime}}{\partial m_{4}^{\prime}}=r_{i j} \sin \left(4 \theta_{i j}\right), \\
\frac{\partial f_{i j}^{\prime}}{\partial m_{5+i}^{\prime}}=1, \quad \text { and } \quad \frac{\partial f_{i j}^{\prime}}{\partial m_{5+N+j}^{\prime}}=1 .
\end{gathered}
$$

The model parameter vector $m^{\prime}$ includes both the slowness coefficients and static corrections, arranged as

$$
\left[\begin{array}{c}
m_{0}^{\prime} \\
\vdots \\
m_{4}^{\prime}
\end{array}\right]=\left[\begin{array}{c}
b_{0}^{1} \\
b_{1} \\
\vdots \\
b_{4}
\end{array}\right],\left[\begin{array}{c}
m_{5}^{\prime} \\
\vdots \\
m_{5+N}^{\prime}
\end{array}\right]=\left[\begin{array}{c}
R_{0} \\
\vdots \\
R_{N}
\end{array}\right] \text {, and }\left[\begin{array}{c}
m_{5+N+1}^{\prime} \\
\vdots \\
m_{5+N+M}^{\prime}
\end{array}\right]=\left[\begin{array}{c}
S_{0} \\
\vdots \\
S_{N}
\end{array}\right]
$$

Solving Equation (32) for $\left[m_{1}^{\prime}, m_{2}^{\prime}, m_{3}^{\prime}, m_{4}^{\prime}\right]=\left[b_{1}, b_{2}, b_{3}, b_{4}\right]$ yields a best-fit solution for slowness variations as a function of azimuth, which can in turn be used to solve for effective elastic stiffness constants via the anisotropic wavespeed parameters in Equation (10).

In practice, delay times are irregularly distributed as a function of azimuth, causing the inversion to preferentially fit data clumped, for example, along line 
azimuths. The data can be regularized by applying a linear smoothing operator $\Lambda$ in Equation (32), giving

$$
\mathrm{T} \Lambda=A^{\prime} m^{\prime} \Lambda
$$

In this study, $\Lambda$ takes moving averages within overlapping azimuth bins that range in width from 5 to $20^{\circ}$.

Receivers, and especially sources, are also irregularly distributed with azimuth. Consequently, the inversion is able to reduce misfit by applying statics that vary with azimuth, distorting measurements of anisotropy. Introducing a weighting scheme that penalizes large statics would mitigate this problem; however, in this study, we choose to ignore the static corrections and attempt to minimize error via the anisotropic parameters alone.

\subsection{Data binning and wavespeed solutions}

We solved for upper mantle anisotropy at the outer rise using delay times from rays that reached maximal depth (i.e., "bottomed") within an 80-km-wide, circular region centered on the outer rise (Figure 11). This bin is roughly centered within the array of sources and receivers and includes paths with source-receiver azimuths that range from 0 to $360^{\circ}$ (Figure 10). We grouped these data by depth of the raybottoming point beneath the Moho (Figure 12) and inverted the data for anisotropic slowness parameters in each depth bin (Figures 13-15). To regularize the distribution of data with azimuth, we used a smoothing operator in the inversion to take moving averages within overlapping azimuth bins. Results for different bin widths are shown in 
Table 1. We then used slowness parameters from these inversions to solve for the equivalent wavespeed parameters in Equation (10) (Figure 16).

\section{Results and discussion}

\subsection{Depth-dependent upper-mantle anisotropy}

Wavespeed models for data grouped by depth of ray-bottoming points indicate that anisotropy varies with depth in the mantle beneath the outer rise of the Middle America Trench (Figure 16 and Table 1). Within $0.1 \mathrm{~km}$ of the Moho, the fastest and slowest wavespeeds differ by 4.40 to $6.90 \%$, with the slow direction oriented along azimuths between 82 and $84^{\circ}$. Over depths of 0.1 to $1 \mathrm{~km}$, this direction is the fast direction, but anisotropy is weak, and wavespeeds only vary by up to 1.57 to $2.27 \%$. Over deeper depth ranges ( 1 to 2 and 1 to $24 \mathrm{~km}$ ), the fast direction is oriented at $\sim 84^{\circ}$ and wavespeeds vary by 1.97 to $2.29 \%$, similar to the anisotropy from depths of 0.1 to $1 \mathrm{~km}$. Over all depth ranges, the largest amplitude variations in wavespeed have a $2 \theta$ periodicity, and larger $4 \theta$ terms are required to fit data from depths just below the Moho.

The phase of wavespeed variations over depths from 0 to $24 \mathrm{~km}$ into the mantle suggests that outer-rise faulting strongly affects upper-mantle anisotropy. Measurements of anisotropy attributed to a $\mathrm{CPO}$ of olivine grains in the Pacific upper mantle (Shearer and Orcutt, 1986; Kawasaki, 1986) suggest that the incoming, unaltered mantle at the Middle America Trench is anisotropic with a fast direction aligned with the $\sim 47^{\circ}$ fossil spreading direction. In models of data from within $0.1 \mathrm{~km}$ of the Moho, the slow-wavespeed direction is orientated at $\sim 45^{\circ}$ to the east of the $\sim 47^{\circ}$ 
fossil spreading direction, which is also roughly the average dip direction for bendingrelated normal faults at the outer rise (Figure 16). Over 1 to $24 \mathrm{~km}$ below the Moho, the fast direction is orientated at $\sim 45^{\circ}$ to the east of the fossil spreading direction, opposite in polarity from the measurement made just below the Moho.

The $\sim 45^{\circ}$ phase shift and polarity reversal may be produced by a combination of jointing and cracking in a relic mantle fabric. Figure 17 shows possible models of transverse isotropy that, when combined with a model of the unaltered Pacific upper mantle, reproduce the measured wavespeed variations. These decompositions were found by a least-squares inversion that solved for effective wavespeed variations from up to three transversely isotropic medias, and the orientation of the symmetry axis in each fabric is independent of the orientation of the other fabrics.

Over 0 to $0.1 \mathrm{~km}$ below the Moho, measured wavespeeds can be generally explained by combining Pacific anisotropy with a model that has a dominate period of $2 \theta$ and a slow direction $\sim 25^{\circ}$ to the east of the relic spreading direction (Figure 17a). This second component is suggestive of wavespeed variations in media with large joints oriented perpendicular to the spreading direction (Figure 2), which is the strike direction of outer-rise faults (Figure 4), but with non-zero $4 \theta$ terms that skew the slow direction by $\sim 15^{\circ}$ to the east. Wavespeeds for rays bottoming within $100 \mathrm{~m}$ of the Moho can be better modeled by introducing a third component that is periodic in $4 \theta$ (Figure 17b), suggestive of wavespeeds in media with aligned cracks (Figure 2). In this three-component media, the slow directions for both the $2 \theta$ and $4 \theta$ components are aligned in the spreading-parallel/fault-normal direction, consistent with a model of both cracks and joints aligned along the fault zones and with the electrical anisotropy 
observed by Key et al (2012). Rays used to solve for anisotropy over this shallow depth range travel $\sim 50$ to almost $100 \%$ of total propagation distance in the crust, and a significant portion of the signal from faulting is likely associated with propagation in the crust.

Over depths of 1 to $24 \mathrm{~km}$ below the Moho, the $4 \theta$ component attributed to cracking is not required to explain wavespeed measurements (Figure 17), implying that, at these depths, cracking may be less intense. A $2 \theta$ component consistent with joints aligned with outer-rise faults is, however, needed to reproduce the measured effective wavespeeds, suggesting that joints may be solely responsible for the change in effective wavespeeds with respect to the unaltered Pacific upper mantle. Rays bottoming at these depths travel $\sim 90 \%$ of total propagation distance in the mantle, and this apparent change in the contribution to anisotropy from cracking, which is a small signal in the upper-most mantle, may result from preferential sampling of mantle versus crustal anisotropy. Both the upper-most and deeper mantle appear to include a significant $2 \theta$ component attributable to joints (Figure 17), suggesting that joints are present in both regions of the mantle and/or both measurements include a signal from joints in the crust, although we have not yet isolated the crustal contribution to total anisotropy.

\subsection{Implications for mantle hydration}

Constraining the extent of serpentinization in the upper mantle will require fully separating the wavespeed effects from faulting in the overlying crust and mantle from wavespeeds at a depth of interest. However, the preliminary models presented here have potential implications for estimates of uppermost mantle hydration. The change in the polarity of anisotropy between depths just below the Moho and deeper depths in the 
mantle indicates that the strength of anisotropy from crustal faulting decreases with respect to the strength of anisotropy from an inherited mantle fabric. While this change may come from changes in relative propagation distance in the mantle versus the crust, this measurement indicates that anisotropy inherited from the incoming Pacific upper mantle is, at least partially, preserved under the outer rise. In the absence of mantle shear, serpentinization is likely to progressively destroy relic anisotropy from a CPO of mantle minerals (Horen et al., 2012; Wallis et al., 2011). This effect is small for small degrees of serpentinization (Horen et al., 2012; Wallis et al., 2011), and this evidence for preservation of mantle fabric does not necessarily preclude estimates that the subducting upper mantle at the Middle America Trench is up to $\sim 30 \%$ serpentinized (Van Avendonk et al., 2011).

Our results indicate that the upper mantle ( 1 to 24 below the Moho) is anisotropic, with azimuthal wavespeed variations of up to $2.29 \%$. These azimuthal variations with must be accounted for when inferring the degree of mantle serpentinization from isotropic velocities found by tomography. In the deeper mantle, measured wavespeeds at the azimuths of both Lines NorthEast and SERP are near mean values (Figure 18). Thus, these values could be compared directly to average wavespeeds measured in mantle rocks with varying degrees of serpentinization, leading to a conclusion that the upper mantle is, on average, $\sim 14 \%$ serpentinized (Figure 19). (Velocity-based estimates by Van Avendonk et al. (2011) range from $\sim 40 \%$ in the upper-most mantle to $0 \%$ at 24 $\mathrm{km}$ below the Moho.) However, residuals for our models of anisotropy suggest that these wavespeeds fail to account for a significant component of anisotropy from a relic mantle fabric (Figure 18). Assuming that the residuals resemble true wavespeeds in the 
mantle places Line SERP inline with the slow-wavespeed direction, reducing the estimate of upper mantle serpentinization to $\sim 10 \%$ (Figure 19). This $\sim 4 \%$ decrease in the estimate of serpentinization is equivalent to reducing the weight fraction of water in the subducting upper mantle from $\sim 2.5$ to $1.5 \mathrm{wt} \%$ (Carlson, 2003), a significant change in the water input to the mantle at subduction zones (Rüpke et al., 2004).

\subsection{Toward better models of effective anisotropy}

Error in our models of transverse isotropy is on the order of the amplitude of wavespeed variations (Figure 18). These residuals are strongly correlated with azimuth, indicating that transverse isotropy is unable to fully explain azimuthal anisotropy in the delay-time measurements and that a model with a lower degree of symmetry (i.e., higher-order in $\theta$ ) is required. Furthermore, these misfits are polarized in the "fast" direction expected for anisotropy in the incoming Pacific upper mantle, implying that at least some component of the residuals comes from an inability to fit relic mantle anisotropy.

There are at least two potential explanations for this misfit and the need for higherorder symmetry. First, our assumption that a cracked and/or jointed upper mantle is transversely isotropic requires that cracks and/or joints be oriented at right angles to the symmetry axis in the unaltered mantle. If these fabrics are oriented at oblique angles, effective wavespeeds are characterized by a lower degree of symmetry (Hudson, 1981). Effective wavespeed variations from a combination of different orientations of transversely isotropic media would have the form

$$
\delta c^{2}=\delta c_{0}(\theta)+\sum_{i} \delta c_{i}\left(\theta+\phi_{i}\right)
$$


where $\delta c_{0}(\theta)$ are wavespeed variations with azimuth in a reference frame defined by $\theta$ and $\delta c_{i}\left(\theta+\phi_{i}\right)$ are wavespeed variations in the $i$ th additional fabric, which is rotated at angle of $\phi_{i}$ from the reference. In this parameterization, the contribution to anisotropy from multiple sources can be found by including an additional 6 parameters $(\phi$ plus the 5 anisotropic parameters) for each fabric in the inversion outlined above. (As a test of this concept, we used this parameterization in the decomposition of the wavespeed models into component sources shown in Figure 17.)

A second explanation for misfit is that, although our models account for delay-time variations due to differences in propagation distance in the mantle, they do not account for variations from differences in the length of crustal paths. In flat-lying crust, Pn paths travel a similar distance through the crust, regardless of the distance traveled in the mantle, and the effect on delay times is negligible. At the outer rise, plate bending causes raypaths from the forearc side of the trench to penetrate the crust at a lower angle, and these crustal paths are longer than those from seaward of the outer rise. Delay times from anisotropy in the faulted crust thus depend on raypaths, and distance through the crust should be accounted for in solutions for anisotropy. Differences in crustal path lengths could be included in an inversion for multi-component anisotropy using Equation (36) by scaling wavespeeds in different layers by distance traveled through each layer, bringing the total number of model parameters to $6 \mathrm{x} \mathrm{N}_{\text {layers }} \mathrm{x}$ $\mathrm{N}_{\text {fabrics. }}$ This scheme would also enable anisotropy in the crust to be isolated from anisotropy in the mantle, which should help to better constrain the distribution of upper mantle faulting and hydration. 
Receiver and source statics also contribute to misfit (Figure 20). This source of error can be reduced by improving the isotropic reference model, and/or by including static correction terms in the inversion for anisotropic models. However, receivers and sources are irregularly distributed as a function of azimuth, and including static terms in the inversion introduces a trade-off between fitting the data via changes to the anisotropic parameters and changes to the static terms. Thus, while the static terms may prove useful in producing better fits to the data, their influence on anisotropy models must be carefully balanced via additional weighting terms.

The region of low velocities extending along the outer rise in tomographic models (Van Avendonk et al., 2011) likely introduces azimuthal variations in wavespeeds that are unrelated to intrinsic anisotropy from crustal or mantle fabrics. This effect could be constrained and removed from wavespeed models by measuring the azimuthal variation in the difference in traveltimes calculated through models with and without a slow velocity region in the mantle under the outer rise (e.g., NorthEast_v1d and NorthEast_v2d).

\section{Conclusions}

Measurements of azimuthal variations in seismic wavespeed indicate that the upper mantle is between $\sim 1.6$ and $4.4 \%$ anisotropic beneath the outer rise of the Middle America Trench. This anisotropy can be explained by combining wavespeed variations from an alignment of olivine grains in a relic mantle fabric with anisotropy from cracks and/or joints aligned along the strike of bending-related normal faults. Measurements made using rays that turn at different depths indicate that anisotropy varies with depth in the mantle, with anisotropy attributable to aligned cracks composing a larger portion 
of the wavespeed variations in the upper-most mantle. Anisotropy in both the uppermost mantle and over depths up to $24 \mathrm{~km}$ below the Moho appears to include a component attributable to large joints aligned with the bending-induced faults. It is unclear, however, how much of this apparent signal from jointing is accumulated along crustal paths, and determining the true depth extent of jointing will require isolating crustal anisotropy.

Accounting for up to $\sim 2.29 \%$ upper-mantle anisotropy reduces current seismicvelocity-based estimates of upper mantle serpentinization at the Middle America Trench by $\sim 4 \%$, or $\sim 1 \mathrm{wt} \%$ in estimates of water stored in the subducting upper mantle. This anisotropy cannot, however, fully explain the up to $10 \%$ slow velocity anomaly imaged by tomography (Van Avendonk et al., 2011), indicating that the upper mantle is significantly serpentinized under the outer rise. These slow velocities, along with measured wavespeed polarizations in the upper mantle, are consistent with the hypothesis that the upper mantle is hydrated by seawater flowing along bendinginduced normal faults at the outer rise. 


\section{References}

Anderson, D.L., Minster, B., and Cole, D., 1974, The effect of oriented cracks on seismic velocities: Journal of Geophysical Research, v. 79, no. 26, p. 4011-4015.

Backus, G.E., 1965, Possible forms of seismic anisotropy of the uppermost mantle under oceans: Journal of Geophysical Research, v. 70, no. 14, p. 3429-3439.

Billen, M., Cowgill, E., and Buer, E., 2007, Determination of fault friction from reactivation of abyssal-hill faults in subduction zones: Geology, v. 35, no. 9, p. 819, doi: 10.1130/G23847A.1.

Carlson, R.L., 2003, Mantle wedge water contents estimated from seismic velocities in partially serpentinized peridotites: Geophysical Research Letters, v. 30, no. 5, p. 1250.

Christensen, N.I., 1966, Elasticity of ultrabasic rocks: Journal of Geophysical Research, v. 71, no. 24, p. $5921-5931$.

Contreras-Reyes, E., and Grevemeyer, I., 2008, Effect of trench-outer rise bending-related faulting on seismic Poisson's ratio and mantle anisotropy: a case study offshore of Southern Central Chile: Geophysical Journal International.

Crampin, S., 1981, A review of wave motion in anisotropic and cracked elastic-media: Wave Motion, v. 3, no. 4, p. 343-391.

Crampin, S., 1984, Effective anisotropic elastic constants for wave propagation through cracked solids: Geophysical Journal International, v. 76, no. 1, p. 135-145.

Davies, J.H., and Stevenson, D.J., 1992, Physical model of source region of subduction zone volcanics: Journal of Geophysical Research, v. 97, no. B2, p. 2037.

Delescluse, M., and Montési, L., 2008, Fault reactivation and selective abandonment in the oceanic lithosphere: Geophysical Research \ldots.

dGB Earth Sciences, 2012, OpendTect:

Faccenda, M., Gerya, T.V., and Burlini, L., 2009, Deep slab hydration induced by bending-related variations in tectonic pressure: Nature Geoscience, v. 2, no. 11, p. 790-793.

Fisher, A.T., Stein, C.A., Harris, R.N., Wang, K., Silver, E.A., Pfender, M., Hutnak, M., Cherkaoui, A., Bodzin, R., and Villinger, H., 2003, Abrupt thermal transition reveals hydrothermal boundary and role of seamounts within the Cocos Plate: Geophysical Research Letters, v. 30, no. 11.

Fujie, G., Kodaira, S., Yamashita, M., and Sato, T., 2013, Systematic changes in the incoming plate structure at the Kuril trench: Geophysical Research Letters, v. 40, p. 88-93.

Gaherty, J.B., Lizarralde, D., Collins, J.A., Hirth, G., and Kim, S., 2004, Mantle deformation during slow seafloor spreading constrained by observations of seismic anisotropy in the western Atlantic: Earth and Planetary Science Letters, v. 228, no. 3-4, p. 255-265.

Gerya, T.V., Connolly, J.A.D., Yuen, D.A., Gorczyk, W., and Capel, A.M., 2006, Seismic implications of mantle wedge plumes: Physics of the Earth and Planetary Interiors, v. 156, no. 1-2, p. 59-74, doi: 10.1016/j.pepi.2006.02.005. 
Grevemeyer, I., Kaul, N., and Diaz-Naveas, J.L., 2005, Heat flow and bending-related faulting at subduction trenches: Case studies offshore of Nicaragua and Central Chile: Earth and Planetary Science Letters, v. 236, p. 238-248.

Grevemeyer, I., Ranero, C.R., and Flueh, E.R., 2007, Passive and active seismological study of bendingrelated faulting and mantle serpentinization at the Middle America trench: Earth and Planetary Science Letters, v. 258, p. 528-542.

Gurevich, B., 2003, Elastic properties of saturated porous rocks with aligned fractures: Journal of Applied Geophysics, v. 54, p. 203-218.

Hacker, B.R., 2008, H2O subduction beyond arcs: Geochemistry, Geophysics, Geosystems, v. 9, no. 3, doi: 10.1029/2007GC001707.

Hirth, G., and Kohlstedt, D.L., 1996, Water in the oceanic upper mantle: implications for rheology, melt extraction and the evolution of the lithosphere: Earth and Planetary Science Letters, v. 144, p. 93108.

Horen, H., Zamora, M., and Dubuisson, G., 2012, Seismic waves velocities and anisotropy in serpentinized peridotites from xigaze ophiolite: Abundance of serpentine in slow spreading ridge: Geophysical Research Letters, v. 23, no. 1, p. 9-12.

Hudson, J.A., 1981, Wave speeds and attenuation of elastic waves in material containing cracks: Geophysical Journal International, v. 64, no. 1, p. 133-150.

Hudson, J.A., Liu, E., and Crampin, S., 1996, The mechanical properties of materials with interconnected cracks and pores: Geophysical Journal International, v. 124, no. 1, p. 105-112.

Hudson, J.A., Pointer, T., and Liu, E., 2001, Effective-medium theories for fluid-saturated materials with aligned cracks: Geophysical prospecting, v. 49, no. 5, p. 509-522.

Ismail, W.B., and Mainprice, D., 1998, An olivine fabric database: an overview of upper mantle fabrics and seismic anisotropy: Tectonophysics, v. 296, no. 1, p. 145-157.

Ivandic, M., Grevemeyer, I., and Berhorst, A., 2008, Impact of bending related faulting on the seismic properties of the incoming oceanic plate offshore of Nicaragua: Solid Earth.

Ivandic, M., Grevemeyer, I., Bialas, J., and Petersen, C.J., 2010, Serpentinization in the trench-outer rise region offshore of Nicaragua: constraints from seismic refraction and wide-angle data: Geophysical Journal International, v. 180, no. 3, p. 1253-1264.

Iwamori, H., 1998, Transportation of $\mathrm{H} 2 \mathrm{O}$ and melting in subduction zones: Earth and Planetary Science Letters, v. 160, p. 65-80.

John, T., and Schenk, V., 2003, Partial eclogitisation of gabbroic rocks in a late Precambrian subduction zone (Zambia): prograde metamorphism triggered by fluid infiltration: Contributions to Mineralogy and Petrology, v. 146, no. 2, p. 174-191.

Jung, H., and Karato, S., 2001, Water-Induced Fabric Transitions in Olivine: Science, v. 293, no. 5534, p. $1460-1463$.

Kaminski, E., and Ribe, N.M., 2001, A kinematic model for recrystallization and texture development in olivine polycrystals: Earth and Planetary Science Letters. 
Kaminski, É., and Ribe, N.M., 2002, Timescales for the evolution of seismic anisotropy in mantle flow: Geochem. Geophys. Geosyst, v. 3, no. 8, p. 1-17.

Karato, S., 2008, Deformation of Earth Materials: An Introduction to the Rheology of Solid Earth: Cambridge University Press, Cambridge.

Kawasaki, I., 1986, Azimuthally anisotropic model of the oceanic upper mantle: Physics of the Earth and Planetary Interiors, v. 43, no. 1, p. 1-21.

Kawasaki, I., and Kon'no, F., 1984, Azimuthal anisotropy of surface waves and the possible type of the seismic anisotropy due to preferred orientation of olivine in the uppermost mantle beneath the Pacific Ocean: Journal of Physics of the Earth, v. 32, no. 3, p. 229-244.

Kerrick, D., 2002, Serpentinite Seduction: Science, v. 298, no. 5597, p. 1344-1345, doi: 10.1126/science.298.5597.1344.

Kerrick, D.M., and Connolly, J., 2001, Metamorphic devolatilization of subducted oceanic metabasalts: implications for seismicity, arc magmatism and volatile recycling: Earth and Planetary Science Letters, v. 189, p. 19-29.

Key, K., Constable, S., Matsuno, T., Evans, R.L., and Myer, D., 2012, Electromagnetic detection of plate hydration due to bending faults at the Middle America Trench: Earth and Planetary Science Letters, v. 351-352, no. c, p. 45-53.

Klaucke, I., Masson, D.G., and Petersen, C.J., 2008, Multifrequency geoacoustic imaging of fluid escape structures offshore Costa Rica: Implications for the quantification of seep processes: Geochemistry.

Landau, L.D., and Lifshiz, E.M., 1970, Theory of elasticity: Pergamon Press, Oxford.

Lefeldt, M., Ranero, C.R., and Grevemeyer, I., 2012, Seismic evidence of tectonic control on the depth of water influx into incoming oceanic plates at subduction trenches: Geochemistry, Geophysics, Geosystems, v. 13, p. 1-17.

Marquart, G., Schmeling, H., and Cadek, O., 2007, Dynamic models for mantle flow and seismic anisotropy in the North Atlantic region and comparison with observations: Geochemistry, Geophysics, Geosystems, v. 8, no. 2, p. 1-26.

Masson, D.G., 1991, Fault patterns at outer trench walls: Marine Geophysical Researches, v. 13, no. 3, p. 209-225.

Maus, S., Barckhausen, U., Berkenbosch, H., Bournas, N., Brozena, J., Childers, V., Dostaler, F., Fairhead, J.D., Finn, C., Frese, von, R.R.B., Gaina, C., Golynsky, S., Kucks, R., Lühr, H., et al., 2009, EMAG2: A 2--arc min resolution Earth Magnetic Anomaly Grid compiled from satellite, airborne, and marine magnetic measurements: Geochemistry, Geophysics, Geosystems, v. 10, no. 8.

Moore, G.F., Bangs, N.L., Taira, A., Kuramoto, S., Pangborn, E., and Tobin, H.J., 2007, ThreeDimensional Splay Fault Geometry and Implications for Tsunami Generation: Science, v. 318 , no. 5853, p. 1128-1131.

Morris, G.B., Raitt, R.W., and Shor, G.G., Jr, 1969, Velocity anisotropy and delay-time maps of the mantle near Hawaii - Morris: Journal of Geophysical Research, v. 74, no. 17, p. 4300-4316.

Moser, T.J., 1991, Shortest path calculation of seismic rays: Geophysics. 
Nedimović, M.R., Bohnenstiehl, D.R., Carbotte, S.M., Canales, J.P., and Dziak, R.P., 2009, Faulting and hydration of the Juan de Fuca plate system: Earth and Planetary Science Letters, v. 284, no. 1-2, p. 94-102.

Plank, T., and Langmuir, C.H., 1998, The chemical composition of subducting sediment and its consequences for the crust and mantle: Chemical Geology, v. 145, no. 3-4, p. 325-394.

Ranero, C.R., and Sallares, V., 2004, Geophysical evidence for hydration of the crust and mantle of the Nazca plate during bending at the north Chile trench: Geology, v. 32, no. 7, p. 549-552.

Ranero, C.R., Grevemeyer, I., and Sahling, H., 2008, Hydrogeological system of erosional convergent margins and its influence on tectonics and interplate seismogenesis: Geochemistry.

Ranero, C.R., Phipps Morgan, J., McIntosh, K., and Reichert, C., 2003, Bending-related faulting and mantle serpentinization at the Middle America trench: Nature, v. 425, no. 6956, p. 367-373.

Rüpke, L.H., Morgan, J.P., Hort, M., and Connolly, J., 2004, Serpentine and the subduction zone water cycle: Earth and Planetary Science Letters, v. 223, p. 17-34.

Ryan, W., Carbotte, S.M., and Coplan, J.O., 2009, Global Multi-Resolution Topography synthesis: Geochemistry, Geophysics, Geosystems, v. 10, no. 3, p. 1-9.

Scherbaum, F., 2007, Of Poles and Zeros: Springer, Dordrecht.

Schmidt, M.W., and Poli, S., 1998, Experimentally based water budgets for dehydrating slabs and consequences for arc magma generation: Earth and Planetary Science Letters, v. 163, no. 1-4, p. 361379, doi: 10.1016/So012-821X(98)00142-3.

Shearer, P.M., and Orcutt, J.A., 1986, Compressional and shear wave anisotropy in the oceanic lithosphere - the Ngendei seismic refraction experiment: Geophysical Journal International, v. 87, no. 3, p. 9671003.

Shipboard Scientific Party, 1982, Site 495: Cocos Plate-Middle America Trench Outer Slope: Deep Sea Drilling Project Initial Reports, v. 67, p. 79-141.

Solomatov, V.S., and Moresi, L.N., 1996, Stagnant lid convection on Venus: Journal of Geophysical Research, v. 101, no. E2, p. 4737.

Staudigel, H., Davies, G.R., Hart, S.R., and Marchant, K.M., 1995, Large scale isotopic Sr, Nd and O isotopic anatomy of altered oceanic crust: DSDP/ODP sites 417/418: Earth and Planetary Science Letters, v. 130, p. 169-185.

Staudigel, H., Plank, T., White, B., and Schmincke, H.-U., 1996, Geochemical fluxes during seafloor alteration of the basaltic upper oceanic Crust: DSDP sites 417 and 418, in Geophysical Monograph Series, Geophysical Monograph Series, American Geophysical Union, Washington, D. C., p. 19-38.

Thomsen, L., 1995, Elastic anisotropy due to aligned cracks in porous rock: Geophysical prospecting, v. 43 , no. 6 , p. $805-829$.

Thomsen, L., 1987, Elastic anisotropy due to aligned cracks: 1987 SEG Annual Meeting.

Thomsen, L., 1986, Weak elastic anisotropy: Geophysics, v. 51, no. 10, p. 1954-1966. 
Van Avendonk, H.J.A., 1998, An investigation of the crustal structure of the Clipperton transform fault area using 3D seismic tomography: University of California, San Diego.

Van Avendonk, H.J.A., and Shillington, D.J., 2004, Inferring crustal structure in the Aleutian island arc from a sparse wide-angle seismic data set: Geochemistry, Geophysics, Geosystems, v. 5, no. 8, p. 124.

Van Avendonk, H.J.A., Harding, A.J., Orcutt, J.A., and McClain, J.S., 1998, A two-dimensional tomographic study of the Clipperton transform fault: Journal of Geophysical Research, v. 103, no. B8, p. 17885 .

Van Avendonk, H.J.A., Holbrook, W.S., Lizarralde, D., and Denyer, P., 2011 , Structure and serpentinization of the subducting Cocos plate offshore Nicaragua and Costa Rica: Geochemistry, Geophysics, Geosystems, v. 12, no. 6.

Wallis, S.R., Kobayashi, H., Nishii, A., Mizukami, T., and Seto, Y., 2011, Obliteration of olivine crystallographic preferred orientation patterns in subduction-related antigorite-bearing mantle peridotite: an example from the Higashi-Akaishi body, SW Japan: Geological Society London Special Publications, v. 360, no. 1, p. 113-127.

Walther, C.H.E., Flueh, E.R., Ranero, C.R., Huene, von, R., and Strauch, W., 2000, Crustal structure across the Pacific margin of Nicaragua:evidence for ophiolitic basement and a shallow mantle sliver: Geophysical Journal International, v. 141, no. 3, p. 759-777.

Wang, K., Mulder, T., Rogers, G.C., and Hyndman, R.D., 1995, Case for very low coupling stress on the Cascadia Subduction Fault: Journal of Geophysical Research, v. 100, no. B7, p. 12907.

Zhang, S., and Karato, S.-I., 1995, Lattice preferred orientation of olivine aggregates deformed in simple shear: Nature, v. 375 , no. 6534 , p. 774-777. 


\section{Tables}

Table 1. Wavespeed model parameters and associated anisotropy.

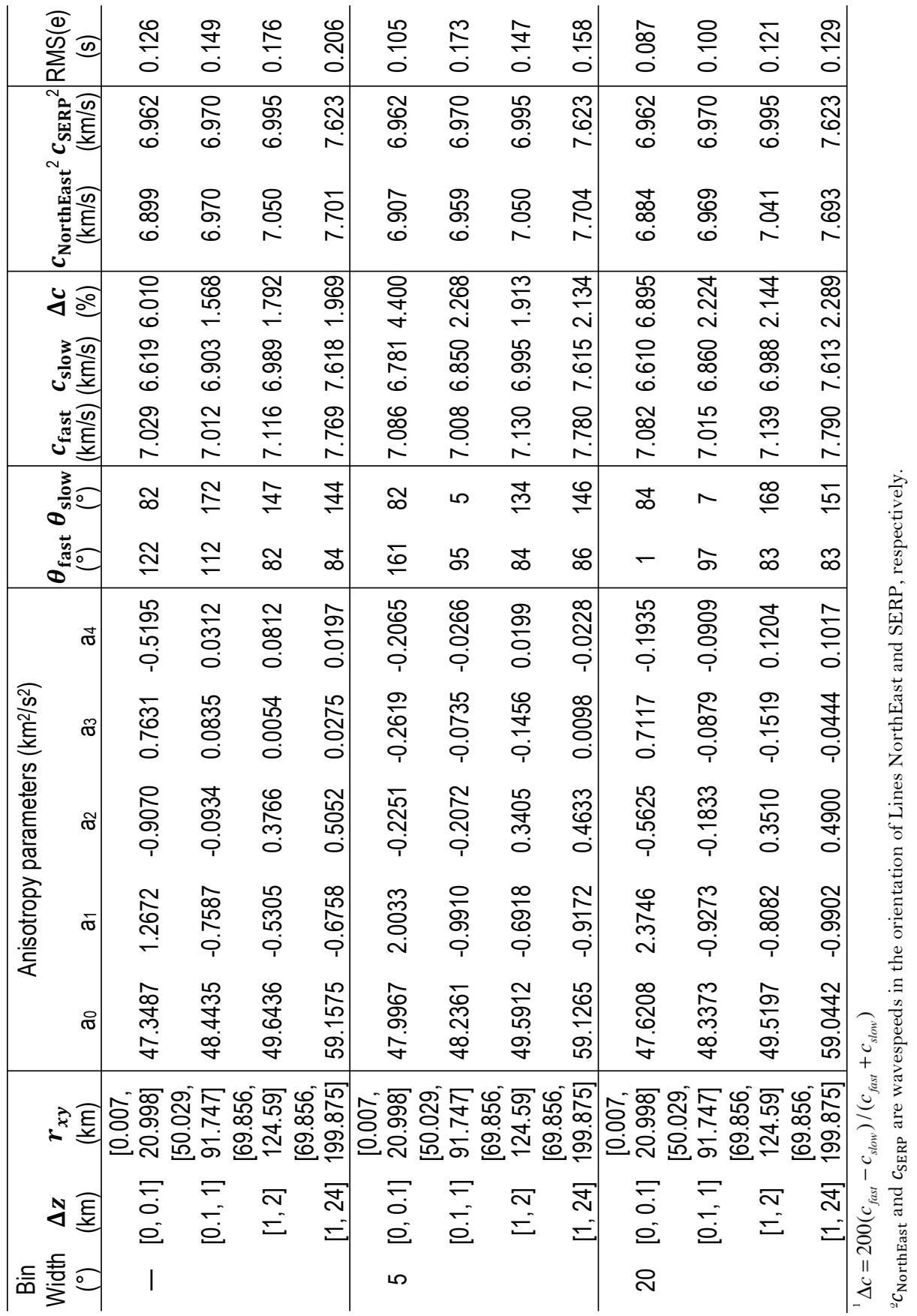




\section{Figures}

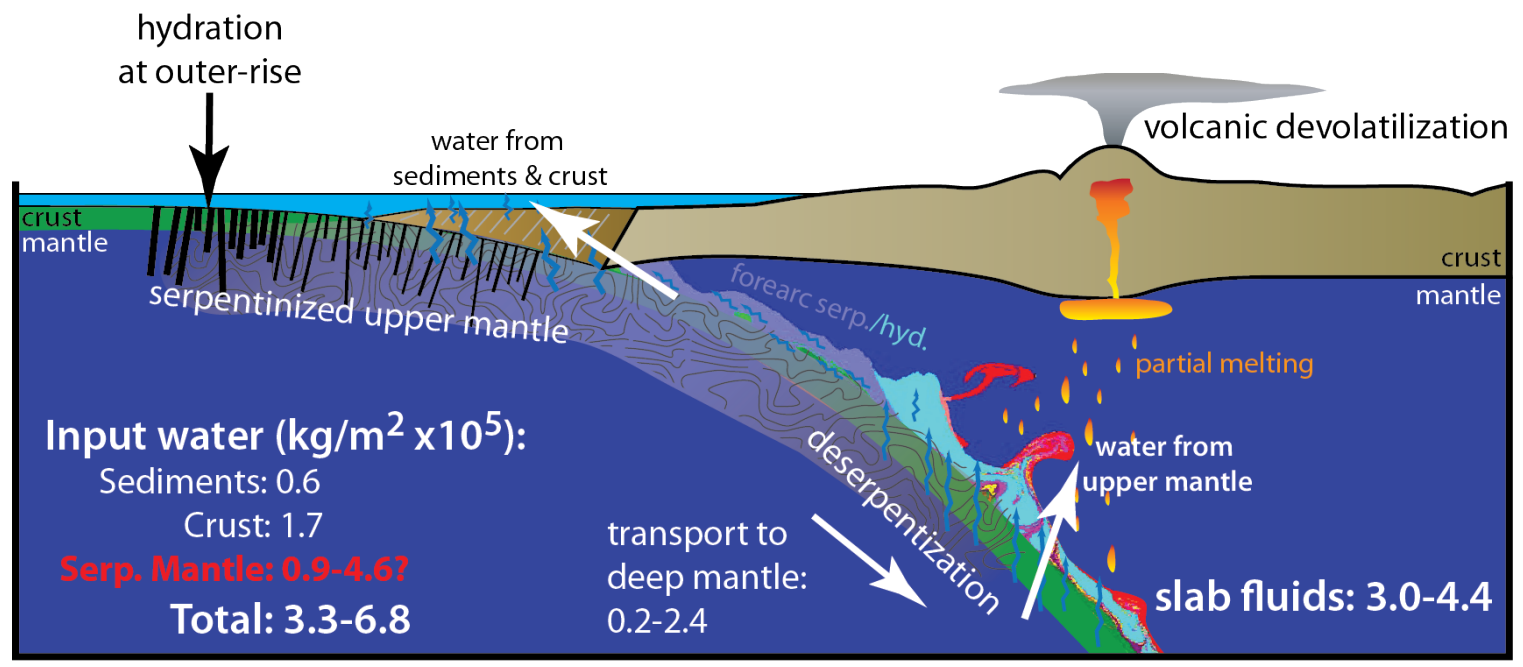

Figure 1. Schematic diagram of the subduction zone water cycle. The subducting lithosphere is thought to deliver 3.0 to $4.4 \times 10^{5} \mathrm{~kg}$ of water per $\mathrm{m}^{2}$ of seafloor to the mantle Idge and $0.2-2.4 \times 10^{5}$ $\mathrm{kg} / \mathrm{m}^{2}$ to the deep mantle. Of this, sediments and oceanic crust account for $\sim 1.2 \times 10^{5} \mathrm{~kg} / \mathrm{m}^{2}$ (Staudigel et al., 1996; Plank and Langmuir, 1998; Kerrick, 2002). Flow of seawater along bendinginduced faults at the outer-rise may serpentinize the oceanic upper mantle, however estimates of this potentially significant component of the input water flux are poorly constrained and vary from 0.6 to $4.6 \mathrm{~kg} / \mathrm{m}^{2}$ (Schmidt and Poli, 1998; Kerrick, 2002; Ranero et al., 2003). After Rüpke et al. (2004) with instability models of Gerya et al. (2006). 
(a) LPO

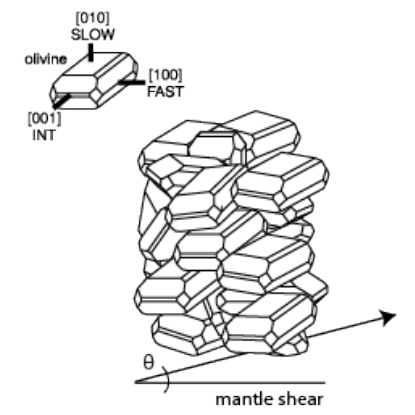

(b) Aligned cracks

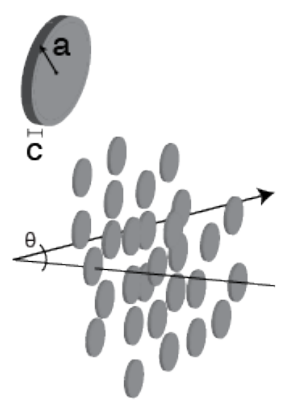

(c) Large joints

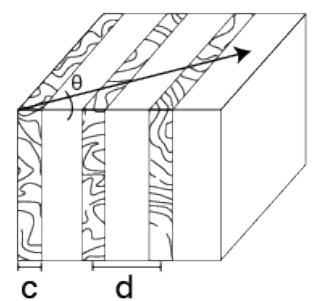

(d) Pervasive Serpentinization

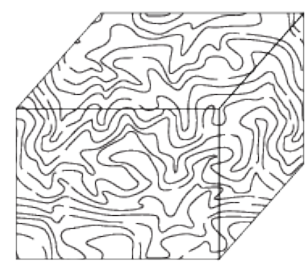

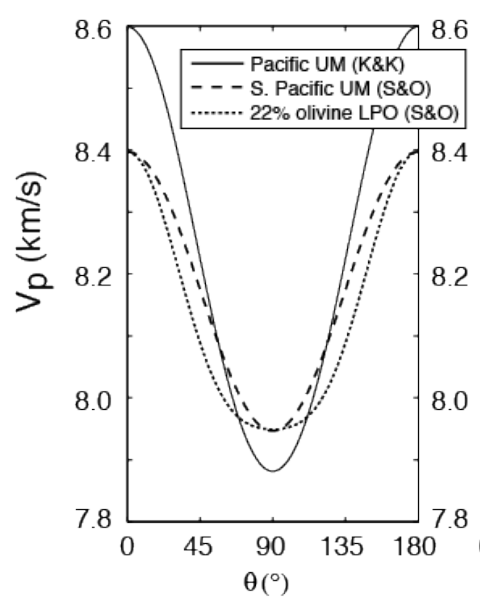
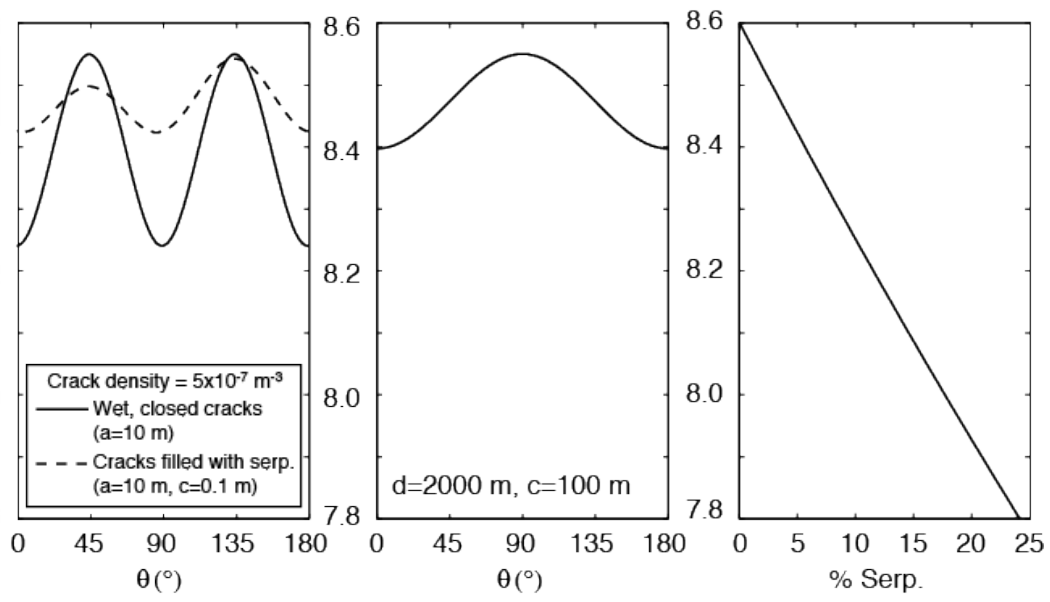

Figure 2. Comparison of the wave speed and delay time $(\mathrm{x}=50 \mathrm{~km})$ effects of anisotropic fabric and pervasive serpentinization on (quassi-)compressional waves (qP) travels through the upper mantle (dunite): (a) Best-fit azimuthal qP-wavespeed models for the uppermost mantle in the Pacific (Kawasaki and Konno, 1984), the south Pacific upper mantle (Shearer and Orcutt, 1986), and calculated velocities predicted for an olivine matrix with 22\% LPO (Shearer and Orcutt, 1986). (b) Effective media theory (Hudson, 1981) calculations for qP in dunite with aligned, water- and serpentinite-filled cracks. (c) Geometrical effect of large, serpentinite-filled, planar joints. (d) Effect of pervasive serpentinization (Christensen, 1966). Olivine crystal drawing is from Lev and Hager (2008). 

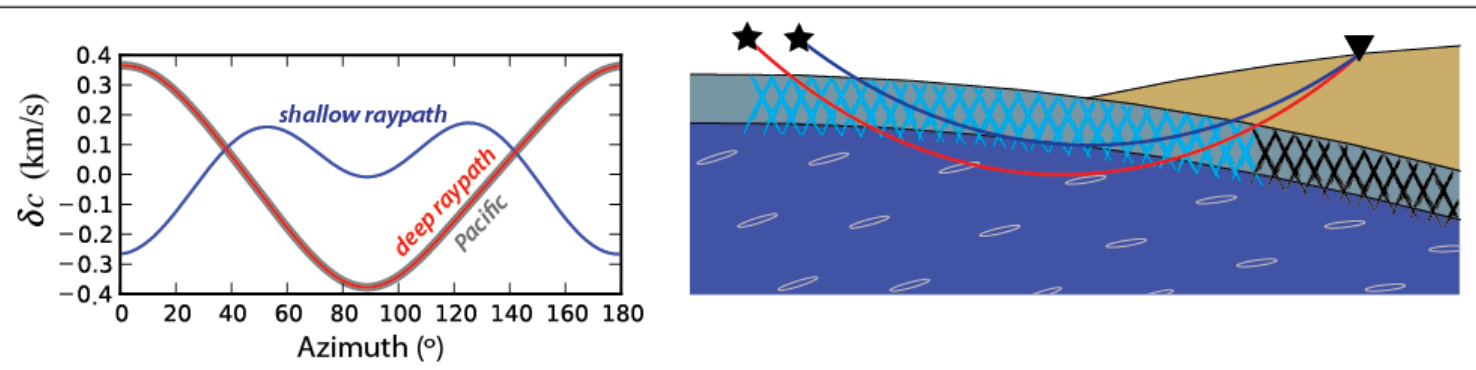

(b) Cracks and joints in crust, decreased relic CPO in mantle from pervaisive serpentinization
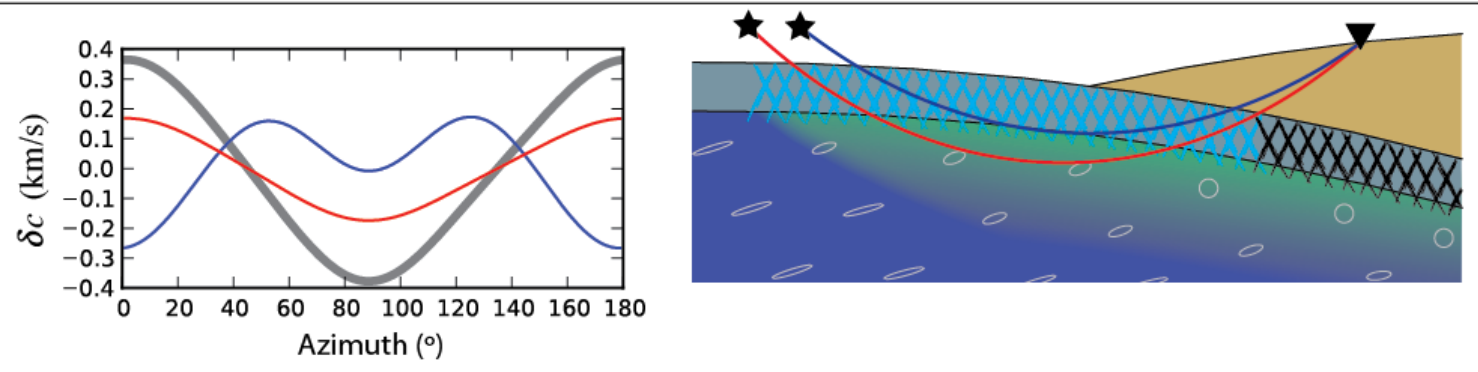

(c) Cracks and joints in crust, serpentinized joints and relic CPO in mantle
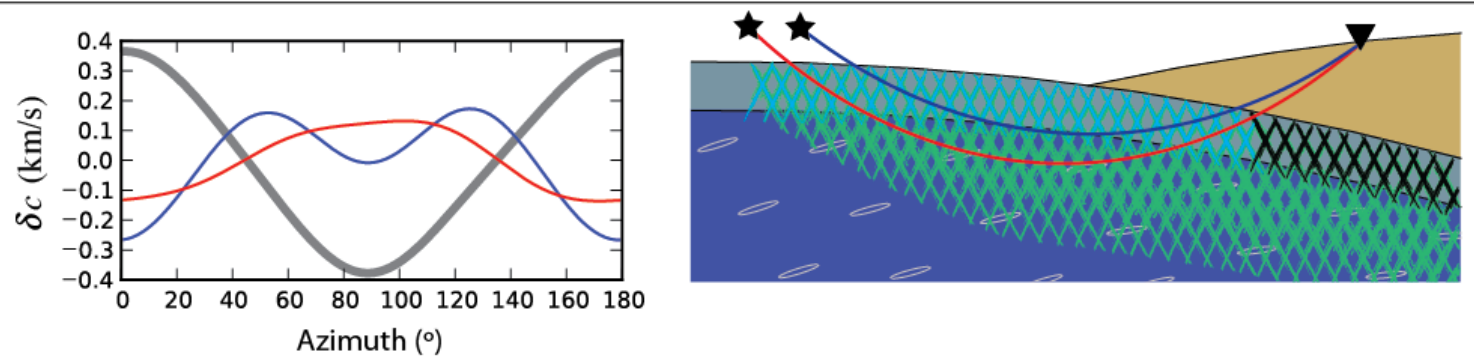

Figure 3. Theoretical wavespeeds through an upper mantle with multiple sources of azimuthal anisotropy. Effective wavespeeds are shown for rays bottoming just below the Moho (blue) and at deeper depths in the mantle (red), and wavespeeds in the Pacific upper mantle are shown in grey (Kawasaki and Kon'no, 1984). In all cases, the crust and upper-most mantle includes cracks and joints. In (a), the deeper mantle fabric consists of an inherited CPO of mineral grains. In (b), the inherited CPO in the deeper mantle is partially erased by pervasive serpentinization. In (c), large serpentinized joints are superimposed over the inherited CPO in deeper mantle. 


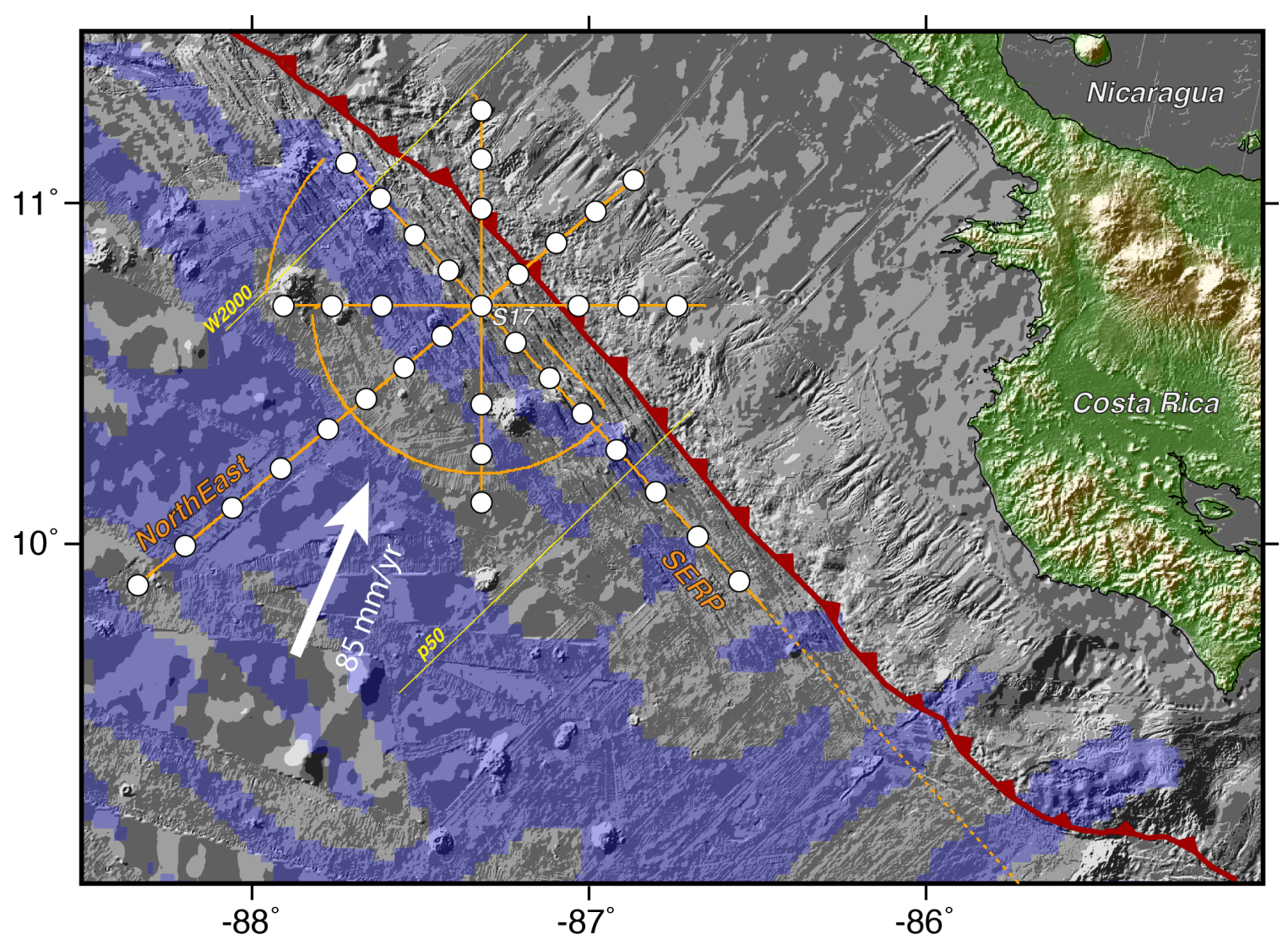

Figure 4. Map of the Middle America Trench offshore of Nicaragua showing the location of oceanbottom seismometers (white circles) and air-gun shots (orange lines) for the TICO-CAVA2 experiment. Also shown are the locations of two-dimensional, isotropic velocity models (W2000: Walther et al., 2000; p50: Ivandic et al., 2008; SERP: Van Avendonk et al., 2011). Negative magnetic anomalies (blue) mark the orientation of relic crustal fabric from formation at mid-ocean ridge (Maus et al., 2009). Bending-related faults can be seen in the illuminated bathymetry data (grey), and topography is shown in green and brown colors (Ryan et al., 2009). 


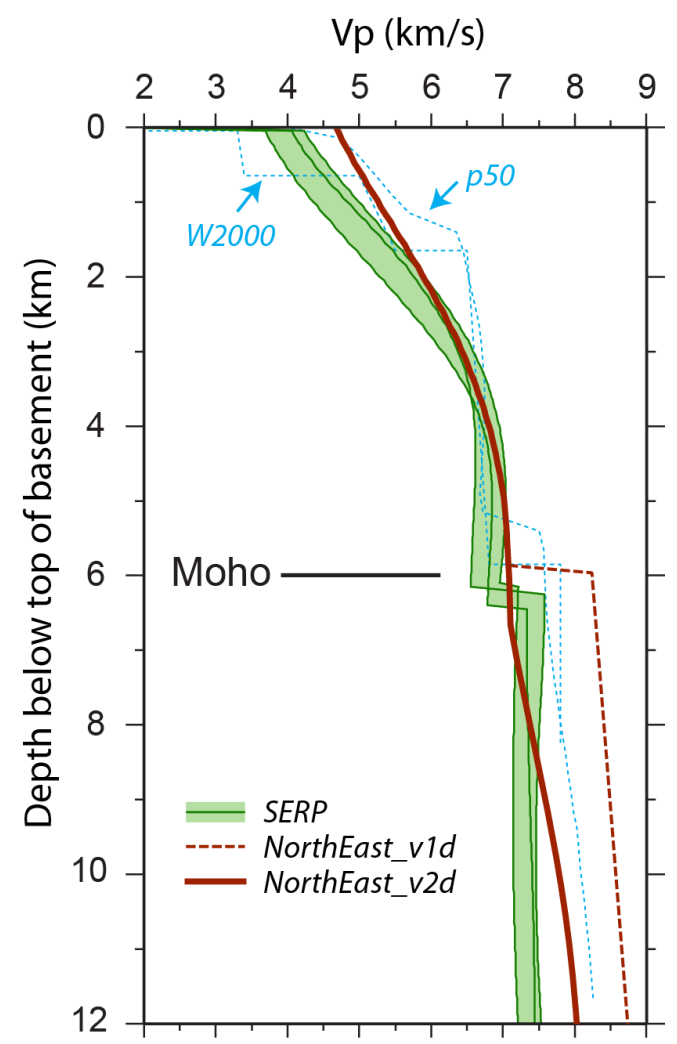

Figure 5. Velocity as a function of depth in two-dimensional isotropic velocity models. Line locations are shown in Figure 4. The NorthEast lines are from this work. Other profiles shown for comparison are: W2000: Walther et al. (2000); $p 50$ : Ivandic et al. (2008); and SERP: Van Avendonk et al. (2011). 


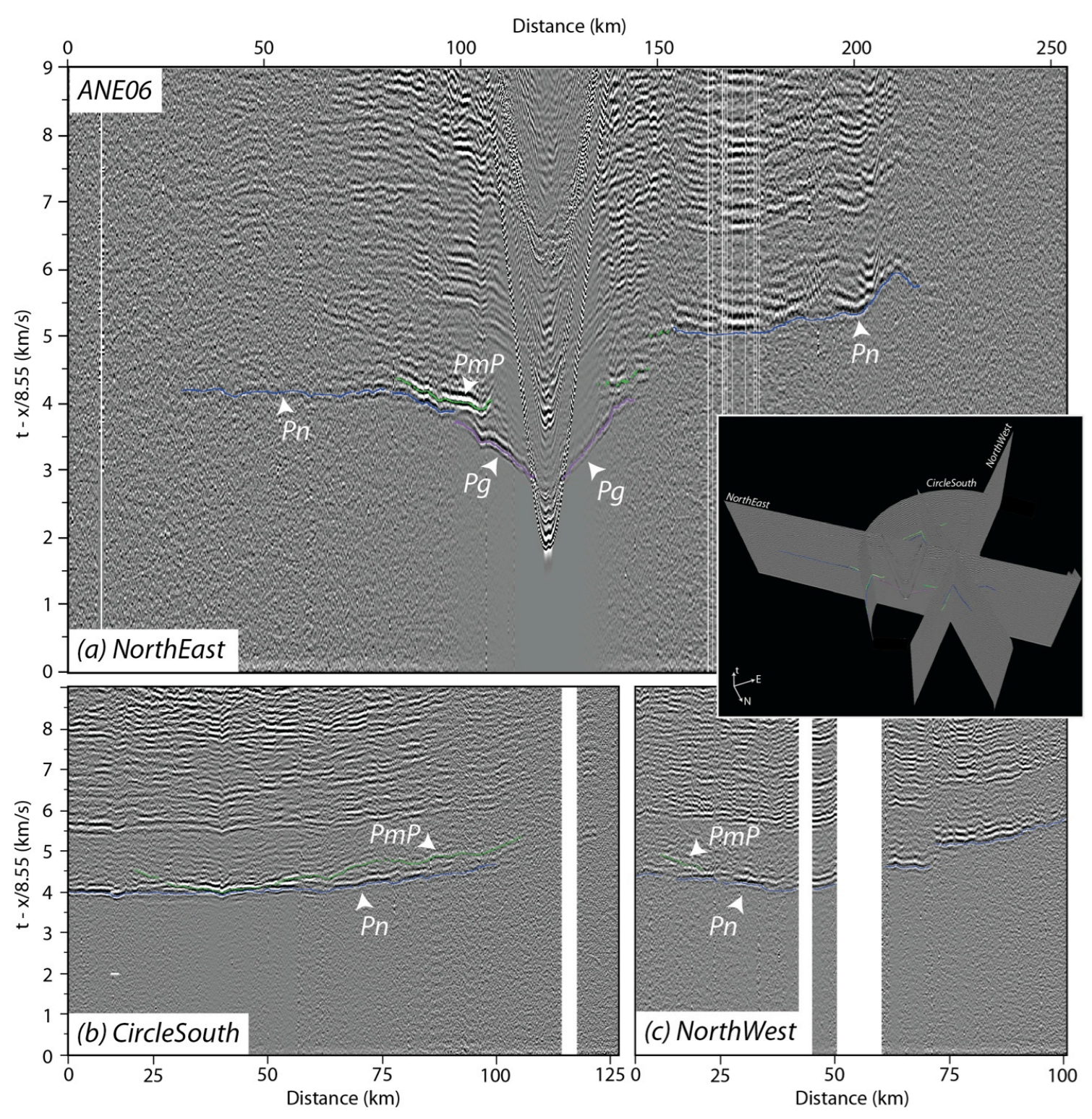

Figure 6. Example of OBS data used to pick traveltimes. Data shown are from site ANE06. The inset is a southeast perspective view showing the relative orientation of the lines with traces plotted at the source location. All data were filtered using a minimum-phase bandpass filter from 3 to $15 \mathrm{~Hz}$ and reduced at $8.55 \mathrm{~km} / \mathrm{s}$. 


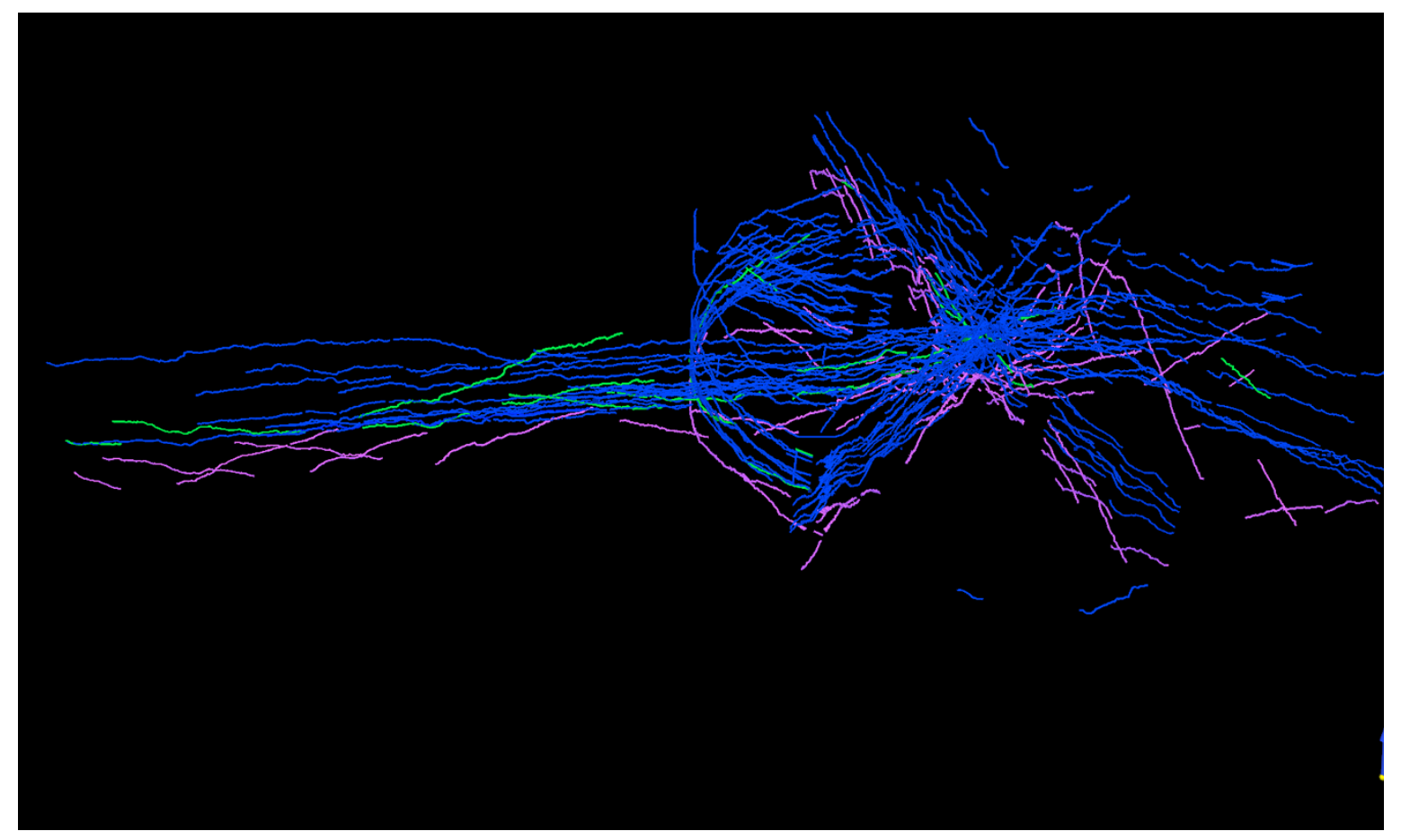

Figure 7. Perspective view of traveltime picks for all instruments looking southeast. Phase shown are Pg (purple), PmP (green), and Pn (blue). 


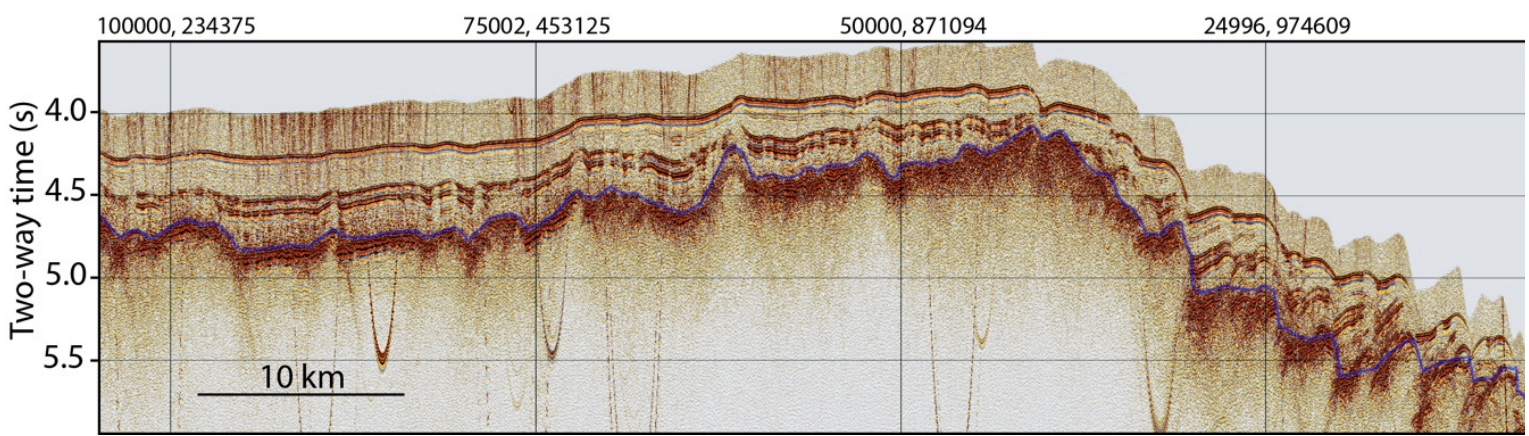

Figure 8. Example of MCS data and basement picks (blue line) from Line AnNE2. The stacks were made with a standard sequence of common-mid-point (CMP) gathering, minimum-phase bandpass filtering from 21 to $120 \mathrm{~Hz}$, normal-move out (NMO) correction using a one-dimensional velocity function hung from the seafloor, spherical divergence correction, trace editing, stacking, and Kirchhoff time migration using velocities based on the stacking velocities. 

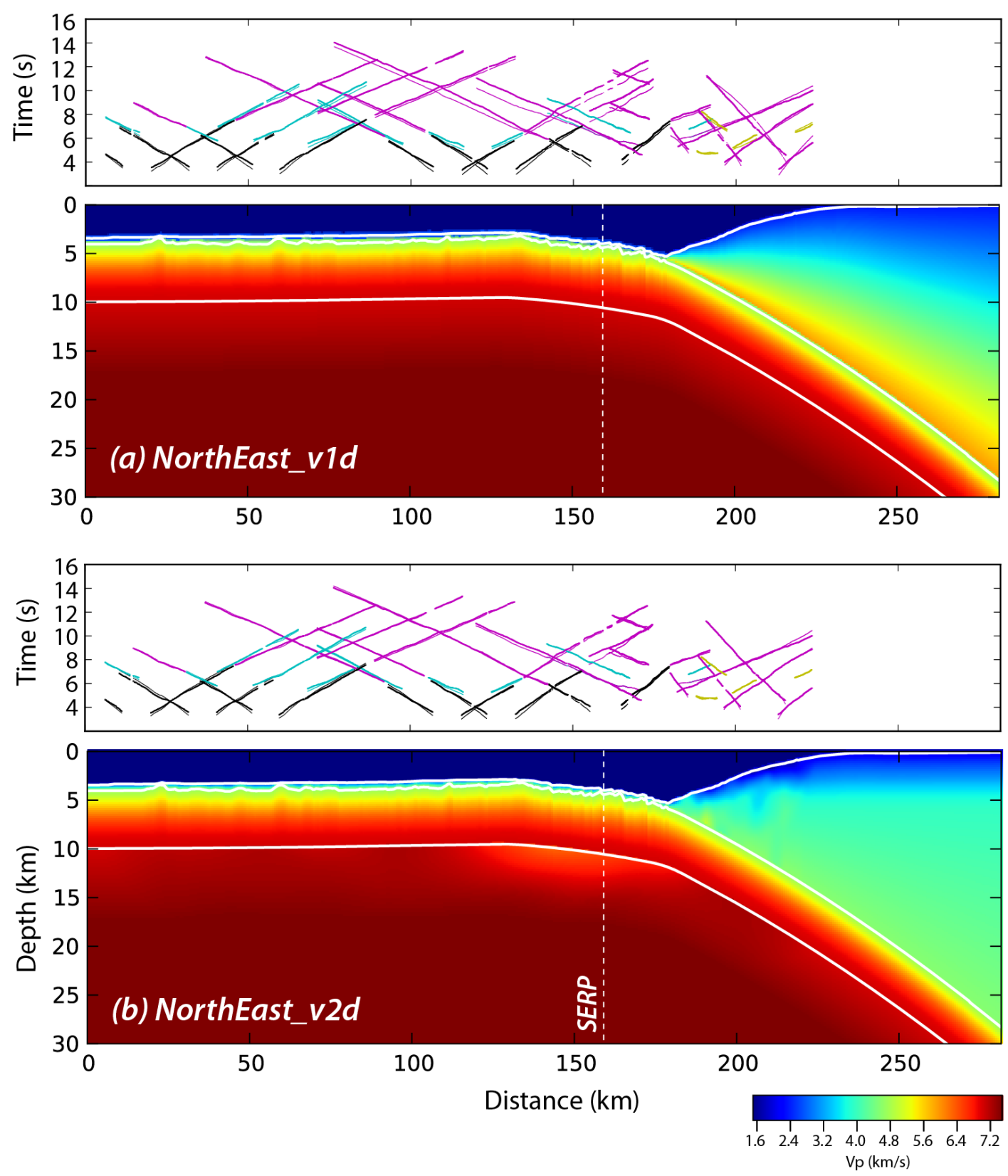

Figure 9. Two-dimensional isotropic velocity models and travel-time residuals for Line NorthEast. In (a), a one-dimensional velocity-depth function that fits Pg and Pn traveltimes from raypaths that bottom seaward of the outer rise (left-hand side) is hung from the slab surface. (b) is the result of a tomographic inversion using (a) as a starting model. The vertical line at the outer rise marks the crossing with Line SERP, as well as the location of velocity profiles shown in Figure 5. 


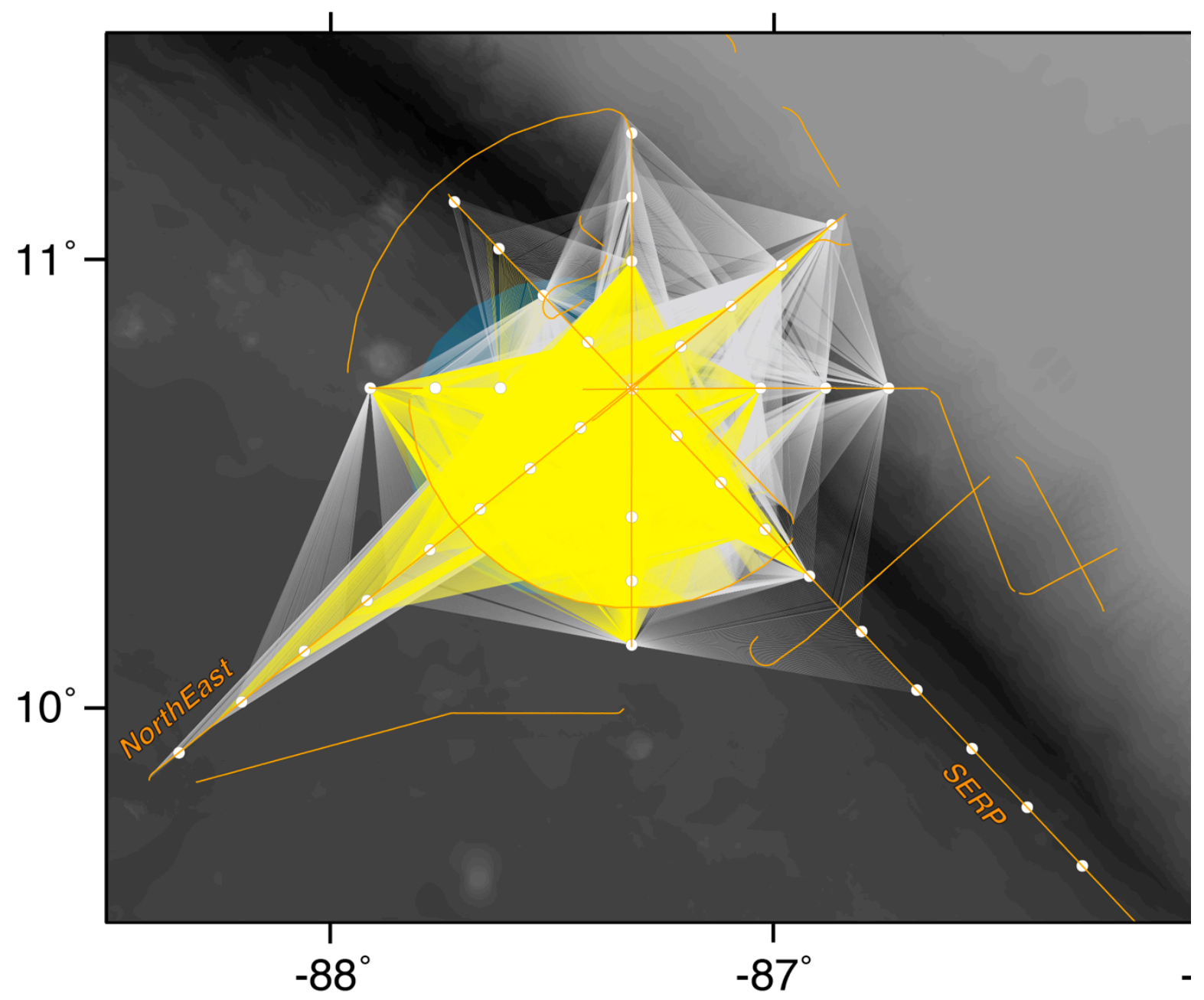

Figure 10. Raypaths for Pn. Paths used in the delay-time analysis for anisotropy under the outer rise are highlighted in yellow. 


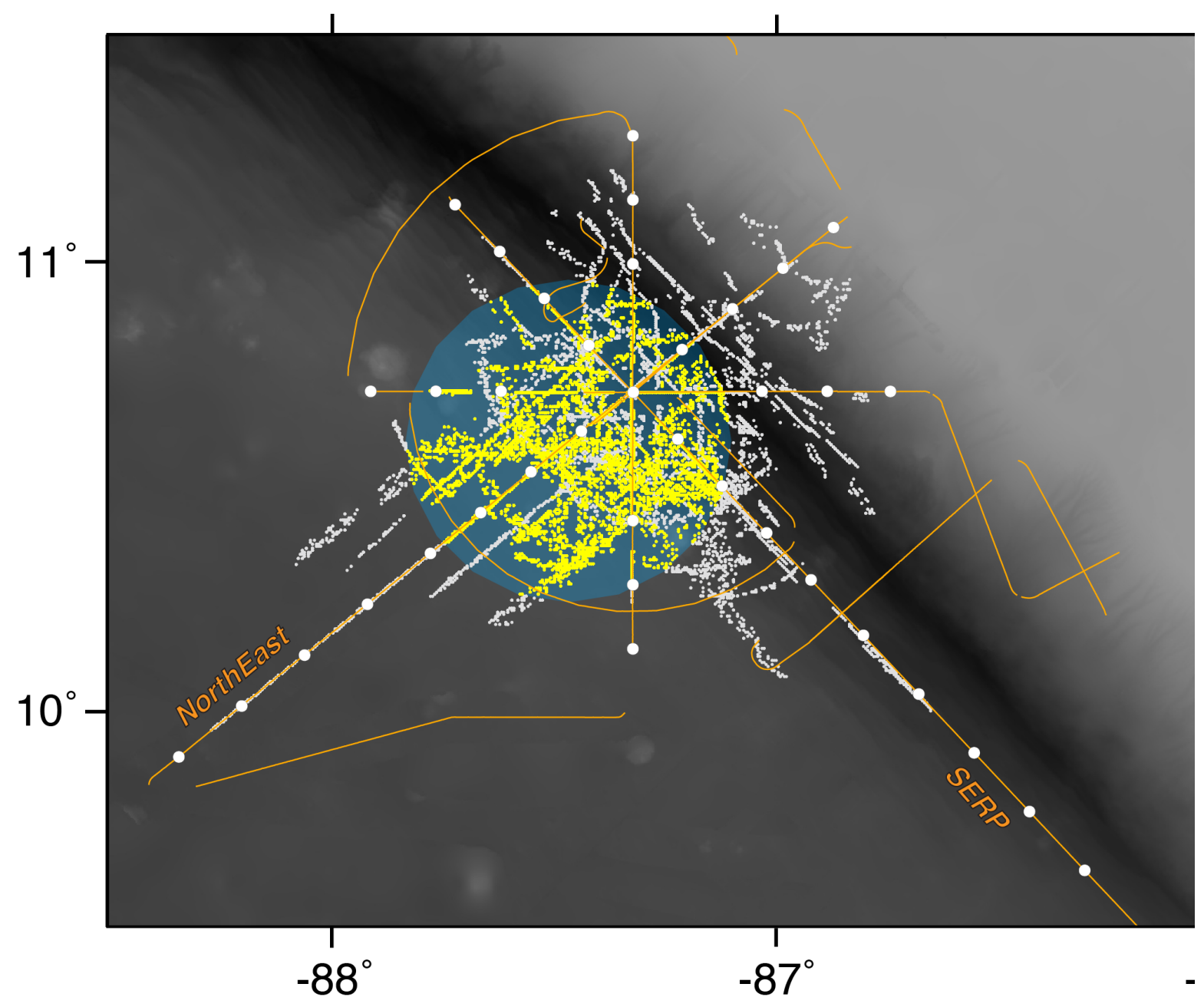

Figure 11. Ray-bottoming points (dots) for Pn. Points for paths used in the delay-time analysis for anisotropy under the outer rise are highlighted in yellow. 


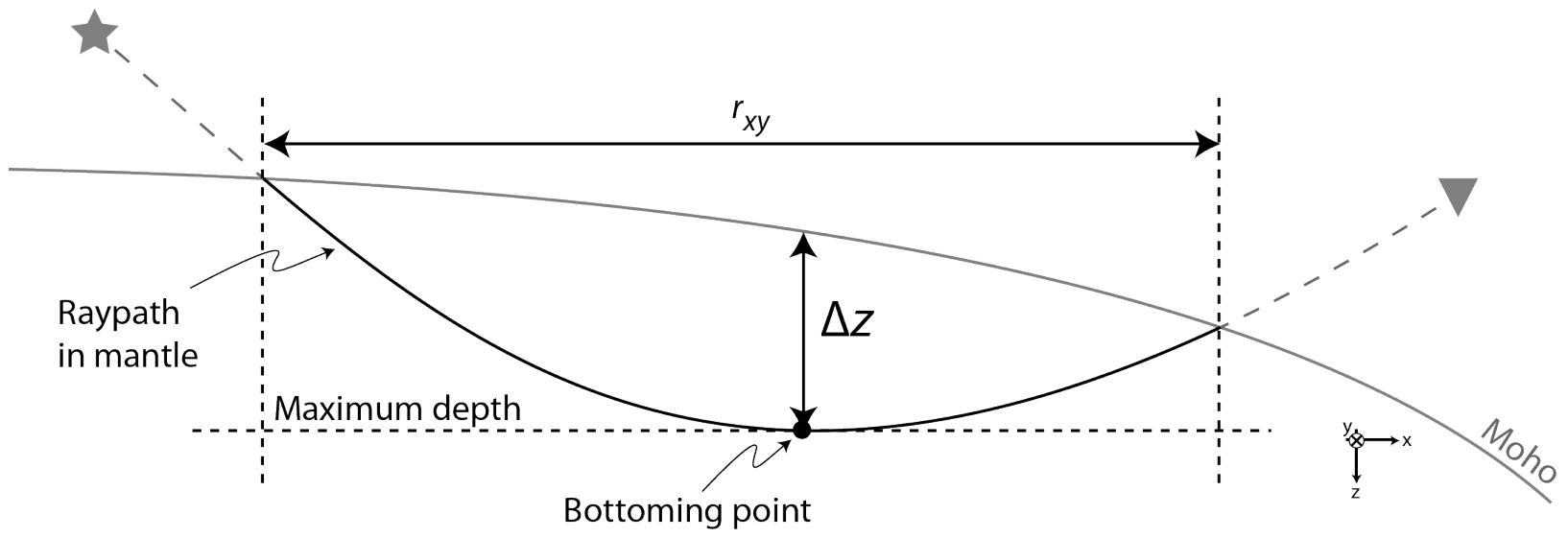

Figure 12. Parameterization of Pn raypaths by the length in the horizontal plane of the portion of the path that is in the mantle $r_{x y}$ and the depth below the Moho of the bottoming point $\Delta z$. 


\section{0 to $0.1 \mathrm{~km}$ below Moho}
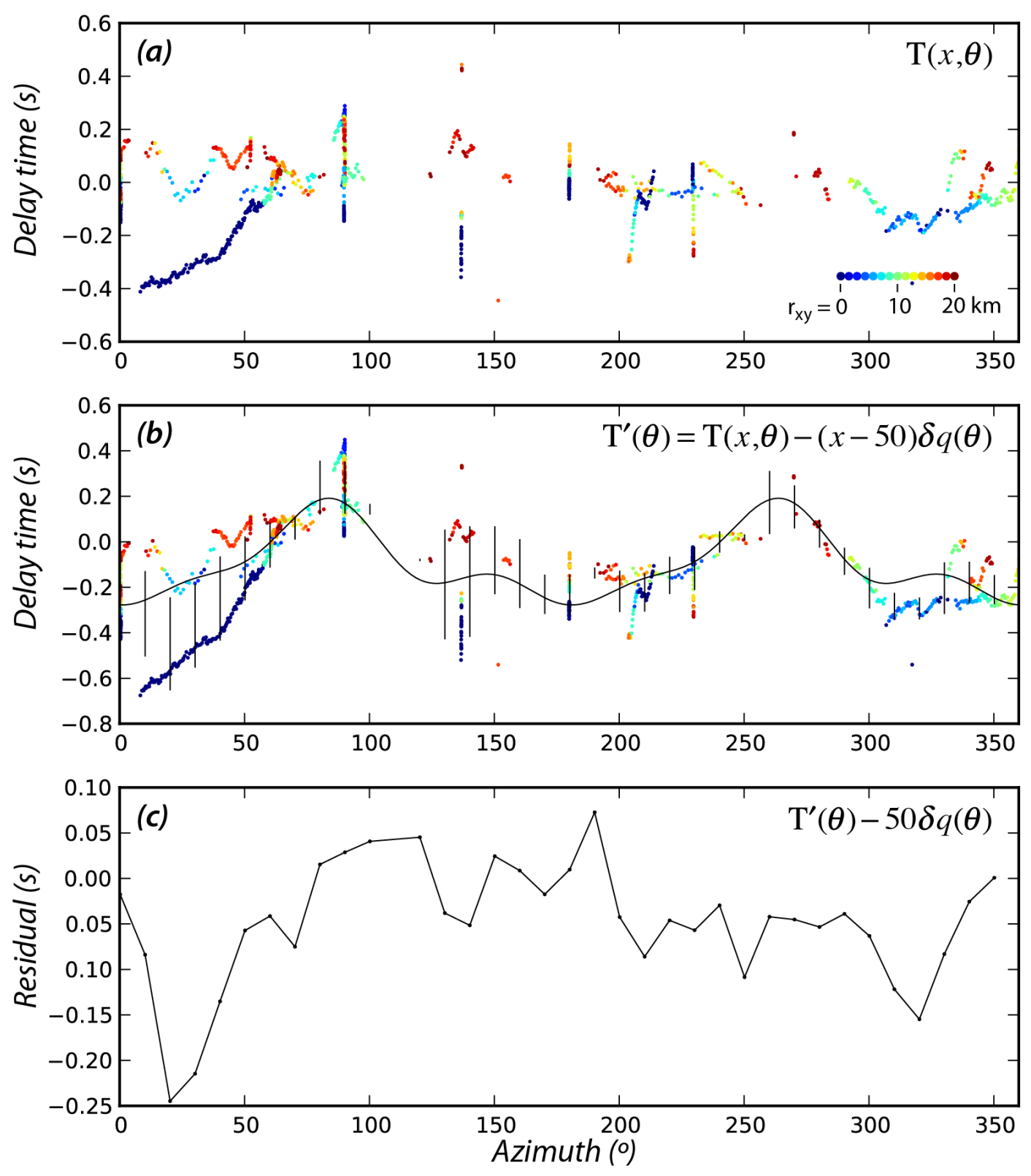

Figure 13. Fits to delay times for rays bottoming at 0 to $0.1 \mathrm{~km}$ below the Moho. (a) Delay times calculated as the difference between observed traveltimes and traveltimes calculated through a reference isotropic model. Points are colored by horizontal propagation distance in the mantle. (b) Data (colored dots) corrected to a common offset of $5 \mathrm{~km}$ using an anisotropy model (black line) found by inversion of delay time data using a $20^{\circ}$-wide moving average smoothing operator. Error bars are one standard deviation of data within each moving-average bin. (c) Misfit between smoothed, offset-corrected data and the model. RMS error for this and other models are listed in Table 1. 


\section{1 to $1 \mathrm{~km}$ below Moho}
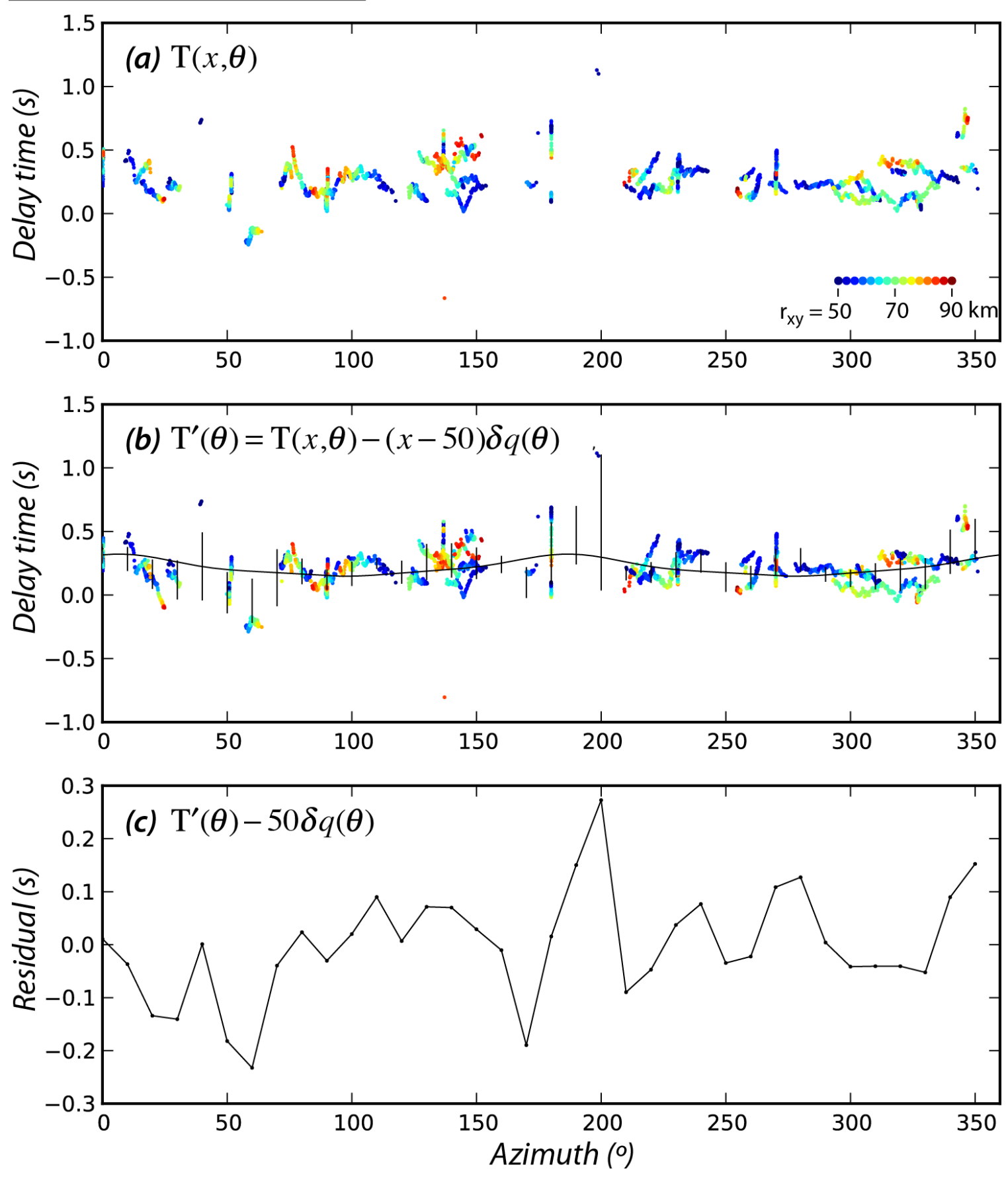

Figure 14. Fits to delay times for rays bottoming at 0.1 to $1 \mathrm{~km}$ below the Moho. Symbols are the same as in Figure 13. 

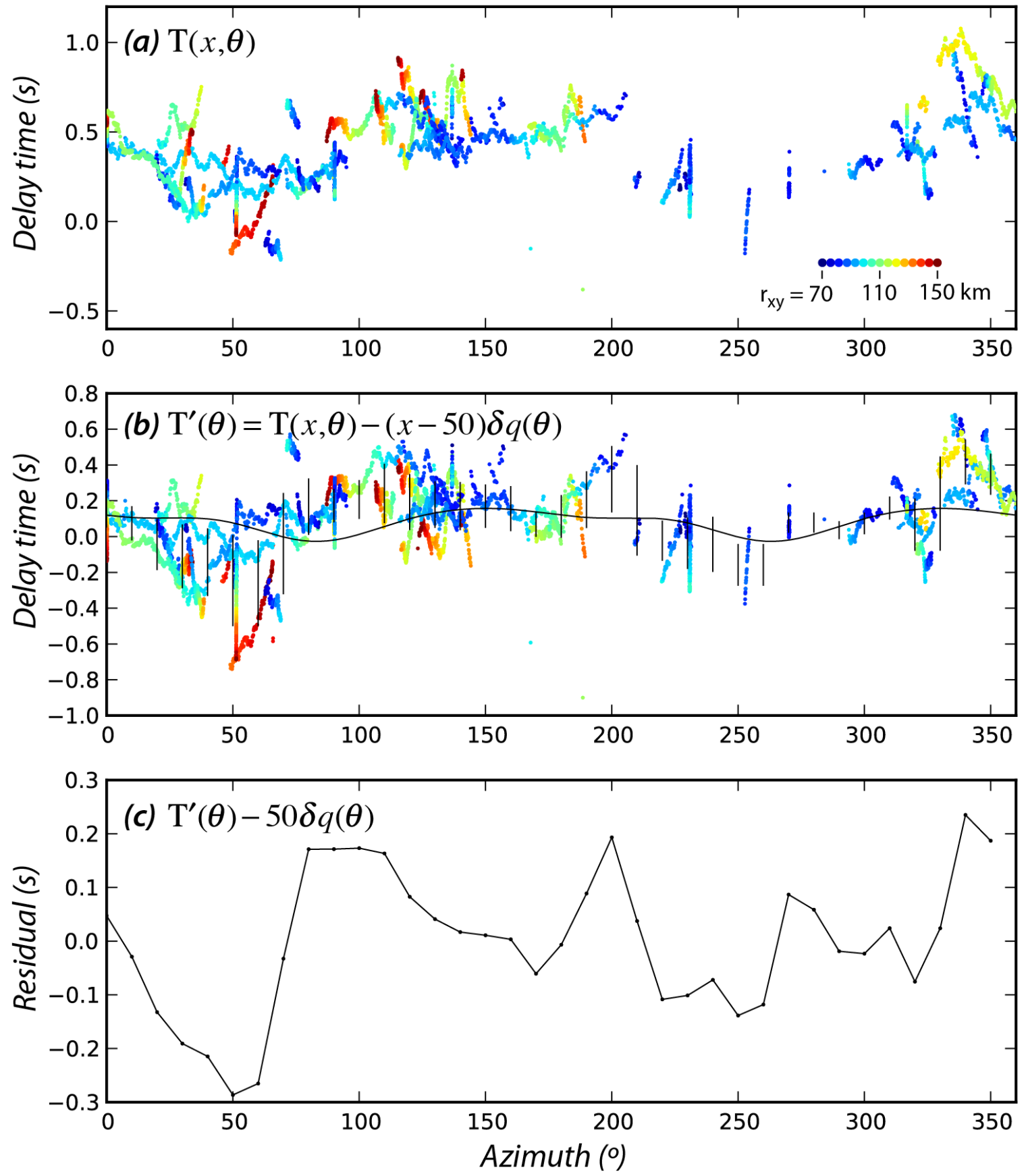

Figure 15. Fits to delay times for rays bottoming at 1 to $24 \mathrm{~km}$ below the Moho. Symbols are the same as in Figure 13. 


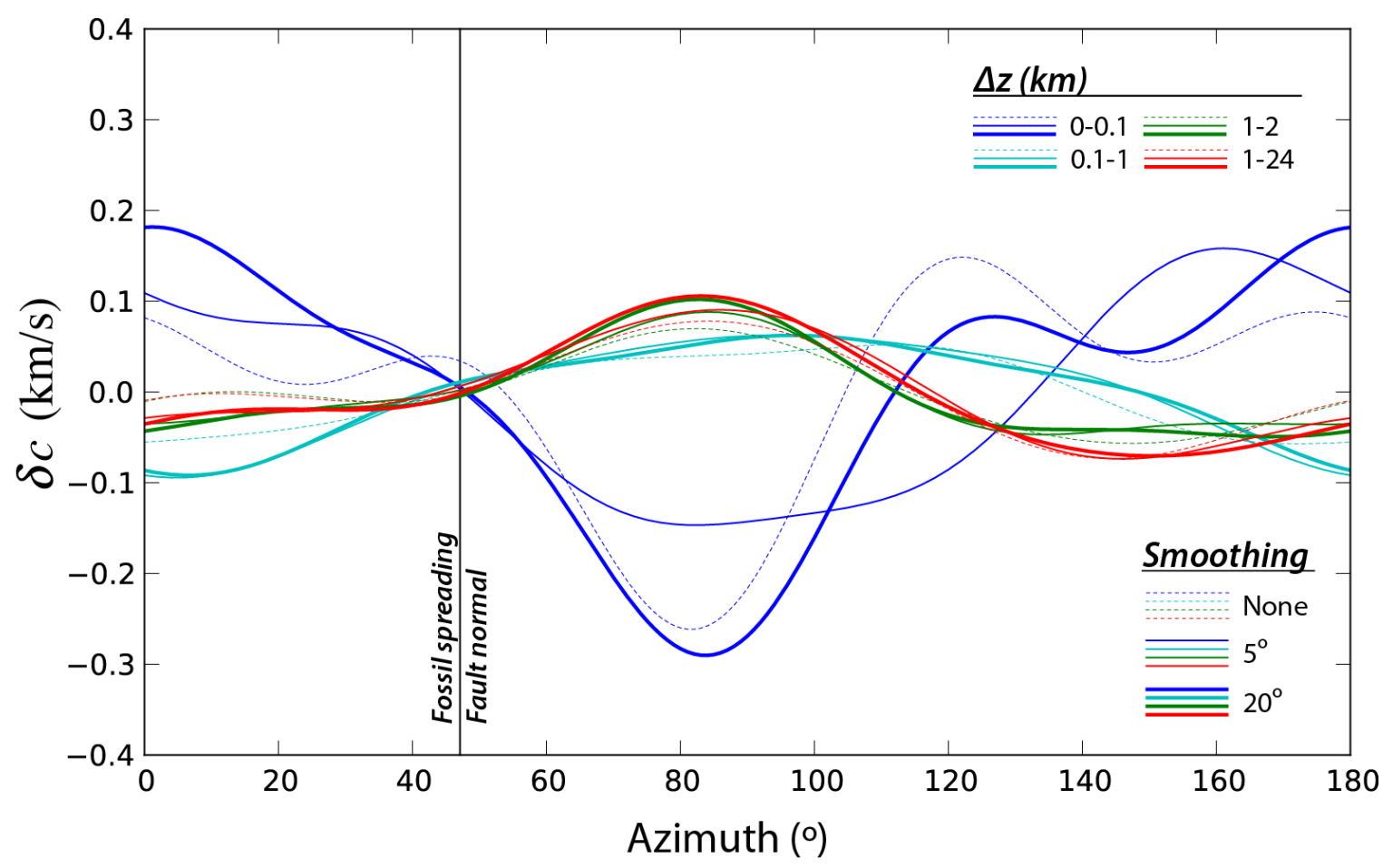

Figure 16. Wavespeed models for different depths below the Moho (colors) and different widths of the smoothing operator (line styles). 
(a) Pacific +1 fabric

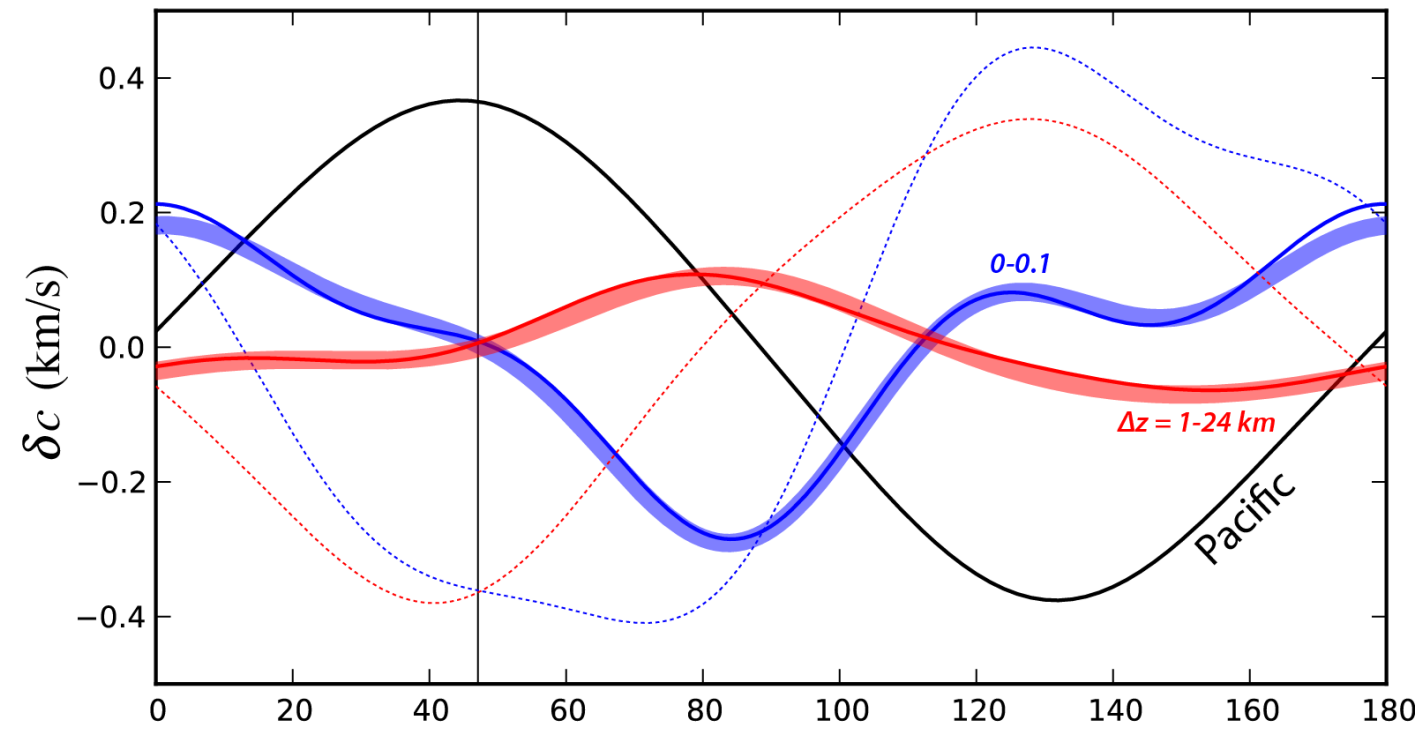

(b) Pacific +2 fabrics

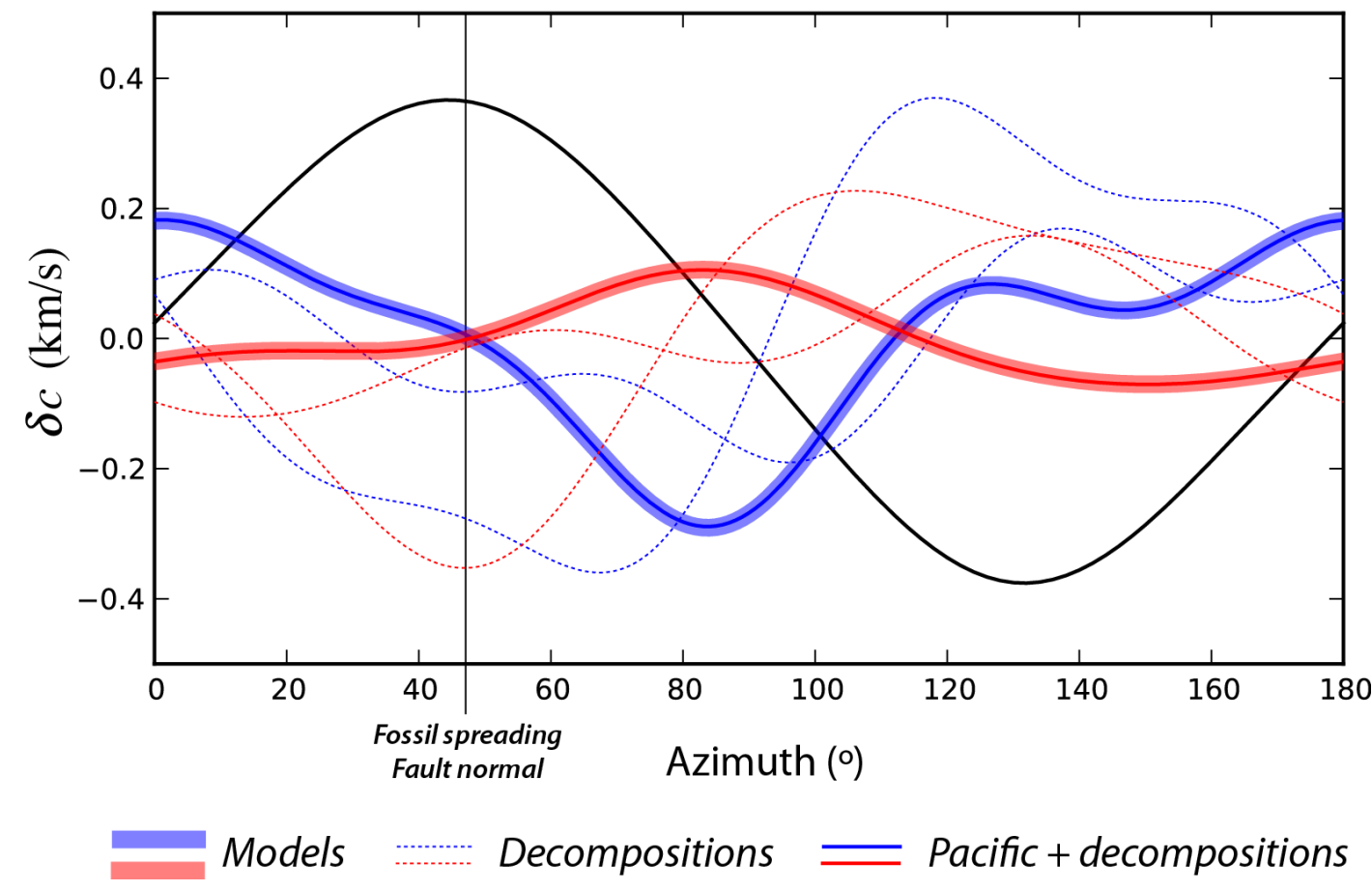

Figure 17. Solutions for wavespeed models that, when summed with measured anisotropy in the unaltered Pacific upper mantle, reproduce best fit models for anisotropy between 0-0.1 and 1-24 km below the Moho. The Pacific model shown here is Shearer and Orcutt's (1986) best-fit solution for the upper mantle using data from the 1983 Ngendiei experiment in the South Pacific. 

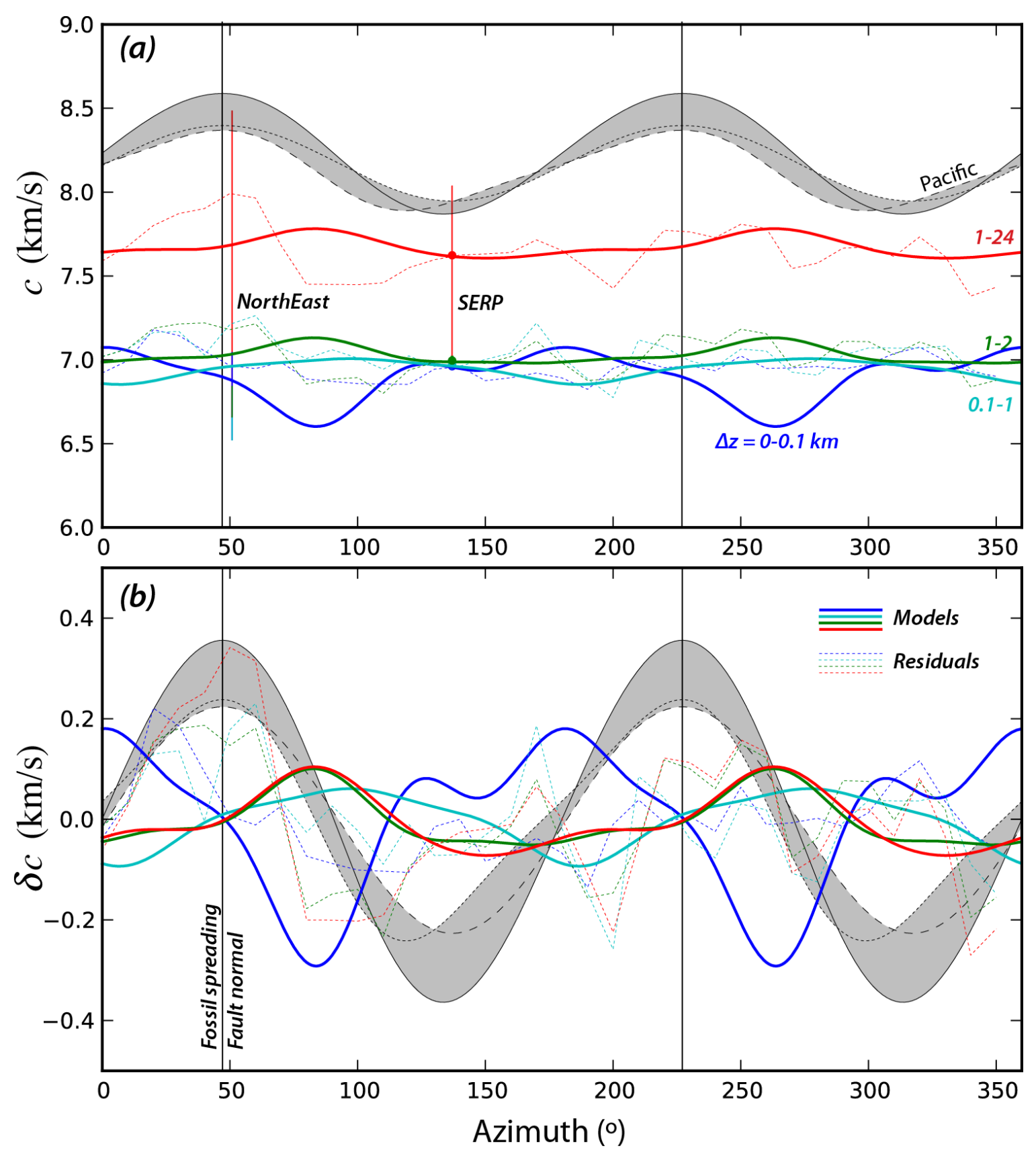

Figure 18. Absolute wavespeeds (a) and wavespeed variations (b) compared to models of Pacific models of wavespeeds in the Pacific upper mantle (Kawasaki, 1986; Shearer and Orcutt, 1986) (grey) and model residuals (dashed lines). In (a), wavespeeds are calibrated to mean velocities (dots) over each depth range in the model along Line SERP (Van Avendonk et al., 2011). The vertical lines show the full range of velocities over each depth range in both the NorthEast_v2d and SERP models. In (b), mean values have been removed from each wavespeed curve to show relative amplitude and phase. 


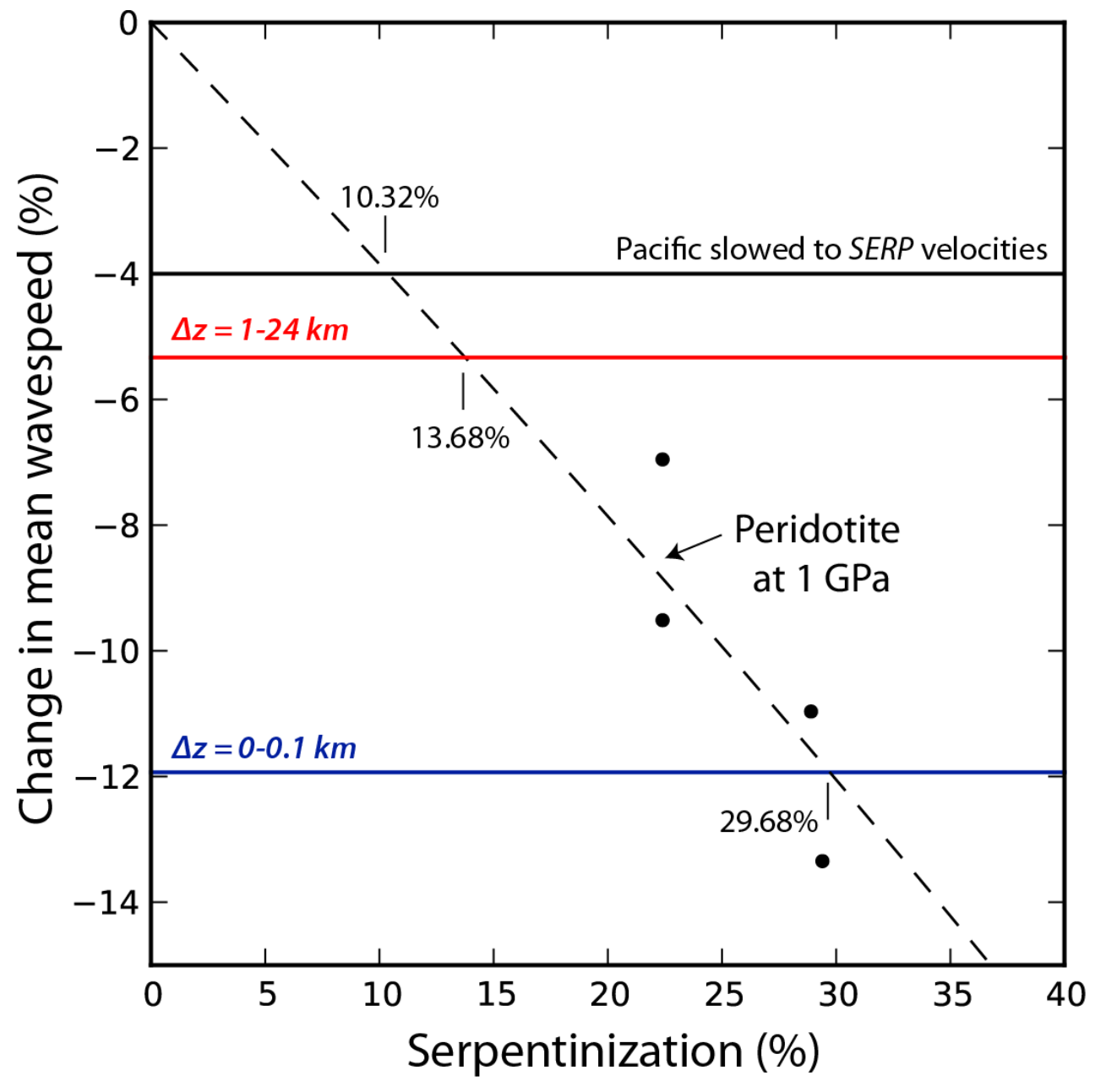

Figure 19. Change in mean wavespeeds with respect to wavespeeds in the unaltered Pacific upper mantle as measured by Shearer and Orcutt (1986). Change in mean values measured for rays bottoming at 0 to 0.1 (blue line) and 1 to $24 \mathrm{~km}$ (red line) below the Moho are compared to a linear fit to mean wavespeeds measured at $1 \mathrm{GPa}$ in mantle rocks with different degrees of serpentinization (black dashed line) (Christensen, 1966). The black line is the change in mean wavespeed if a model of Pacific upper mantle wavespeeds (Shearer and Orcutt, 1986) is slowed to match velocities along the azimuth of Line SERP. 

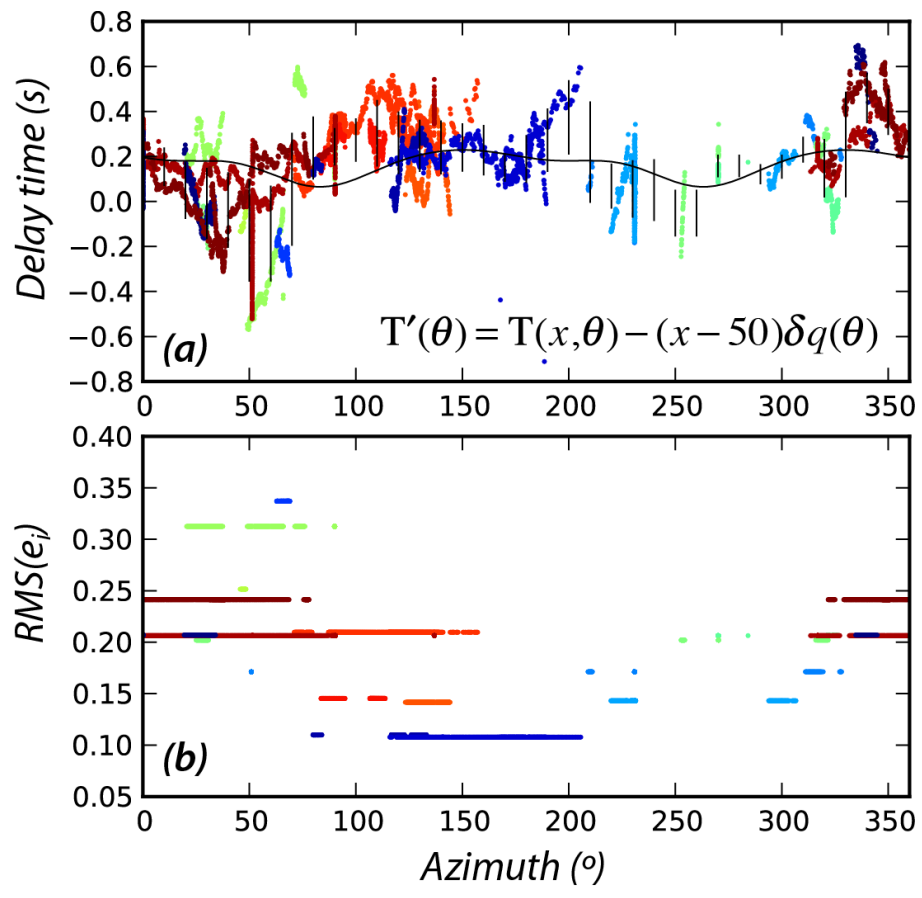

Figure 20. Example of RMS error for each receiver (colors). Data shown are from rays bottoming between 1 and $24 \mathrm{~km}$ below the Moho, and a $20^{\circ}$-wide smoothing operator is used in an inversion for the model shown by the black line. 